\title{
Aeroelastic and Aerothermoelastic Analysis in Hypersonic Flow: Past, Present, and Future
}

\author{
Jack J. McNamara \\ Ohio State University, Columbus, Ohio 43210-1276 \\ and \\ Peretz P. Friedmann \\ University of Michigan, Ann Arbor, Michigan 48109-2140 \\ DOI: $\underline{10.2514 / 1 . J 050882}$
}

\section{Introduction}

$\mathbf{H}$ YPERSONIC flight began in February 1949 when a WAC Corporal rocket was ignited from a U.S.-captured V-2 rocket [1]. In the six decades since this milestone, there have been significant investments in the development of hypersonic vehicle technologies. The NASA X-15 rocket plane in the early 1960s represents early research toward this goal $[2,3]$. After a lull in activity, the modern era of hypersonic research started in the mid-1980s with the National Aerospace Plane (NASP) program [4], aimed at developing a single-stage-to-orbit reusable launch vehicle (RLV) that used conventional runways. However, it was canceled due mainly to design requirements that exceeded the state of the art [1, 5] A more recent RLV project, the VentureStar program, failed during structural tests, again for lack of the required technology [5].

Despite these unsuccessful programs, the continued need for a low-cost RLV, as well as the desire of the U.S. Air Force (USAF) for unmanned hypersonic vehicles, has reinvigorated hypersonic flight research. An emergence of recent and current research programs [] demonstrate this renewed interest. Consider, for example, the NASA Hyper-X experimental vehicle program [7], the University of Queensland HyShot program [8] , the NASA Fundamental Aeronautics Hypersonics Project [9], the joint U.S. Defense Advanced Research Projects Administration (DARPA)/USAF Force Application and Launch from Continental United States (FALCON) program [10], the X-51 Single Engine Demonstrator [11,12], the joint USAF Research Laboratory (AFRL)/Australian Defence Science and Technology Organisation Hypersonic International Flight Research Experimentation project [13], and ongoing basic hypersonic research at the AFRL (e.g., [14-20]).

The conditions encountered in hypersonic flows, combined with the need to design hypersonic vehicles, have motivated research in the areas of hypersonic aeroelasticity and aerothermoelasticity. It is evident from Fig. 1 that hypersonic vehicle configurations will consist of long, slender lifting body designs. In general, the body, surface panels, and aerodynamic control surfaces are flexible due to minimum-weight restrictions. Furthermore, as shown in Fig. $\underline{2}$, these

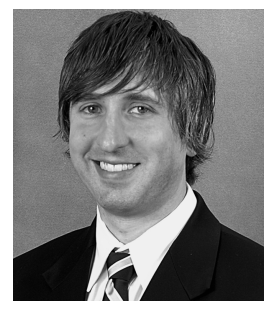

Jack J. McNamara is an Assistant Professor in the Department of Mechanical and Aerospace Engineering at Ohio State University. He received his B.S., M.S., and Ph.D. (2005) degrees in aerospace engineering from the University of Michigan. Before joining Ohio State in 2006, Dr. McNamara was a Research Assistant and Postdoctoral Researcher in the FXB Center for Rotary and Fixed Wing Air Vehicle Design, under the direction of Dr. Friedmann. Dr. McNamara is actively engaged in research on hypersonic aeroelasticity and aerothermoelasticity, multidisciplinary analysis and control of hypersonic vehicles, wind turbine aerodynamics and aeroelasticity, and turbomachinery aeromechanics. His research in hypersonic aeroelasticity and aerothermoelasticity was recognized with the 2004 ASME/Boeing Structures and Materials Award. He is currently a Senior Member of the AIAA.

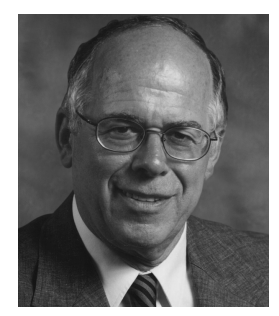

Peretz P. Friedmann is the François-Xavier Bagnoud Professor of Aerospace Engineering in the Aerospace Engineering Department of the University of Michigan. He received his B.S. and M.S. degrees in aeronautical engineering from the Technion-Israel Institute of Technology, and he received his Sc.D. (1972) in aeronautics and astronautics from the Massachusetts Institute of Technology (MIT). Before entering the academia, Dr. Friedmann worked at Israel Aircraft Industries, and he was a Research Assistant at the Aeroelastic and Structures Laboratory at MIT. He has been with the University of Michigan since January 1999. Between 1972 and 1998, he was a Professor in the Mechanical and Aerospace Engineering Department of the University of California, Los Angeles. Between 1988 and 1991, he served as the Chairman of the Department. Dr. Friedmann has been engaged in research on rotary-wing and fixed-wing aeroelasticity, active control of vibrations, hypersonic aeroelasticity and aerothermoelasticity, flutter suppression, structural dynamics, and structural optimization with aeroelastic constraints, and he has published extensively (over 310 journal and conference papers). His accomplishments have been recognized by several awards: the AIAA Ashley Award for Aeroelasticity (2009), the Dryden Lectureship in Research (AIAA, 2009), the Spirit of St. Louis Medal [American Society of Mechanical Engineers (ASME), 2003], the AIAA Structures, Structural Dynamics and Materials Award (1996), the AIAA SDM Lecture Award (1997), and the ASME/Boeing Structures and Materials Award (1984, 2004, 2010). He is currently the Editor-in-Chief of the AIAA Journal, and he is a Fellow of the AIAA and the American Helicopter Society.

Presented as Paper 2007-2013 at the 48th AIAA/ASME/ASCE/AHS/ASC Structures, Structural Dynamics, and Materials Conference, Honolulu, HI, 23-26 April 2007; received 23 August 2010; revision received 4 January 2011; accepted for publication 26 January 2011. Copyright @ 2011 by J. J. McNamara and P.P. Friedmann. Published by the AIAA, Inc., with permission. Copies of this paper may be made for personal or internal use, on condition that the copier pay the $\$ 10.00$ per-copy fee to the Copyright Clearance Center, Inc., 222 Rosewood Drive, Danvers, MA 01923; include the code 0001-1452/11 and \$10.00 in correspondence with the CCC. 
$\mathrm{X}-33$

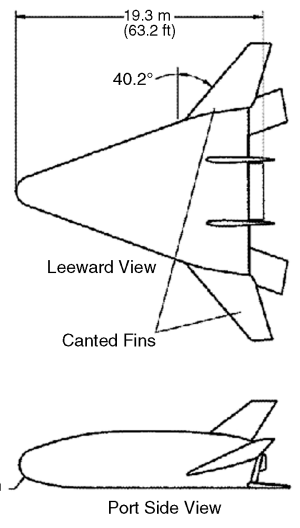

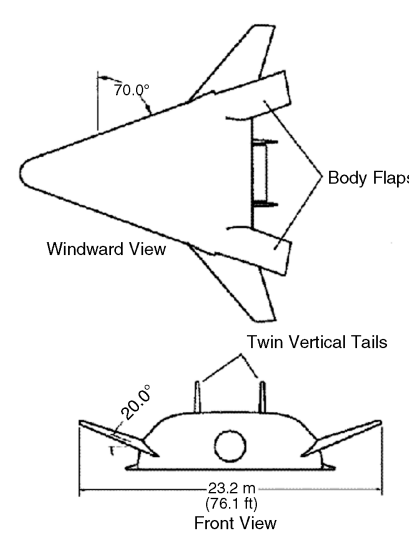
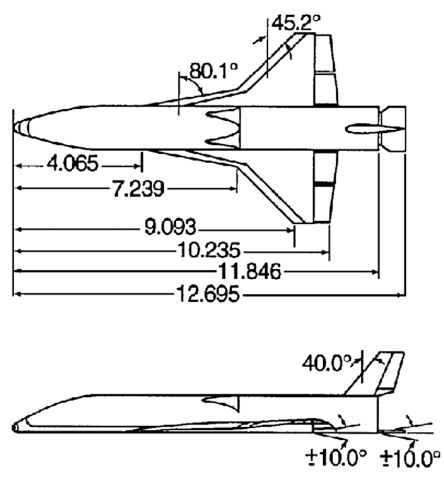

$\mathrm{X}-34$
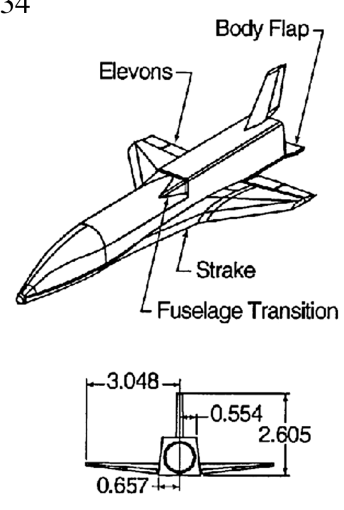

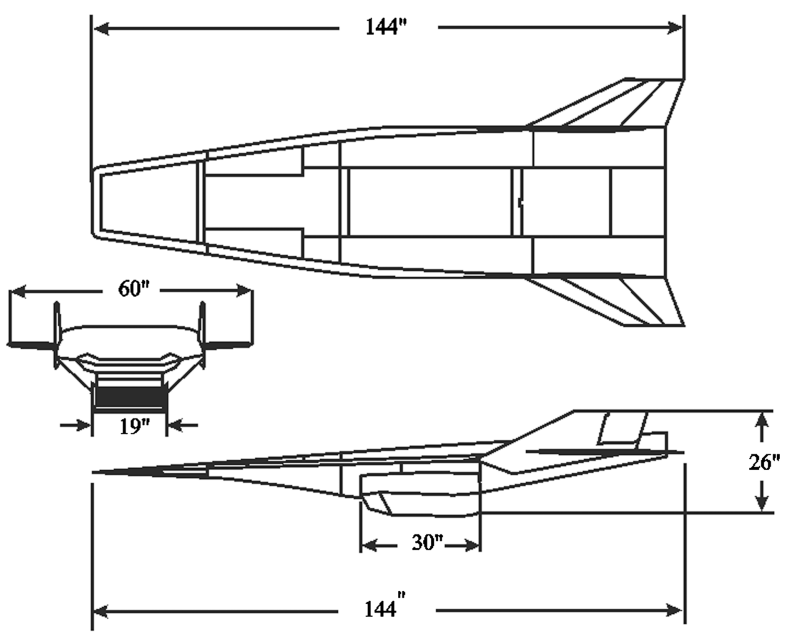

$\mathrm{X}-43$

Fig. 1 Schematic description of several hypersonic vehicles.

vehicles operate $[7,12, \underline{21}-25]$ over a broad range of Mach numbers and must fly within the atmosphere for sustained periods of time to meet the needs of an airbreathing propulsion system [26]. The combined extreme aerodynamic heating and pressures acting on the system produce complex fluid-thermal-structural-propulsive interactions $[\underline{2}, 25,27-30]$. These interactions have received only limited attention in the past.

Classically, aeroelasticity is defined as the mutual interaction of inertial, elastic, and aerodynamic forces in a particular system, when there is feedback between deformation and flow [31,32]. However, modern aeroelasticity encompasses a much broader set of problems $[3,30,33]$, as illustrated by the aeroservothermoelastic hexahedron [34] shown in Fig. 3. Classical aeroelasticity is represented by the triangular domain constructed from the elastic, inertia, and aerodynamic vertices. The upper tetrahedron represents the domain of aeroservoelasticity, where the control system is included in the aeroelastic analysis. Similarly, the lower tetrahedron represents the domain of aerothermoelasticity, where thermal effects are included in the aeroelastic analysis.

Hypersonic aeroelasticity and aerothermoelasticity were active areas of research in the late 1950s and during the 1960s, as is evident from [3, 35-51]. This research was instrumental in providing the basis for the aerothermoelastic design of the X-15 and the space shuttle. Because of the previously unattainable technology requirements necessary to design and operate hypersonic vehicles, this early research has been followed by periods of dormancy and intermittent spurts of activity. However, it is clear from recent advances that sustained airbreathing hypersonic flight is on the horizon. Thus, the objective of this paper is to survey the status of research in the areas of hypersonic aeroelasticity and aerothermoelasticity in order to provide 1) a comprehensive review of the state of the art and 2) insight into important challenges and future directions.
An overview of the problem and governing equations is provided in Sec. II. In Sec. III, modeling approaches and coupling strategies for the fluid, thermal, and structural problems are reviewed. A survey of experimental research, aerothermoelastic similarity, panel flutter, and computational studies of lifting surfaces and complete vehicles is provided in Secs. IV, V, VI, and VII, respectively. In Sec. VIII, emerging frontiers are discussed, namely, the study of aeroservothermoelastic-propulsive (ASTEP) interactions for comprehensive analysis of hypersonic vehicles and inflatable aerodynamic decelerators (IADs) for planetary entry. The paper closes with conclusions and identification of potential future directions.

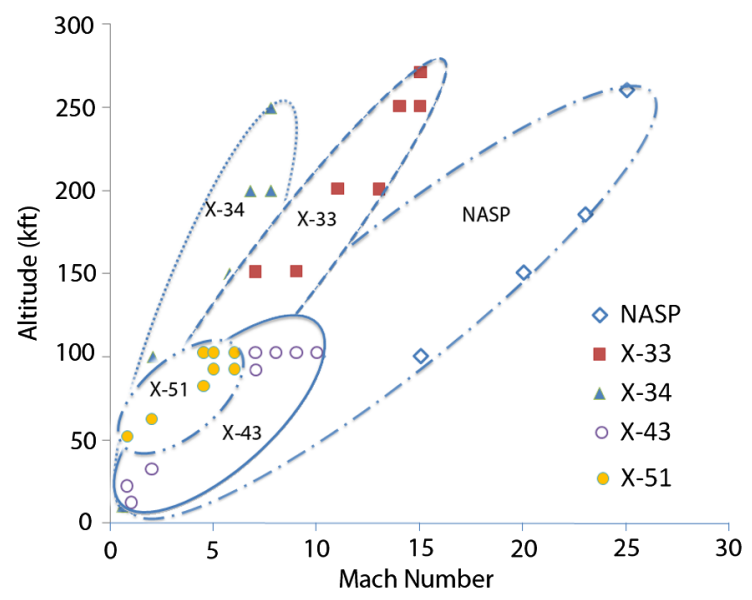

Fig. 2 Operating envelopes for several modern hypersonic vehicles. 


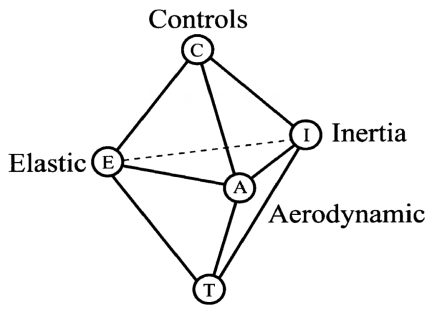

Thermal Effects

Fig. 3 Aeroservothermoelastic hexahedron [34].

\section{Characterization of Problem}

To provide a comprehensive survey of the current state of hypersonic aeroelastic and aerothermoelastic research, it is helpful to summarize the principal characteristics of hypersonic flow, hypersonic vehicles, and the governing equations.

The boundary that separates hypersonic flight from supersonic flight is not set at a particular Mach number. Rather, hypersonic is generally used to designate the regime where certain flow phenomena become progressively more important as the Mach number is increased to higher values [1]. Typically, a flow is characterized as hypersonic starting at Mach numbers between three to five [1,52]. An important consequence of high-speed flow is the need to retain nonlinear aspects of the governing equations, since the velocity perturbations are large compared with the ambient speed of sound. This increases the complexity of computing the aerodynamic loading when compared with supersonic flows. Furthermore, as the Mach number is increased, the shock, which is very strong, moves close to the body while the boundary layer grows rapidly. Therefore, at high Mach numbers, viscous interactions between the outer inviscid flow, the shock, and the boundary layer become significant $[1,26,52]$. Also, extreme temperatures are present in both the inviscid flow behind the shock and the boundary layer, due to significant flow compression and viscous dissipation $[1,26,52]$. This intense aerodynamic heating can cause dissociation and ionization within the gas, resulting in chemically reacting boundary layers. Such complex phenomena are generally not required in the analysis of subsonic and supersonic aircraft. Thus, the exact solution to the hypersonic aerothermodynamic problem can only be obtained by solving the unsteady Navier-Stokes (NS) equations, including real-gas effects; a task that presents a significant computational challenge [53].

Aside from these important flow characteristics, another important aspect of hypersonic flight is the tight coupling of subsystems in hypersonic vehicles [1]. It is evident from the schematic of the X-43 in Fig. 1 that, unlike subsonic and supersonic aircraft, modern hypersonic vehicles are based on an integrated airframe-propulsion concept; where the entire lower vehicle surface is part of a scramjet propulsion system. This integration produces interactions between the various airframe components that cannot be neglected in analysis of complete vehicles $[2,27,30]$.

The multidisciplinary nature of hypersonic vehicles requires inclusion of unsteady aerothermodynamics, temperature-dependent structural dynamics, and heat transfer analysis, as well as appropriate

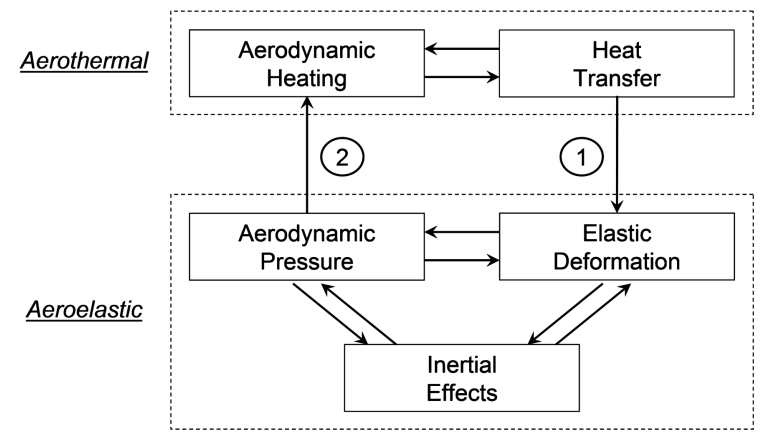

Fig. 4 Basic structure of the aerothermoelastic problem. coupling mechanisms between each discipline. Figure 4 illustrates that the hypersonic aerothermoelastic problem can be conceptually divided into two parts [54]: 1) an aerothermal problem and 2) an aeroelastic problem. The aerothermal problem consists of computation of the aerodynamic heating and resulting heat transfer between the fluid and the structure, and its solution provides the temperature distribution $T(x, y, z, t)$ in the structure. Since the aerodynamic heat flux is a function of surface temperature, a mutual coupling exists between the aerothermodynamics and heat transfer. Furthermore, the aerodynamic heat flux is a function of surface geometry, which varies as a result of flexibility that is associated with transient aeroelastic behavior. Thus, exact computation of the temperature distribution requires a continuous time-marching solution along a trajectory of interest.

The governing equations for the aerothermoelastic problem are given by Michopoulos et al. [55] as

$$
\left.\frac{\partial(\boldsymbol{J} w)}{\partial t}\right|_{\xi}+J \nabla_{x} \cdot\left[\boldsymbol{F}(\boldsymbol{w})-\left.\frac{\partial x}{\partial t}\right|_{\xi} \boldsymbol{w}\right]=J \nabla_{x} \cdot \boldsymbol{R}(\boldsymbol{w})+\boldsymbol{J} S(\boldsymbol{w})
$$

in the fluid domain,

$$
\rho_{s} \frac{\partial^{2} \boldsymbol{u}_{S}}{\partial t^{2}}-\nabla_{x} \boldsymbol{\sigma}_{S}\left(\boldsymbol{\epsilon}_{S}, T_{S}\right)=\boldsymbol{b}
$$

and

$$
\rho_{s} c_{p S} \frac{\partial T_{S}}{\partial t}+\nabla_{x} \cdot\left(-\lambda_{S} \nabla_{x} T_{S}\right)-\sigma_{S} \frac{\partial \epsilon_{S}}{\partial t}-Q_{i}-Q_{b}=0
$$

in the structural domain.

Equation (1) is the NS equation, where $\boldsymbol{w}$ represents the conservative fluid state vector; $\boldsymbol{F}$ and $\boldsymbol{R}$ are the convective and diffusive fluxes; and $\boldsymbol{S}(\boldsymbol{w})$ is a source term associated with turbulence modeling in computational solutions. Note that Eq. (1) is derived in an arbitrary Lagrangian-Eulerian (ALE) reference frame to account for fluid-structure coupling [55]. Thus, the reference frame of the fluid is allowed to move, where $\boldsymbol{x}(\boldsymbol{\xi}, t)$ is the time-dependent position vector of a fluid point, $\xi$ its position vector in a reference configuration, and $\boldsymbol{J}=|\partial \boldsymbol{x} / \partial \boldsymbol{\xi}|$ is the Jacobian determinant of the deformation gradient. For the numerical solution of Eq. (1), an additional equation is required in order to adjust the fluid mesh to accommodate the surface motion. A common approach is to represent the mesh in the fluid domain as a dynamic pseudostructural system using [55]

$$
\left.\rho_{f} \frac{\partial^{2} \boldsymbol{x}}{\partial t^{2}}\right|_{\xi}-\nabla_{\xi} \sigma_{f}\left(\boldsymbol{x}-\left.\boldsymbol{x}\right|_{t=0}\right)=0
$$

where $\rho_{f}$ and $\sigma_{f}$ represent a fictitious density and stress tensor in the fluid mesh. The values for these quantities are set to maintain fluidmesh quality during deformation and to prevent negative volumes.

The structural dynamics and heat conduction are governed by Eqs. (2) and (3), where $\rho_{S}$ is the material density; $\boldsymbol{\sigma}_{S}$ and $\boldsymbol{\epsilon}_{S}$ are the structural stress and strain tensors; $\boldsymbol{u}_{S}$ is the displacement vector; $\boldsymbol{b}$ is the body force vector; $c_{p S}$ is the specific heat; $\lambda_{S}$ is the structural heat conductivity tensor; $T_{S}$ is the structural temperature field; $Q_{i}$ is the heat flux from an internal energy source; and $Q_{b}$ is the heat flux at the fluid-structure interface [55].

Finally, note that the fluid and structure are coupled through an interface, where the following boundary and compatibility conditions must be satisfied [55]:

$$
\begin{gathered}
\boldsymbol{\sigma}_{S} \cdot \boldsymbol{n}=\left(-p+\boldsymbol{\sigma}_{F}\right) \cdot \boldsymbol{n}+\boldsymbol{\tau} \\
\frac{\partial \boldsymbol{x}}{\partial t}=\frac{\partial \boldsymbol{u}_{S}}{\partial t}=\boldsymbol{v} \\
\boldsymbol{x}(t)-\left.\boldsymbol{x}(t)\right|_{t=0}=\boldsymbol{u} \\
T_{S}=T_{F}
\end{gathered}
$$




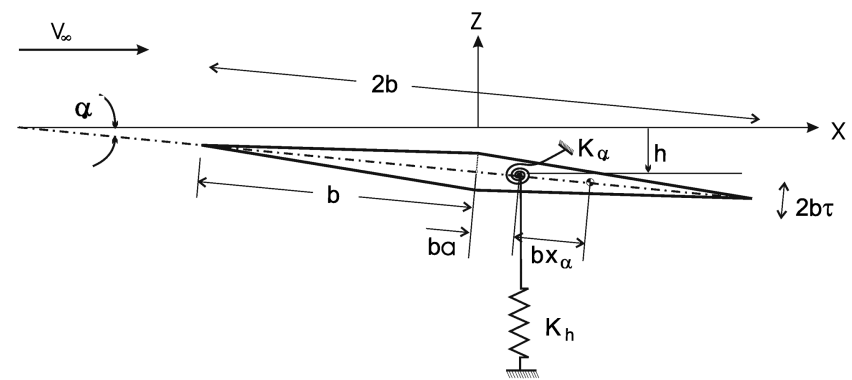

Fig. 5 Two-DOF typical section geometry [71]].

and

$$
\lambda_{S} \nabla T_{S} n=-\lambda_{F} \nabla T_{F} n
$$

Here, $p$ is the fluid pressure, $\boldsymbol{\sigma}_{F}$ is the viscous fluid stress tensor, $\boldsymbol{\tau}$ are nonaerodynamic tractions, $\boldsymbol{v}$ is the fluid velocity field, $T_{F}$ is the fluid temperature field, $\lambda_{F}$ is the fluid heat conductivity tensor, and $\boldsymbol{n}$ is the normal vector to the surface [55].

\section{Modeling Approaches}

There are two components to modeling an aerothermoelastic system. The first corresponds to individual modeling of the fluid, thermal, and structural disciplines. Modeling approaches vary from simple approximate theories to high-fidelity numerical approaches, such as computational fluid dynamics (CFD) and computational thermostructural dynamics (CTSD). However, the high computational cost of CFD and CTSD typically make these approaches impractical for use in hypersonic aerothermoelasticity [3] . An alternative is to use hybrid numerical-theoretical approaches, where a high-fidelity solver is coupled to simple models, depending on the required level of accuracy in each field. For example, a CFD solver for the unsteady aerothermodynamics might be coupled to a theoretical model for the heat transfer and structural response. Similarly, a finite element method (FEM)-based CTSD solver for the heat transfer and structural response might be coupled to an approximate model for the unsteady aerothermodynamics. Beyond these hybrid approaches, recent research has focused on developing computationally efficient reduced-order models (ROMs) from CFD and FEM solvers using mathematical techniques that identify and retain only the relevant physics in the fluid, thermal, and structural systems.

The second component associated with performing an aerothermoelastic analysis deals with fluid-thermal-structural coupling. As shown in Fig. 4, there are numerous coupling mechanisms in the system. Furthermore, each mechanism has different levels of importance, depending on the desired analysis. Different approaches for both aspects (i.e., modeling and coupling) are discussed next.

\section{A. Low-Fidelity Modeling}

1. Aerodynamic Pressure

Commonly, the unsteady aerodynamics are approximated using either piston theory (PT) [56,57] or a similar Van Dyke second-order theory (VD), which is essentially equivalent to second-order PT at hypersonic Mach numbers. However, other methods such as shockexpansion theory (SE) [60], unsteady Newtonian impact theory (NI) $[61,62]$, and lifting surface/panel approaches $[63,64]$ have also been employed. Each assumes inviscid hypersonic flow and neglects realgas effects. Furthermore, they are based on quasi-steady flow assumptions. However, despite these limitations, such approximate tools have produced sufficiently accurate results in specific cases $[22,52,63,65-71]$. The computational efficiency and ease of implementation make these methods attractive for preliminary design and trend-type studies of hypersonic configurations.

Recently, an assessment of low-fidelity modeling approaches was conducted in [71] by comparing flutter predictions to those computed using NS aerodynamics. The comparisons were made, using the double-wedge typical section shown in Fig. 5, over a wide range of operating conditions by varying both the elastic axis location and operating altitudes. The approximate aerodynamics considered were PT, VD, unsteady SE, and unsteady NI [71].

Results from this comparison are shown in Fig. 6. Note that since the analysis was carried out in the absence of aerodynamic heating, which weakens the structure and lowers the flutter Mach number, relatively low altitudes were required in order to produce flutter at Mach numbers below 30. It is clear from these results that, with the exception of first-order PT (which neglects thickness effects) and NI (which is applicable to high Mach numbers and surface inclination angles), each of the approximate aerodynamic models produced reasonably accurate flutter predictions up to Mach 30. A convenient parameter for the study of hypersonic aerodynamics is the hypersonic similarity parameter, which governs similarities between different flow/body combinations [1]. For a double-wedge airfoil, hypersonic similarity is given by the product of Mach number and surface inclination. For the typical section studied, Mach 30 corresponds to a hypersonic similarity parameter of $\mathcal{O}(1)$. This implies that simple aerodynamic models, such as VD and third-order PT, are reasonably accurate when the product of Mach number and surface inclination is less than one. However, since these comparisons were conducted on a relatively simple geometry, more work is needed using realistic configurations [e.g., three-dimensional (3-D) geometries] to more thoroughly assess the accuracy of these approaches.
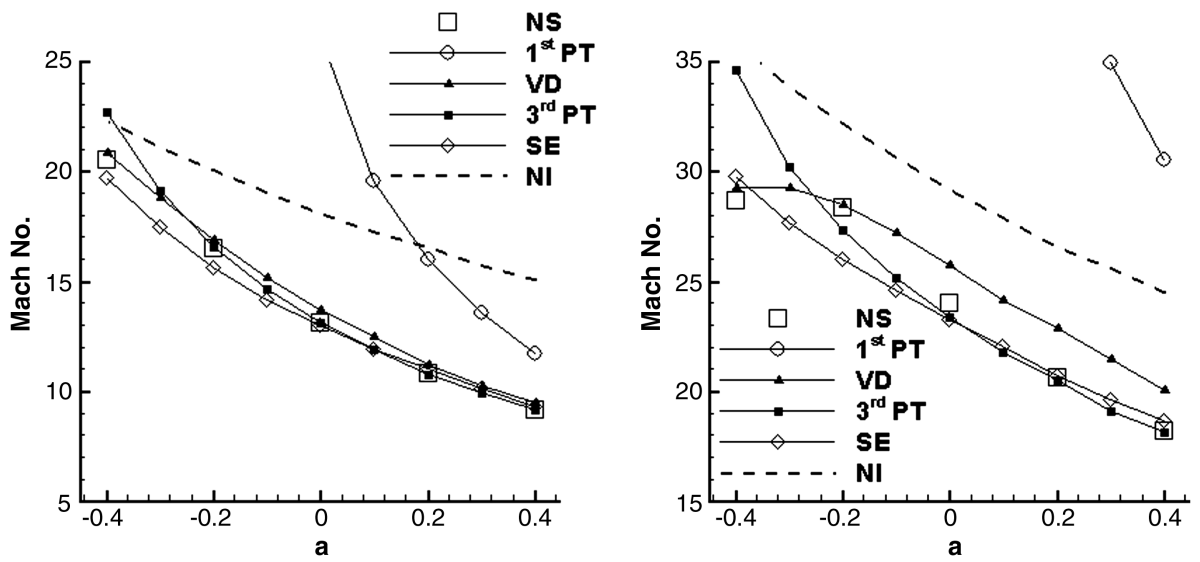

a) 40,000 feet

b) 60,000 feet

Fig. 6 Variation in the flutter Mach number of a double-wedge typical section, as a function of elastic axis offset parameter $a$, computed using several different aerodynamic models [71]. 


\section{Aerodynamic Heating}

Relatively simple and efficient approximations for the aerodynamic heating can be computed using the Eckert reference methods $[1,72]$. The reference enthalpy method uses boundary-layer relations from incompressible flow theory, with flow properties evaluated at a reference condition that accounts for the effects of compressibility in high-speed flow. The reference temperature method is derived from the reference enthalpy approach using the assumption of a calorically perfect gas to replace the reference enthalpy with a reference temperature. Eckert reference methods have been used extensively to efficiently approximate viscous drag and convective heating of aerospace vehicles $[1,73]$. Note that these methods are dependent on the inviscid mean flow properties. Thus, they can be conveniently combined with one of the approximate aerodynamic methods described previously in order to couple the aerothermodynamics to the response of a structure [73].

\section{Thermoelastodynamics}

The most straightforward approach for modeling the thermoelastic problem is to develop equivalent models using basic structural components such as beams, plates, or shells. However, exact solutions to the governing differential equations can be obtained only for simple configurations. Thus, typically low-fidelity modeling of the thermoelastic problem uses a finite difference solution for the heat transfer problem, while low-fidelity modeling of the structural dynamics uses Rayleigh-Ritz or Galerkin methods [74]. As mentioned earlier, and shown in Fig. 1, hypersonic vehicles are composed of low-aspect-ratio components. Therefore, the structural dynamics typically resemble that of plates undergoing chordwise, spanwise, and torsional deformations. Note that when the aerodynamic heating is included in the analysis, the use of simple structural components, such as equivalent beams and plates, becomes questionable due to the dependence of heat transfer on internal structural layout. This characteristic, combined with the requirement to accurately model complex structural configurations, implies that FEM is the preferred approach for modeling hypersonic vehicle thermoelastodynamics.

\section{B. High-Fidelity Modeling}

With rapid increases in computational power, high-fidelity aeroelastic analysis using CFD and CTSD has emerged as a viable approach for hypersonic aeroelasticity $[30,55,70]$. For an aeroelastic analysis in hypersonic flow that neglects heating effects, there are only practical differences compared with other flow regimes: e.g., time step and grid construction for CFD modeling. Specifically, there are large spatial gradients in hypersonic flow associated with shocks and expansion fans. This requires a high grid density in the fluid domain near surface gradients. Furthermore, the boundary layers in hypersonic flow are relatively thick. This enables the use of a less dense grid near the surface of the wall for computing the boundary layer. The high-speed flow combined with stiff low-aspect-ratio structures implies that, for temporal accuracy, smaller time steps are needed to capture aeroelastic behavior when compared with other flow regimes.

While CFD and CTSD approaches are viable for modeling unheated aeroelastic behavior, there are significant concerns when using such an approach for the more realistic problem of performing an aerothermoelastic analysis. For instance, few CFD codes are capable of reliably predicting important hypersonic aerothermodynamic phenomena such as turbulent heating rates, nonequilibrium real-gas effects, hypersonic transition, shock-boundary-layer interactions, shock-shock interactions, etc. [53,75]. Each of these phenomena affect the heat loads to the structure. These issues will remain active research areas in numerical modeling of hypersonic aerothermodynamics and boundary layers for the foreseeable future [53].

From heat transfer and structural modeling perspective, shockshock and shock-boundary-layer interactions lead to high intensity, localized heat and pressure loads $[\underline{1}, \underline{2}, 76]$. Furthermore, these loads may be unsteady due to interactions in the turbulent boundary layer
[77-79] and transient structural responses. This may cause difficulties in localized mesh refinement in the thermal and structural models. A potential alternative to localized refinement is the generalized FEM [80], which augments FEM shape functions with higher-order functions to capture localized effects. However, careful additional study is needed to demonstrate that this approach can accurately capture the aerothermoelastic behavior of a structure subject to shock impingements.

\section{Reduced-Order Modeling}

In addition to numerical issues, an aerothermoelastic analysis using coupled CFD-CTSD approaches presents a significant computational burden due to disparate time scales, very large numbers of degrees of freedom (DOFs), and the need for a high number of repeated analyses due to uncertainties and design optimization $[\underline{3}, \underline{33}]$. These issues have motivated research on reduced-order modeling, which seeks to provide an accurate description of a system at a computational cost that is a fraction of that needed for a full-order analysis. Here, the term "order" refers to the number of computational DOFs of the model. For the specific example of hypersonic aerothermoelasticity, a full-order model might consist of a nonlinear time domain fluid-thermal-structural analysis that is, in general, computationally intractable.

Typical approaches for constructing aerodynamic ROMs are proper orthogonal decomposition (POD) [81-84], Volterra series $[82,85]$, and surrogates [71,86-92]. Each of these approaches seeks to identify the primary features of a system from a limited number of full-order flow solutions. The generation of the required data set requires an up-front computational investment. However, this process can be efficiently carried out using parallel computing facilities. POD represents a spectral method for ROM, where an orthogonal modal basis is computed from snapshots of the full-order system response to relevant inputs [82]. The Volterra series method uses the assumption that the response of any nonlinear system is exactly represented by an infinite series expansion of multidimensional convolution integrals of Volterra kernels. A Volterra series ROM is constructed by computing a truncated set of kernels from the full-order system response to a set of known inputs [82]. Surrogate-based approaches identify a continuous approximate function (i.e., surrogate function) from a discrete sampling of an unknown, nonlinear function over a bounded set of inputs [93,94]. Methods for constructing the surrogate function include autoregressive moving average (ARMA) models, radial basis functions, neural networks, polynomial response surfaces, and kriging $[\underline{86}, \underline{91,93]}$

Despite extensive research into aerodynamic ROMs over the last decade, only a limited number of studies have considered hypersonic flow. Lucia [95] examined POD to model aerodynamic systems with strong shocks or nonlinearity in their parameter space. Tang et al. [84] developed a POD-based ROM for predicting steady-state pressure and temperature distributions on the surface of a rigid vehicle. These studies found that a POD-based ROM is suitable for accurate representation of high-speed flows with shocks and nonlinearity in the parameter space. Gupta et al. [22] and Gupta and Bach [88] developed an ARMA aerodynamic surrogate to perform a CFDbased aeroelastic analysis of the NASA X-43 vehicle. The ARMAbased analysis was found to yield an accurate model, and it was four times faster than the full-order analysis. Recent work has focused on using kriging surrogates to efficiently model static hypersonic aerodynamic pressure, force coefficients, and heating to both the effect of arbitrary surface temperature and structural deformation $[71,92]$. Kriging is an interpolation method useful for replacing expensive computer models with computationally efficient approximations of nonlinear functions $[93,96,97]$. Typical prediction times are on the order of a fraction of a second. Kriging interpolation was used in these studies, since the method is well suited to approximating nonlinear functions and does not require a priori assumptions on the form of the full-order function that is to be approximated. The kriging surrogates typically had less than $5 \%$ error relative to the full-order CFD predictions, and they had computation times of 100ths of a 
second. Furthermore, the kriging surrogates were generally more accurate than POD-based ROMs [92].

A somewhat different approach for reducing the computational expense of high-fidelity analysis in hypersonic flow is to develop approximate aerodynamic pressure and heating models from steadystate CFD flow solutions [71, 92, 98, 99]. This approach is reasonable, since the high speed of the flow results in relatively low reduced frequencies and there are typically large differences in time scale between the fluid-structural dynamics and the heat transfer. Thus, the primary features of the flow are contained within a quasi-steady flow approximation for the pressure [71] and a static approximation for the aerodynamic heating [73,92]. The use of steady-state CFD is advantageous, since it is significantly faster to compute compared with time-accurate flow analysis. Scott and Pototzky [98] developed such an approach using separate steady-state flow solutions for the static and harmonic components of pressure. The static component of pressure was computed using the deflected mode shape, while the harmonic component was computed using either a transpiration boundary condition $[100,101]$ or manipulation of the expression for wash velocity to relate surface geometry to surface velocity. In [71,99], a local PT (LPT) approach [61] was implemented to compute the unsteady generalized aerodynamic forces (GAFs) on lifting surfaces. In this approach, the freestream flow quantities in PT are replaced with local flow quantities computed using steady-state CFD. In both studies, the LPT method resulted in improved flutter boundary predictions relative to classical nonlinear PT at a fraction of the computational cost for time-accurate CFD $[71,99]$.

Another approach considered in [71] was to augment the pressure computed from steady-state CFD, with unsteady terms extracted from PT. Figure 7 provides a comparison of the LPT and the hybrid CFD-PT approach $\left(\mathrm{NS}_{S S-\mathrm{PT}}\right)$, with VD and time-accurate NS for predicting the flutter boundary of the typical section shown in Fig. 5. Note that the Van Dyke theory is included here, since it provided the best agreement with the NS predictions compared with the other classical aerodynamic theories considered in [71]. For this configuration, the hybrid CFD-PT approach provided the best agreement with the flutter boundaries computed using time-accurate NS flutter compared with the LPT and VD methods.

A novel aspect of [71] was the use of a highly efficient kriging surrogate for the CFD, further reducing the computational expense of the hybrid CFD-piston and LPT approaches. In a follow-on study, this approach has been used to construct a surrogate-based 3-D aerodynamic heating ROM for control surfaces [92].

Recently, methods for ROM of the thermoelastic problem have also been investigated, both for linear [102-104] and nonlinear thermostructural responses [16,105-110]. Falkiewicz and Cesnik [104] provide a thorough review of past studies on reduced-order thermal modeling and identify several potential approaches: namely, Gunyan reduction and component mode synthesis [111], modal identification method [112-114], augmented eigenmodes [115], Lanczos method $[\underline{116}, 1 \overline{17]}]$, the force-derivative method $[\underline{118}, \underline{119}]$, and POD [103,104,120,121]. It is argued in [104] that POD is the superior approach for coupled fluid-thermal-structural problems, since it identifies a modal basis that captures the most energy from the fewest modes and is relatively robust to extrapolation in time and thermal loading conditions. This latter feature implies that a modal basis can be identified a priori to implementation in a fluid-thermalstructural analysis without the need to update the basis when the boundary conditions deviate from those used to generate the sampling data. To demonstrate this, Falkiewicz and Cesnik [104] computed POD modes from the first $500 \mathrm{~s}$ of a transient thermal response to a constant, uniform heat flux load, and then they used these modes to compute the transient thermal response to a temporally varying heat flux for $2000 \mathrm{~s}$ of response. The average spatial error norm of the ROM was less than $10 \%$ for the entire $2000 \mathrm{~s}$ of response. In related work, Falkiewicz and Cesnik [102] and Falkiewicz et al. [103] have developed a structural ROM framework, for coupling with their thermal ROM, using the Ritz method with a set of assumed discrete modes. The assumed modes are computed from a free vibration analysis of the full-order system at a reference thermal state.

Przekop and Rizzi $[108,109]$ investigated approaches for FEMbased ROMs intended for nonlinear response prediction to thermoacoustic loads. This work concluded that temperature increases in the structure primarily affect the linear stiffness coefficients. Furthermore, a modal basis consisting of symmetric transverse, antisymmetric transverse, symmetric in-plane, and antisymmetric in-plane modes is necessary for accurate nonlinear response prediction. The nonlinear stiffness coefficients were computed from the indirect stiffness approach. In an extension of this work [110], the problem of time-varying spatial acoustic loads, due to oscillating shocks as shown in Fig. , on modal basis selection was investigated. Results illustrated that a load-independent modal basis can be identified (and used to accurately represent the nonlinear structural dynamics) using POD system identification combined with a subsequent modal expansion to identify normal modes.

Spottswood et al. $[16,105]$ studied the nonlinear dynamic response of a curved beam with applied thermoacoustic loads. In [105], the nonlinear stiffness coefficients were computed using implicit condensation. Despite the added complexity of a curved structure, the use of the unheated linear free vibration bending modes as the modal basis provided sufficient fidelity for exploration of a design space. In a follow-on study [16], the modal basis was expanded to include membrane effects through an assumed quadratic functional form. Furthermore, an alternative ROM approach was considered that used a modal basis consisting of both linear free vibration bending modes and dual modes. The dual modes represented the high-frequency membrane displacements and were computed using POD on a set of snapshots of likely transverse motions generated from nonlinear finite element analysis (FEA). As shown in Fig. 9, both approaches provided good accuracy in capturing the dynamic response of the curved beam. Note that, in Fig. $\underline{9}$, the higher loading
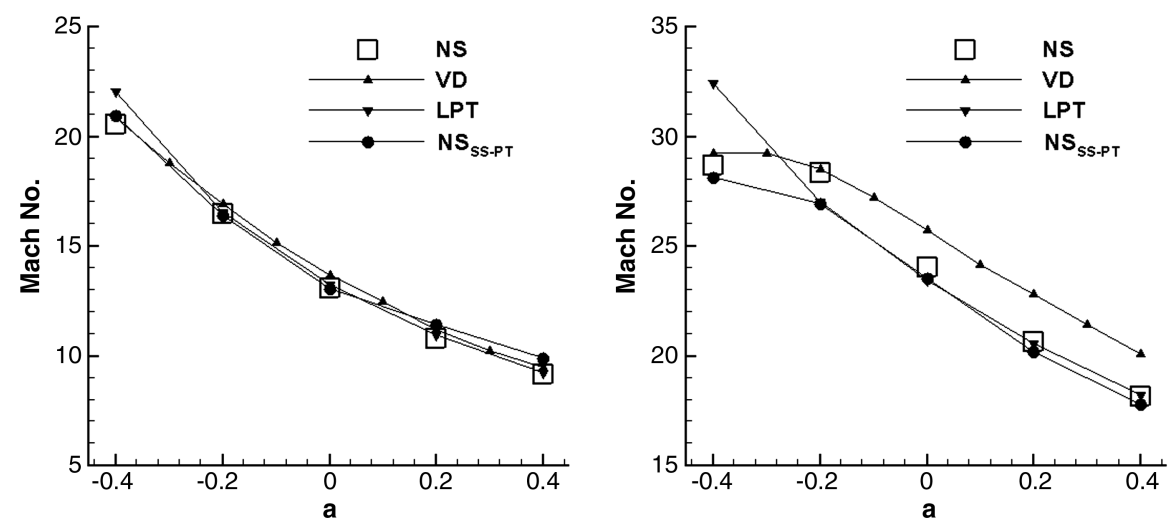

a) 40,000 feet

b) 60,000 feet

Fig. 7 Variation in the flutter Mach number of a double-wedge typical section, as a function of elastic axis offset parameter $a$, computed using several different aerodynamic models [71]. 


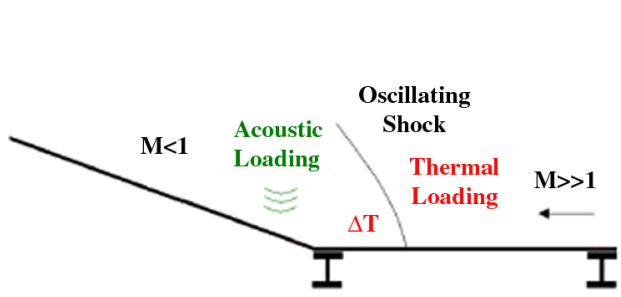

a) Schematic of shock oscillations

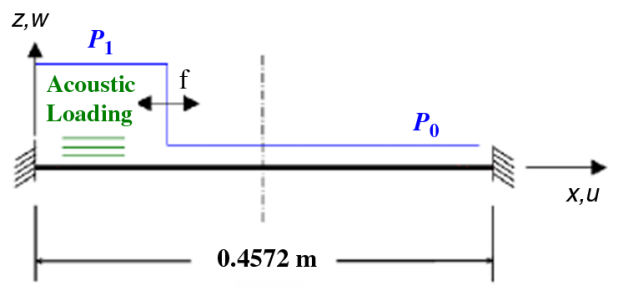

b) Fundamental model of time-varying spatial acoustic loads

Fig. 8 Time-varying spatial acoustic loads from an oscillating shock in hypersonic flow over a compression ramp [110].

cases included intermittent and nearly continuous snap-through events.

Reduced-order modeling of the nonlinear thermoelastic problem has been recently considered by Perez et al. [106,107]. Their approach uses a modal expansion of the spatial and temporal thermoelastic variables combined with a Galerkin approach to derive a set of coupled reduced-order nonlinear differential equations. Dual modes, in conjunction with problem specific enrichment functions, were used as a modal basis for the structural dynamics. For the steady thermal problem, thermal basis functions were selected as those satisfying the through-thickness one-dimensional (1-D) steady heat conduction equation, eigenvectors of the linear finite element approximation of the transient heat conduction problem on the top and bottom surfaces, and a set of linear in-plane functions to homogenize the thermal boundary conditions. For the transient thermal problem, under rapid heating conditions, the basis was augmented with a cubic through-thickness polynomial. Verification for several different cases, including structures composed of functionally graded materials, transient thermoacoustic loadings, and varying boundary conditions, indicated good accuracy relative to full-order FEA. Furthermore, the ROM predicted stresses with comparable accuracy to the temperature and displacement predictions.

\section{Fluid-Thermal-Structural Coupling}

As shown in Fig. 4, prediction of the dynamic response of a flexible structure in a hypersonic flow requires the simultaneous solutions of the fluid, structure, and heat transfer problems. Furthermore, it is evident from Eqs. (5-9) that the boundary conditions of these three fields are mutually dependent and transient due to coupling at the fluid-structural interface. Therefore, accurate coupling of the three systems is complicated. A detailed description

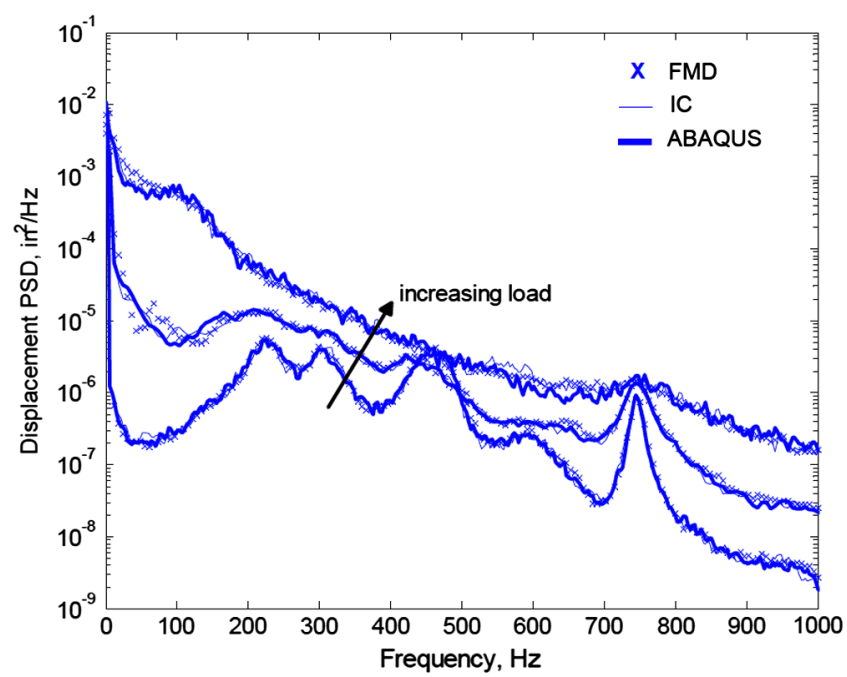

Fig. 9 Center displacement for a curved beam subject to a temperature rise of $\Delta T=150^{\circ}$ and random acoustic load, predicted using FEM and two different structural dynamic ROMs (IC denotes implicit condensation, FMD denotes full model with dual modes, and PSD denotes spectral density) [16]. of the various coupling mechanisms is conveniently carried out by considering three different problems, namely, 1) aerothermal coupling 2) fluid-structural coupling, and 3) aerothermal-aeroelastic coupling.

\section{Aerothermal Coupling}

As illustrated in the aerothermal part of Fig. 4, aerothermal coupling involves the mutual dependence of the aerodynamic heat flux and structural temperature at the fluid-structure interface. To demonstrate the primary features of this coupling, consider a simplified form of Eq. (3), where internal heat source and heat generation due to straining are neglected:

$$
\dot{q}_{\text {aero }}=\dot{q}_{\text {rad }}+\dot{q}_{\text {cond }}+\dot{q}_{\text {strd }}
$$

where

$$
\begin{gathered}
\dot{q}_{\text {aero }}=h_{h t}\left(T_{A W}-T_{W}\right) \\
\dot{q}_{\text {rad }}=\sigma_{S B} \epsilon T_{W}^{4} \\
\dot{q}_{\text {cond }}=\left(\lambda_{S} \frac{\partial T}{\partial \mathbf{n}}\right)_{S} \\
\dot{q}_{\text {strd }}=\rho_{S} c_{p S} \frac{\partial T_{S}}{\partial t}
\end{gathered}
$$

Thus, the heat transfer is governed by an energy balance between the convective heating by the fluid $\dot{q}_{\text {aero }}$ and heat conduction into the structure $\dot{q}_{\text {cond }}$, radiation out to space $\dot{q}_{\text {rad }}$, and energy stored in the wall $\dot{q}_{\text {strd }}[26,74]$. Note that $h_{h t}$ is the convection heat transfer coefficient, $\bar{T}_{A W}$ is the adiabatic wall temperature (i.e., fluid temperature where there is no heat transfer at the wall), $T_{W}$ is the wall temperature at the fluid-structure interface, $\sigma_{S B}$ is the StefanBoltzmann constant, and $\epsilon$ is the surface emissivity.

The heat transfer problem is driven by Eq. (11) or, more specifically, the adiabatic wall temperature $T_{A W}$ [74]. The dependence of the aerodynamic heat flux on the surface wall temperature is evident in Eq. (11), which indicates that the heat flux decreases with increasing wall temperature. In addition to this direct coupling, note that the convection heat transfer coefficient is also a relatively weak function of wall temperature, where recent study [122] has shown that neglect of this coupling in a quasi-static aerothermoelastic analysis results in $\mathcal{O}(10 \%)$ overprediction of the surface temperature.

\section{Fluid-Structural Coupling}

As shown in Fig. 4, fluid-structural coupling involves simultaneous interactions at the fluid-structural interface between the aerodynamic, inertial, and elastic forces in the system. For lowfidelity modeling approaches, exact coupling of the structural equations of motion to the unsteady aerodynamics is straightforward, since the approximate aerodynamics provide point function relationships between the surface motion and aerodynamic pressure. Thus, the approximate unsteady aerodynamic theories can be directly incorporated into the structural equations of motion as 


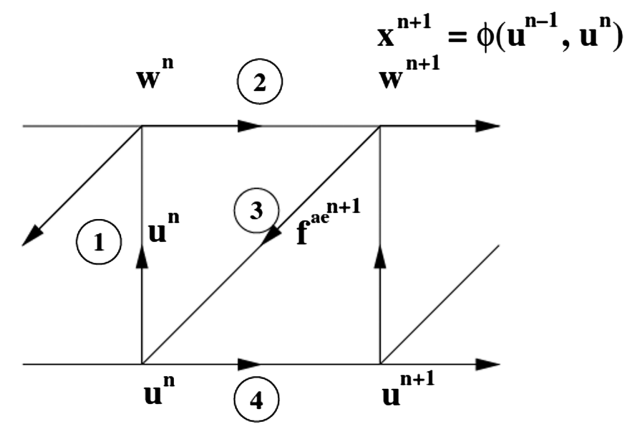

Fig. 10 Cycle of the conventional serial staggered time-marching approach for partitioned fluid-structural coupling [132].

deformation-dependent loads, leading to nonlinear aerodynamic stiffness and damping terms.

Fluid-structural coupling using high-fidelity numerical approaches represents a significant challenge. A basic requirement of fluid-structural coupling is to maintain accurate and stable time integration of the governing equations. The complexity is due to the requirement to accommodate the differences in reference frame between the governing equations of the fluid and structure (i.e., Eulerian vs Lagrangian) $[55,123]$. This issue has produced different techniques, such as the transpiration boundary condition approach $[100,101]$, the ALE approach [124], the corotational approach [125], and the space-time formulation [126,127]. An additional constraint, as evident from Eqs. (5-7), is to enforce both kinematic and kinetic boundary conditions $\overline{-}$ at the moving fluid-structure interface $[\underline{55,123]}$.

There are two basic categories of fluid-structural coupling: namely, monolithic or partitioned [128-132]. For monolithic solvers, the governing equations of the fluid and structure are combined into a consistent scheme and marched forward in time simultaneously. In a partitioned approach, the fluid and the structure are solved using separate CFD and computational structural dynamic solvers. Each approach has advantages and disadvantages. An advantage of monolithic schemes is the use of consistent time advancement, which results in inherent time accuracy of the solution. However, development of these schemes requires considerable refinements due to different mathematical properties of the governing equations [132]. In addition, monolithic schemes eliminate modularity between the fluid and structural solvers, which complicates the integration of new numerical schemes and models as the state of the art in the each solver improves [132]. The principal advantage of a partitioned approach is modularity of the fluid and structural solvers. Thus, advances in technology in each area can be readily incorporated. Furthermore, the governing equations for the fluid and structure are solved using the most suitable numerical schemes for each class of problem $[128,132]$. Despite these advantages, partitioned schemes must address two issues: namely, accurate
1) projection of loads/deformation between each solver and 2) time advancement. The first issue is a challenge, since the fluid and structural solvers commonly have mismatched grids [130,133-135]. The challenge of time advancement in partitioned approaches arises due to lag of the structural and fluid response during each cycle of information between solvers, as shown by the conventional serial staggered sequence [132] in Fig. 10. Such delays can lead to degradation of time accuracy and numerical instabilities that may produce spurious aeroelastic instability $[\underline{123}, 132]$.

The advantages of partitioned approaches over monolithic schemes has led to a significant body of research that effectively eliminates concern over time accuracy $[128,129,132]$ and load/ displacement projection [130,133-135]. For example, Jaiman et al. [135] have demonstrated integration over a commonly refined surface, depicted in Fig. 11, achieves numerical accuracy and conservative load transfer on mismatched grids. As shown in Fig. 11, the commonly refined surface represents the intersection of elements between the fluid and structural meshes; that is, every fluid and structural node has a node on the commonly refined surface. These nodes are then used to form subelements, over which the fluid loads are integrated for application to the structure. A common approach for maintaining time accuracy on partitioned numerical integration schemes is the use of subiterations between each time step (i.e., strongly coupled) [136-139]. However, work by Farhat et al. [132] has proved that subiteration free (i.e., loosely coupled) second-orderaccurate fluid-structure numerical integration approaches can be constructed, provided 1) the fluid time integrator is second-order time-accurate on moving grids, 2) a second-order time integrator is used as a predictor for structural motion, 3) the algorithm for timeintegrating fluid-mesh motion is carefully designed, 4) load transfer is at least first-order time-accurate, and 5) the structural dynamics are time integrated using the midpoint rule [132].

\section{Aerothermal-Aeroelastic Coupling}

The need to incorporate aerodynamic heating effects in an aeroelastic analysis of hypersonic configurations poses difficulties due to orders of magnitude differences in time scales between the heat transfer and aeroelastic responses, as well as the dependency of the heat transfer process on the vehicle trajectory. These two attributes of the problem imply that a realistic aerothermoelastic analysis must be carried out over many time steps for long time records. Even when employing relatively simple fluid, thermal, and structural models, such an analysis is computationally expensive [73]. Historically, the aerothermoelastic problem shown in Fig. 4 has been simplified by making three basic assumptions that decouple the aerothermal and aeroelastic problems $[35,45,54,140]$ :

1) Thermodynamic coupling between heat generation and elastic deformation is negligible.

2) Dynamic aeroelastic coupling is small; that is, the characteristic time of the aerothermal system is large relative to the time periods of the natural modes of the aeroelastic system.

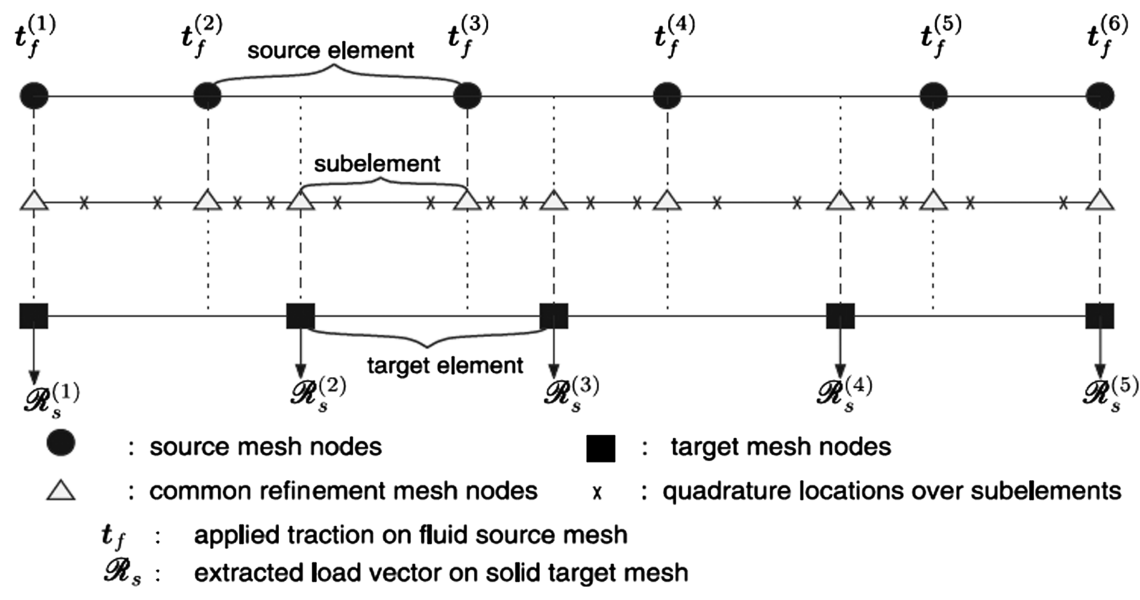

Fig. 11 Conservative load transfer using a commonly refined surface [135]. 
3) Static aeroelastic coupling is small; that is, total elastic deflections are insufficient to alter the temperature distribution. When using these assumptions, the aerothermal solution is obtained first in order to compute the transient temperature distribution in the structure, and the aeroelastic analysis is then carried out on the heated structure. This approach is sometimes denoted one-way coupling, since it neglects path 2 in Fig. 4. A common implementation of this approach is to assume a temperature distribution in the structure before performing the aeroelastic analysis.

Among the different assumptions used to decouple the aerothermal and aeroelastic solution sequences, the third is the most questionable. As shown in Fig. 12, surface deformations will locally modify the flow by introducing shocks/expansion fans and lead to spatially varying temperature distributions. The inclusion of these effects is denoted here as two-way coupling, since it includes path 2 in Fig. 4.

Despite its potential importance, only a limited amount of studies have considered two-way coupling in hypersonic flow. Two-way coupling was considered for aerodynamically heated panels [141] and leading edges [142] using a staggered procedure to couple the finite element flow-thermal, thermal, and structural models. The solution sequence alternated between coupled flow-thermal analysis of the fluid-structure and thermal analysis of the structure. At select times, the quasi-static structural deformation due to thermal loading was updated. Two-way coupling was also considered for metallic thermal protection panels using a two-dimensional boundary element method [143] and the FEM [144] for thermal and structural models, each loosely coupled to a hypersonic CFD code. Bowing of the metallic panels into the flow was modeled using an iterative procedure to compute the quasi-static deformation under transient heating [144]. Two-way coupling was approximated in two panel flutter studies $[145,146]$ by setting the panel temperature equal to the steady-state adiabatic wall temperature combined with the instantaneous local fluid temperature. The instantaneous local fluid temperature as a function of deformation was computed using an isentropic pressure-temperature relationship, where the deformation-dependent pressure was computed from linear PT [57,147]. This is a crude approximation for the aerothermodynamics, particularly since it has been found that linear PT is unreliable in hypersonic flow [71].

A comprehensive study on the importance of two-way coupling on aerothermoelastic stability and response prediction was completed recently in [73]. To obtain a tractable configuration, cylindrical bending of a von Kármán panel was assumed. The aerodynamic pressure was modeled using third-order PT [ [56,57], and the aerodynamic heating was computed using the Eckert reference enthalpy method [72]. The aerodynamic heating was coupled to the structural displacement using the pressure from PT combined with an isentropic flow assumptions for the inviscid fluid properties required for the Eckert heating method. Also, arbitrary through-thickness and chordwise temperature distributions were included for the in-plane thermal loads and temperature-dependent material properties. Results indicated that two-way coupling can significantly impact the aerodynamic heating and transient temperature distributions and nonlinear transient panel response. The results also indicated that the importance of two-way coupling increases with the duration of the

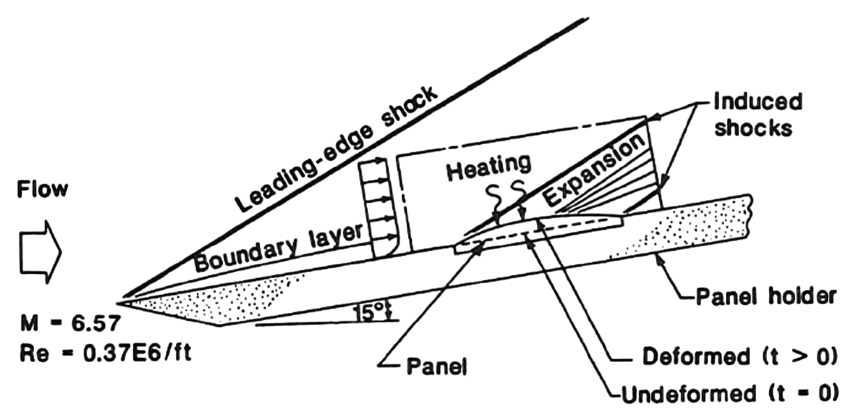

Fig. 12 Aerothermoelastic response of a skin panel in hypersonic flow [149]. hypersonic trajectory. Also, due to large differences in time scale between the heat transfer and aeroelastic problems, the implementation of a quasi-static and time-averaged dynamic (i.e., average of structural response for several aeroelastic time steps per aerothermal time step) aerothermal-aeroelastic coupling leads to substantial reductions in computational expense with negligible loss of accuracy. For the case studied, quasi-static coupling required less than $1 \%$ of the computational time of a simultaneous time-marching solution. Time-averaged dynamic coupling required less than $4 \%$ of the computational time.

In an expanded follow-on study [122], the simple thermoelastic panel model was replaced with a FEM model of the stiffened carboncarbon panel shown in Fig. 13. This configuration is based on a stiffened-skin panel located on the inlet ramp of a conceptual airbreathing hypersonic vehicle [148]. The skin temperatures and surface ply failure index from a quasi-static analysis are shown in Fig. 14. The surface ply failure index is based on the Tsai-Hill criterion, where a value of zero corresponds to zero stress and values of one or greater indicate ply failure. Each case considered has a fourdigit number that corresponds to a different type of coupling considered, where each digit corresponds to the labeled arrows in Fig. 15. For example, type S-1234 represents a quasi-static analysis of a complete set of interactions, whereas type S-1030 includes only the arrows labeled 1 and 3. Note that a quasi-static decoupled analysis is represented by the arrows labeled 1 (i.e., type S-1000).

Uncertainty of in-plane boundary conditions was also investigated in [122] by considering two cases: 1 ) free expansion ( $0 \%$ spring) and 2) linear spring (10\% spring). The spring stiffnesses for the linear spring case were set to $10 \%$ of the product of fiber Young's modulus and plate thickness. It is clear from Fig. 14 that mechanical in-plane boundary conditions have a strong influence on the magnitude of aerothermal-aeroelastic coupling. For the free expansion cases, outof-plane displacements are small, and a one-way aerothermalaeroelastic coupling is sufficient. However, the linear spring cases resulted in an order of magnitude increase in out-of-plane displacement: increasing the importance of two-way aerothermalaeroelastic coupling (case S-1234). For the linear spring case, the neglect of two-way aerothermal-aeroelastic coupling (i.e., cases S-1000, S-1030, and S-1034) resulted in surface ply index failure predictions well below the failure criteria, while the two-way coupled analysis predicted panel failure.

These results, combined with other results in [122], indicate that, for small panel displacements $[\mathcal{O}(1 \%)$ of panel length], neglecting the dependence of aerodynamic heating on structural deformation results in $\mathcal{O}(10 \%)$ uncertainty in surface temperature and $\mathcal{O}(100 \%)$ uncertainty in surface ply failure index.

\section{Coupled Analysis Using Combined Computational Fluid Dynamics and Computational Thermostructural Dynamics}

A comparison of Figs. $\underline{4}$ and 16 indicates that aerothermalaeroelastic coupling for an integrate $\overline{\mathrm{d}} \mathrm{CFD}-\mathrm{CTSD}$ aerothermoelastic analysis is a complex endeavor. In this case, the aerothermoelastic problem cannot be divided conveniently into distinct aerothermal and aeroelastic problems. Thus, in addition to substantial increases in computational requirements, formulating an accurate and efficient coupling process poses another hurdle. To the authors' knowledge, a tightly coupled CFD-CTSD dynamic aerothermoelastic analysis has not been conducted to date.

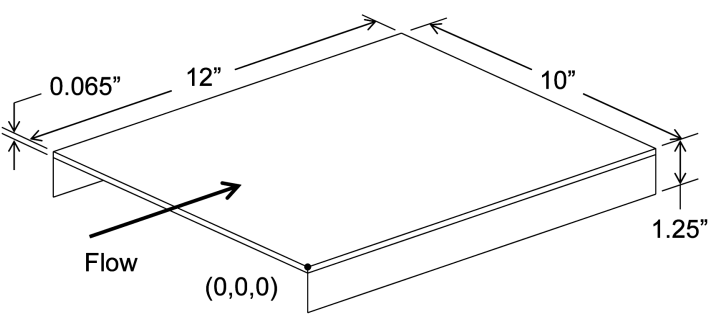

Fig. 13 Representative stiffened carbon-carbon skin panel from a generic hypersonic vehicle $[\underline{122,148]}$. 


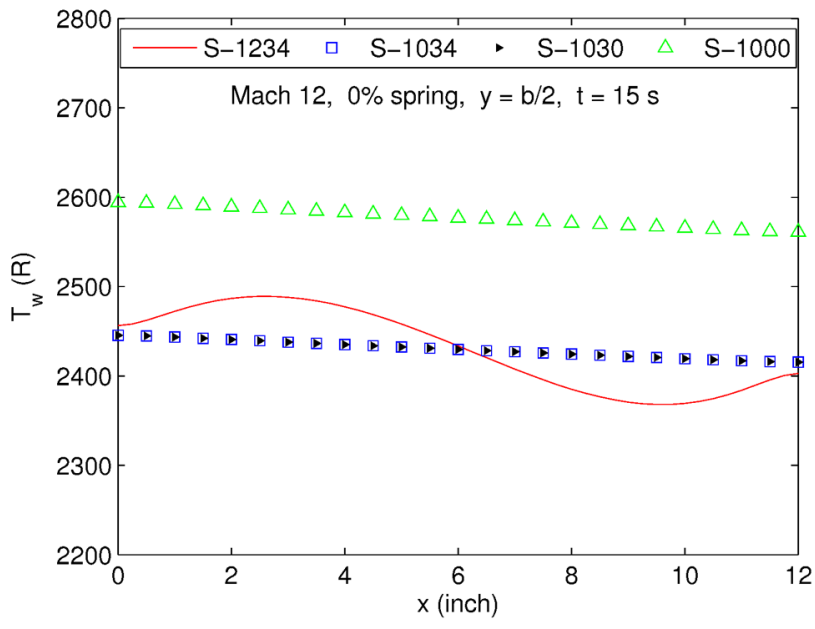

a) Skin temperature: $0 \%$ spring

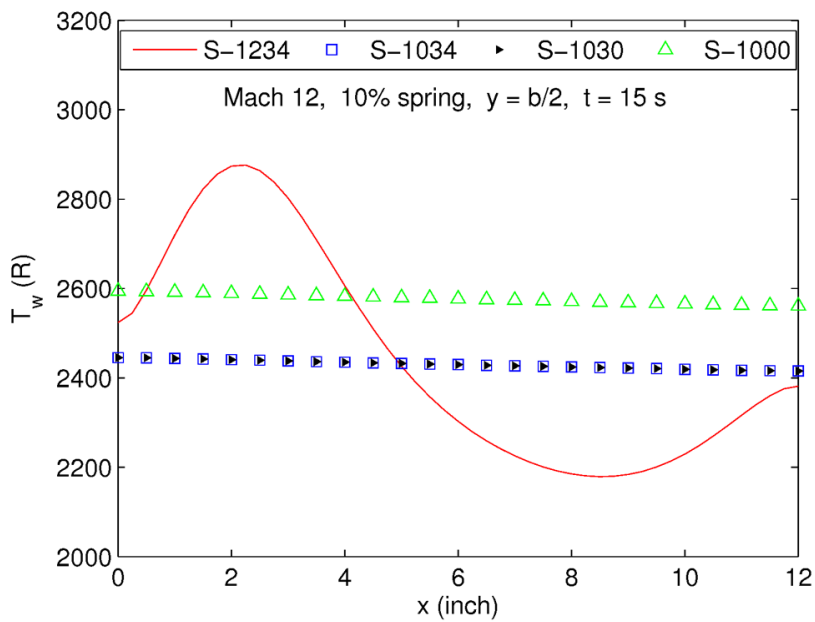

c) Skin temperature: $10 \%$ spring

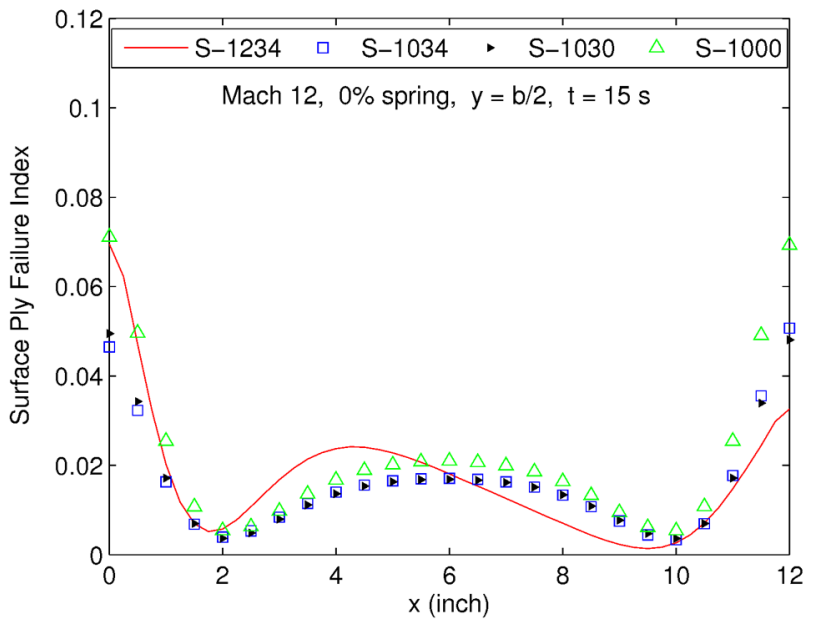

b) Surface ply failure index: $0 \%$ spring

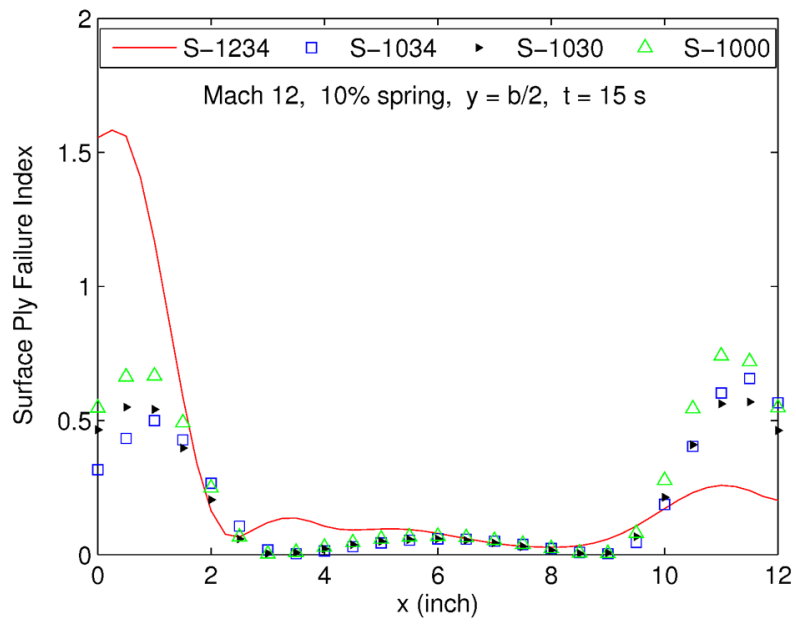

d) Surface ply failure index: $10 \%$ spring

Fig. 14 Center displacement, deformation, temperature, and failure index along flow-direction centerline of a carbon-carbon skin panel (Mach 12, and 0 and $10 \%$ spring) [122].

As mentioned, Thornton and Dechaumphai [141], Dechaumphai et al. [142], and Wieting et al. [149] implemented a quasi-static finite element approach for an integrated CFD-CTSD code. The aerodynamic heating was computed by solving the NS equations. In a related study, Loehner et al. [150] implemented a loosely coupled algorithm, which combined existing CFD and CTSD codes. The authors chose the CFD code FEFLO98 [151], the CTSD codes COSMIC-NASTRAN [152] (linear structure and heat transfer), and DYNA3D $[153,154]$ (nonlinear structure). Loose coupling of these codes was accomplished by selecting a master surface for a specific variable and interpolating/projecting that variable to the other codes at each time step. The method was applied to several examples, including a generic weapons fragmentation, a nose-cone configuration, and an aerodynamically heated panel configuration studied by Thornton and Dechaumphai [141].

Tran and Farhat [155] used an integrated fluid-structure-thermal solver to perform an analysis on the aerodynamic heating of an F-16 airfoil and a computational aerothermoelastic (CATE) stability analysis of a flat panel. The aerothermoelastic formulation [155] was an extension of a previous aeroelastic formulation developed by Farhat et al. [131]. In the aerothermoelastic analysis, only one-way thermal coupling was considered. In this case, stress and deformations due to temperature changes are included; however, feedback is neglected between the stress/deformations and the aerodynamic heating computations. The fluid, structure, and mesh dynamics were solved separately in a serial manner, and the solutions from each computational domain were then transferred via the interface boundary in order to account for interaction effects.

A CATE methodology that incorporated the heat transfer between the fluid and the structure using CFD-based aerodynamic heating computations was described in [70]. This CATE analysis procedure was used to study the aerothermoelastic behavior of a low-aspectratio wing in hypersonic flow. For the CATE analysis, the aerodynamic heating conditions were obtained from the CFD solver

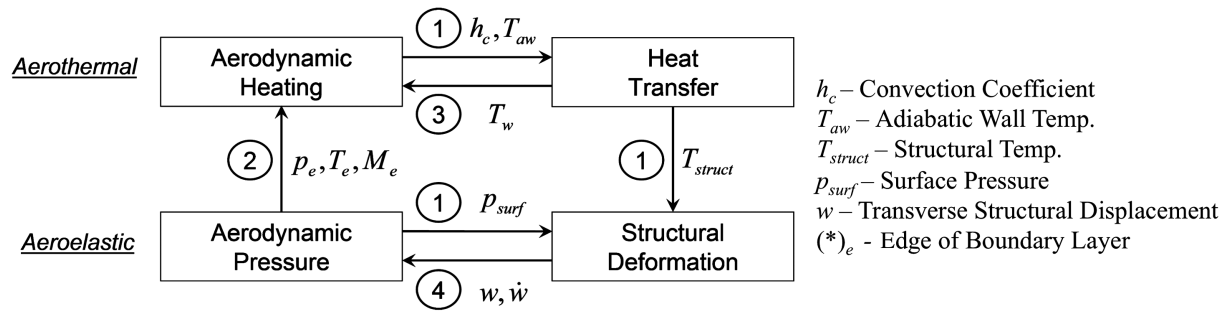

Fig. 15 Mechanisms for flow-thermal-structural coupling. 


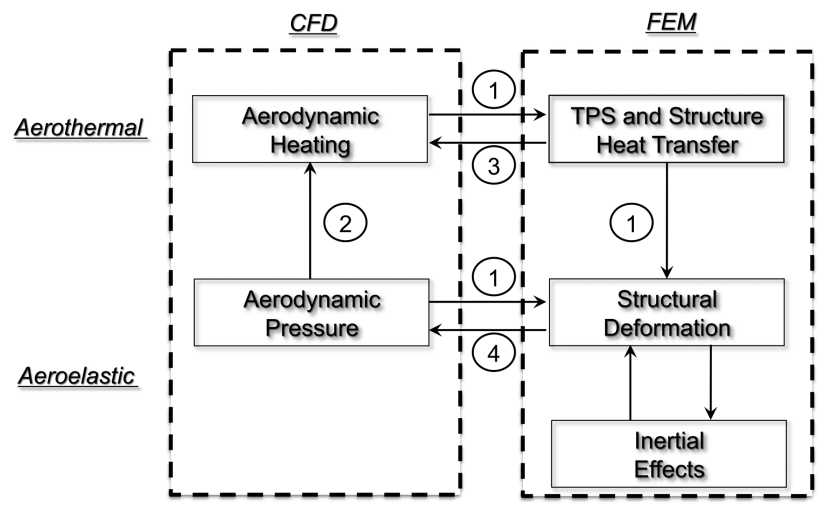

Fig. 16 Basic structure of the aerothermoelastic problem when solved using coupled CFD and CTSD solvers (TPS denotes thermal protection system).

and passed to the FEA module. A finite element heat transfer analysis was conducted and subsequently used to compute the heated free vibration modes and frequencies. Similar to Tran and Farhat [155], only a one-way aerothermal-aeroelastic coupling was considered.

\section{Experimental Research}

The majority of experimental studies on hypersonic aeroelasticity and aerothermoelasticity was conducted in the 1950s and early 1960s $[36-42,49,50]$. Early interest in high-speed flight during the 1950s motivated two experimental hypersonic studies $[36,37]$ aimed at examining the flutter of wings proposed for high-speed vehicles. Lauten et al. [36] conducted experimental tests on a dynamically and elastically scaled model of a proposed all-movable horizontal tail surface for the X-15. The prototype had an aspect ratio of 2.5, a taper ratio of 0.305 , and a sweep angle at the quarter-chord of $45^{\circ}$. No flutter was observed at the tunnel test conditions for $M_{\infty}=6.86$. Analytical calculations of the flutter speed, using PT aerodynamics, indicated a flutter speed approximately four times higher than the velocity obtained in the tests. This behavior can be attributed to the high stiffness of the model, where the first four free vibration frequencies were 44, 115, 148, and $172 \mathrm{~Hz}$, respectively. In a similar study [37], the flutter of a low-aspect-ratio boost-glide-vehicle wing prototype was considered at $M_{\infty}=3.0$ and $M_{\infty}=7.3$. As shown in Fig. 17, none of the models tested experienced flutter at the tunnel operating conditions. Similar to [36], this can also be attributed to high model stiffness. The most flexible model had free vibration frequencies of $\omega_{1}=36.1 \mathrm{~Hz}, \omega_{2}=126.6 \mathrm{~Hz}$, and $\omega_{3}=244.1 \mathrm{~Hz}$.

This initial work was followed by more systematic, parametric studies conducted by several researchers. In [39], the effects of planform geometry, airfoil thickness, and leading-/trailing-edge radii on the aeroelastic behavior of single- and double-wedge airfoils was studied experimentally for $0.7<M_{\infty}<6.86$. The tests in hypersonic flow were conducted on square planform, double-wedge airfoil, allmovable-control-type models having leading- and trailing-edge radii from 0 to $6 \%$ chord and airfoil thicknesses from 9 to $20 \%$ chord. For supersonic and hypersonic Mach numbers, analytical flutter results were computed using second-order PT. Increasing airfoil thickness had a destabilizing effect at the supersonic and hypersonic Mach numbers [39]. Also, increasing airfoil bluntness had a stabilizing effect at the upper Mach number range. It was also found that the agreement between the PT and experimental analysis improved with increasing Mach number. At $M_{\infty}=6.86$, the flutter boundary predicted using second-order PT aerodynamics was within $20 \%$ of the experimental flutter boundary. In general, the PT results were nonconservative when compared with the experimental flutter boundaries.

Sewall et al. [40] conducted an analytical and experimental flutter study of spring-mounted cones at $M_{\infty}=6.83$ and $M_{\infty}=15.4$. The analytical results were obtained using second-order PT, SE, and unsteady Newtonian aerodynamics. The cones tested had both pitch and plunge DOFs and a thickness-to-chord ratio of $26 \%$. The flutter-

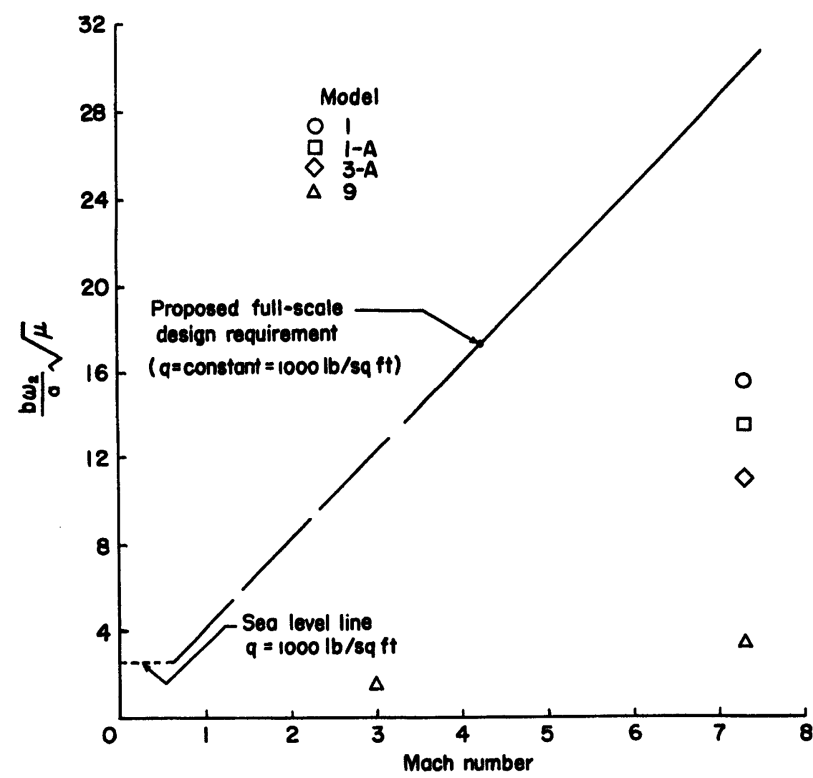

Fig. 17 Comparison of model test conditions (no flutter occurred at any conditions) with proposed design requirement of full-scale vehicle [37].

speed index for this configuration as a function Mach number and the ratio of plunge to pitch natural frequency are depicted in Figs. 18 and 19. It is evident that unsteady Newtonian aerodynamics provide the best correlation with the experimental results, particularly for $M_{\infty}=15.4$. This is most likely due to the use of a relatively thick cone geometry, for which the use of Newtonian aerodynamics is most appropriate [1].

Young [41] examined the effect of angle of attack and airfoil thickness on the binary flutter of a double-wedge airfoil section wing at $M_{\infty}=10.0$. The analytical results were generated using thirdorder PT aerodynamics. In particular, both an 11- and 15\%-thick airfoil section were tested at angles of attack ranging from 0 to $10^{\circ}$. Results shown in Fig. 20 indicate that increasing the thickness and angle of attack of the airfoils decreased the flutter boundary. Also, the flutter velocity predicted using PT aerodynamics was generally within $6 \%$ of the experimental results.

Goetz [42] conducted experimental and analytical aeroelastic studies on the effect of leading-edge bluntness for square planform, double-wedge airfoils at $M_{\infty}=15.4$. The leading- and trailing-edge radii were varied from $0,1,3$, and $6 \%$ of chord. The results shown in Fig. 21 indicate that increasing leading-edge bluntness to $1 \%$ chord has a stabilizing effect, and additional increases in bluntness are destabilizing. Analytical results were generated using both unsteady Newtonian aerodynamics as well as a combined Newtonian-PT method. In the combined method, Newtonian aerodynamics were used in the leading-edge regions, while PT was used in the remaining sections. The ratio of theoretical flutter velocity to experimental flutter velocity is shown in Fig. 22. Differences between the theoretical and analytical results of up to $20 \%$ were observed in the flutter velocity. In general, it was found that the combined Newtonian-PT approach generated conservative results, while the Newtonian approach was nonconservative.

In a follow-on study [49], the effect of leading-edge sweep on the aeroelastic behavior of delta-planform lifting surfaces was examined. Again, the tests were conducted at $M_{\infty}=15.4$. Several profile shapes were investigated, such as blunt single wedges, double wedges, and slabs, where each shape had leading-edge radii of 1.25, 1.25 , and $2.5 \%$ of their local chord, respectively. All of the profile shapes had a 5\% maximum thickness-to-chord ratio [49]. Results in Fig. 23 indicate that increasing the leading-edge sweep angle from $60^{\circ}$ to approximately 65 or $70^{\circ}$ was destabilizing; however, further increases were stabilizing. It was noted, however, that wind-tunnel effects may have contributed to the higher sweep angle results. Goetz [49] also compared the results to those computed using PT and Newtonian unsteady aerodynamics, as shown in Fig. 24. It was found 

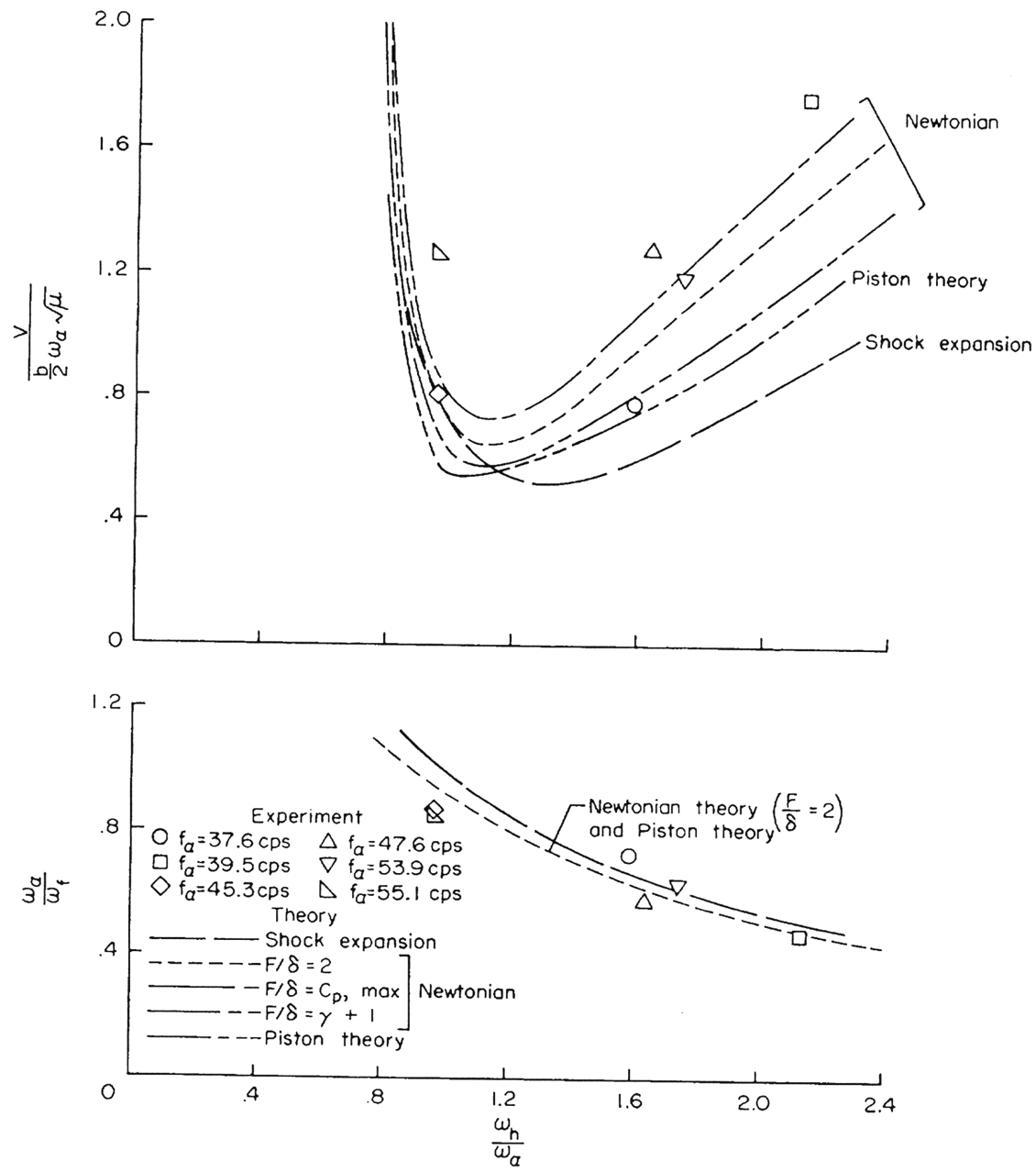

Fig. 18 Experimental and analytical flutter boundary of a 2-DOF cone in Mach 6.83 flow [40].
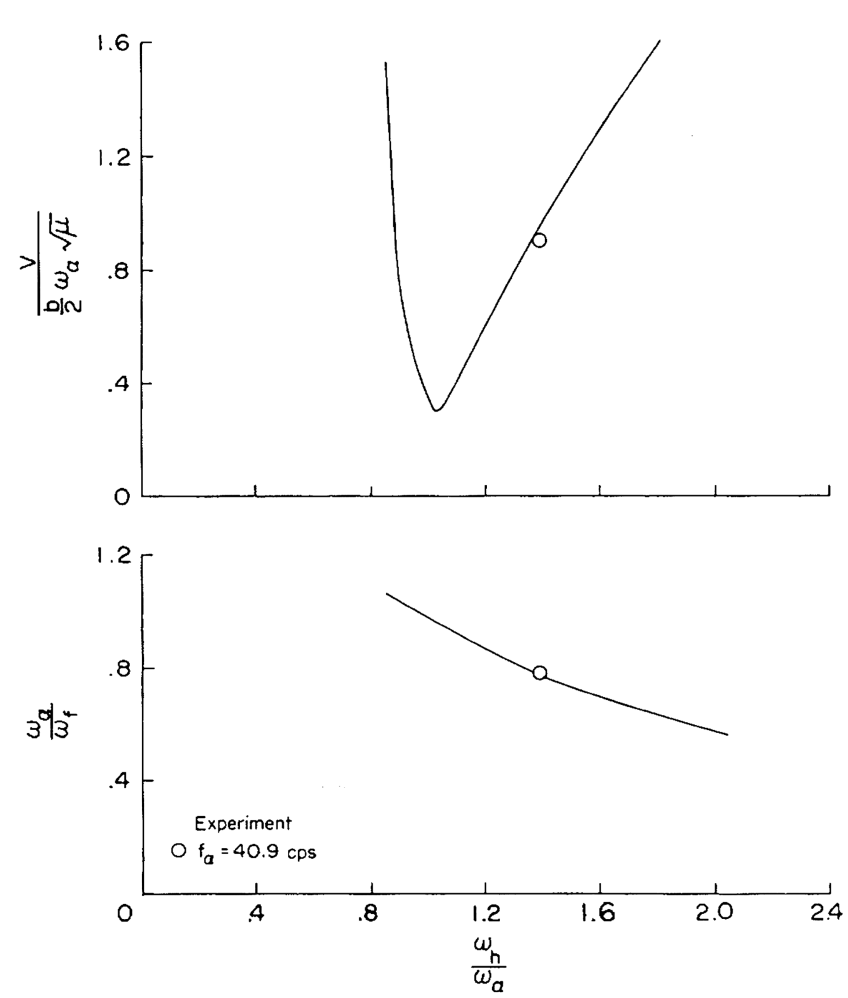

Fig. 19 Experimental and analytical (Newtonian aerodynamics) flutter boundary of a 2-DOF cone in Mach 15.4 flow [40]. that the PT and Newtonian results for flutter speed were conservative when compared with the experimental results. Furthermore, the Newtonian-based predictions were closer to the experimental flutter velocities for all of the cases considered. The PT flutter velocities were up to $50 \%$ lower than the experimental flutter velocities, while the Newtonian flutter velocities were only $25 \%$ lower than the experimental results.

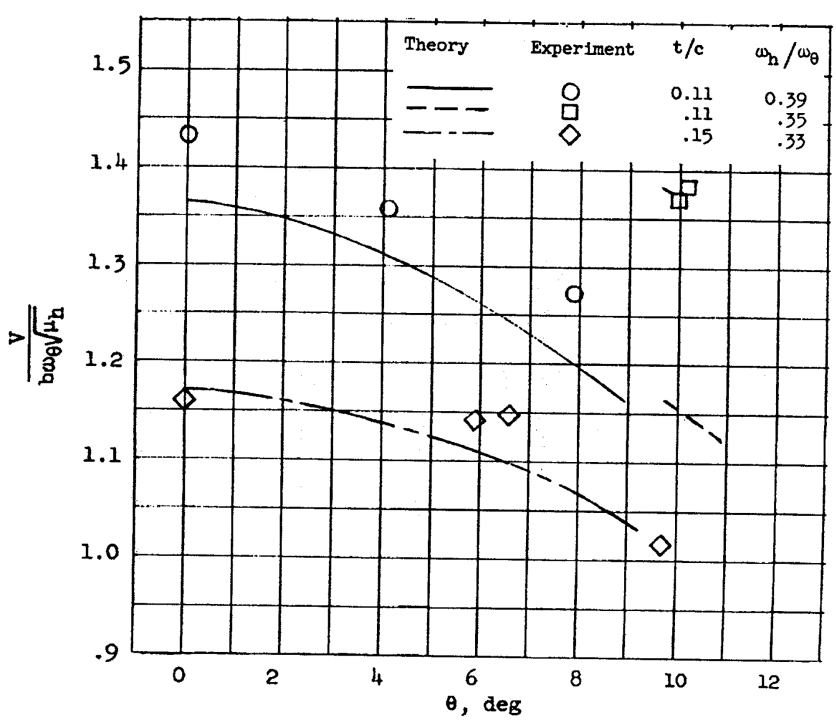

Fig. 20 Comparison of experimental and theoretical flutter results for several double-wedge airfoil configurations at varying angles of attack [41]. 


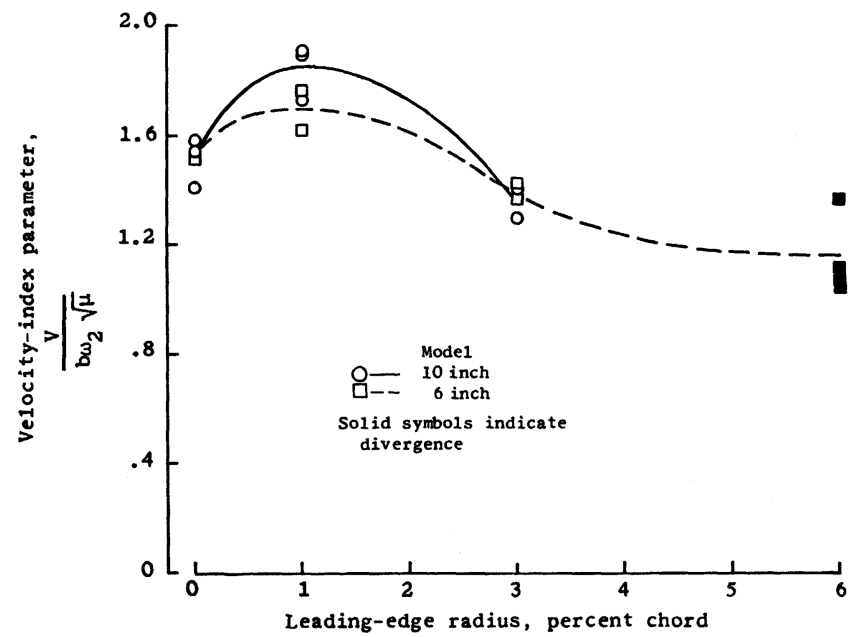

Fig. 21 Variation of velocity-index parameter as a function of leadingedge radius [42].

In a third study, Goetz and Sewall [50] conducted an experimental investigation of a wing-fuselage configuration at $M_{\infty}=15.4$. In parallel, results were also generated, analytically employing both PT aerodynamics and a combination of PT and Newtonian aerodynamics. Results indicated that, while the analytical flutter boundary predictions followed similar trends to the experimental data, they were nonconservative by anywhere from 3 to $80 \%$. The use of combined Newtonian-PT aerodynamics did not produce significant

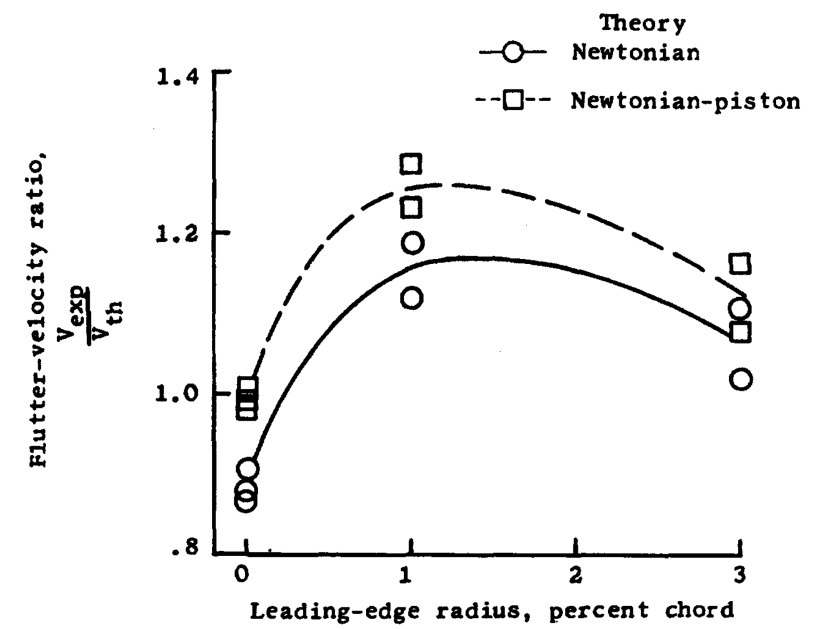

a) 10-in models

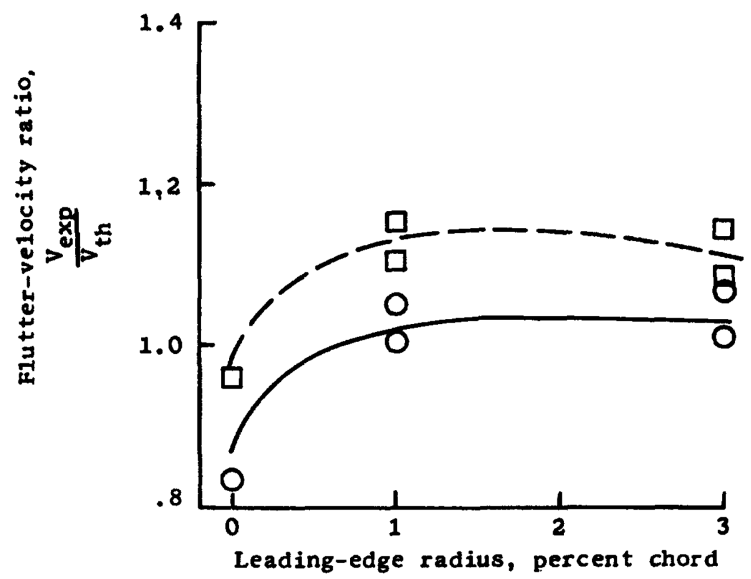

b) 6-in models

Fig. 22 Variation of flutter-speed index parameter as a function of leading-edge radius [42].

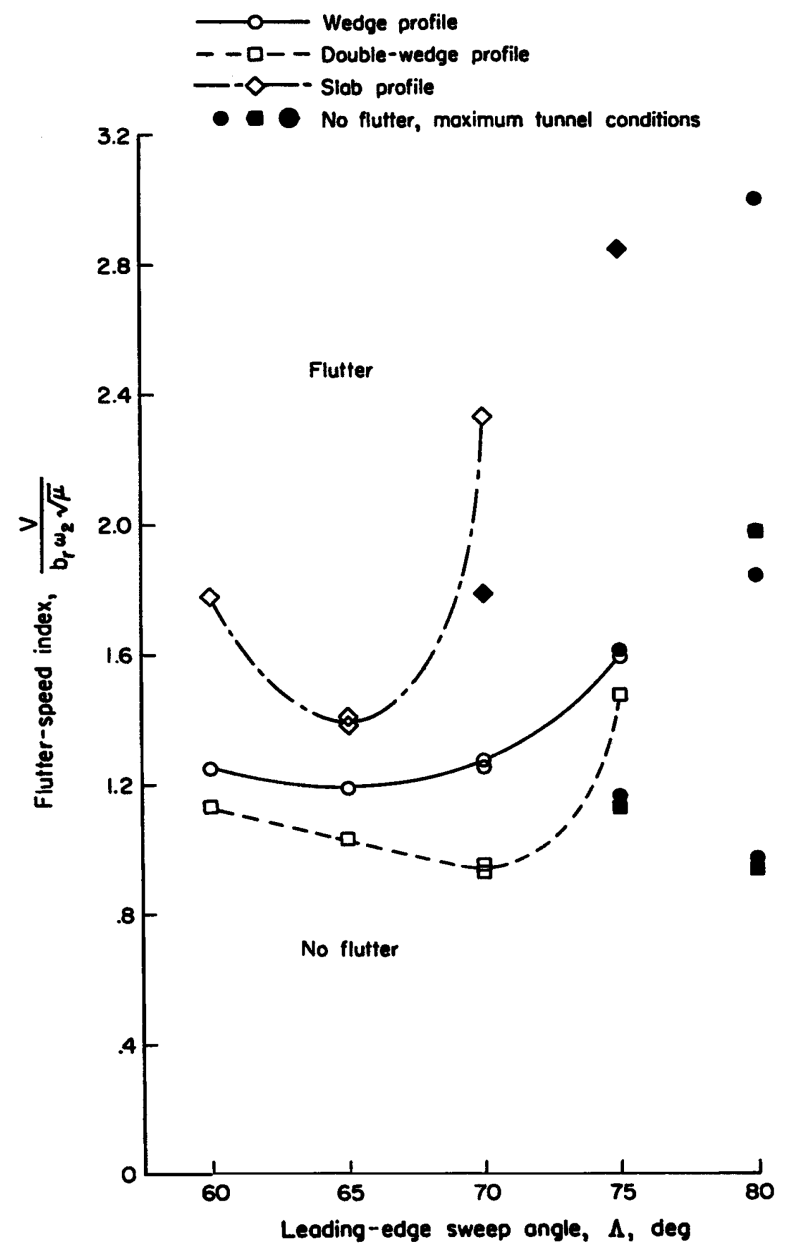

Fig. 23 Variation of flutter-speed index parameter with leading-edge sweep angle [49].

improvements in the flutter solution compared with those obtained using only PT aerodynamics. A possible explanation for the large discrepancies was the use of only the first four symmetric structural modes in the analysis. Thus, better correlation between the approximate and experimental results, due to higher-order modes, could not be ruled out. Unfortunately, the model was destroyed during testing before higher-order modes could be measured.

In a fourth study by Goetz [51], empirical lift curve slopes and aerodynamic center locations were used to conduct a quasi-steady flutter analysis of 2-DOF double-wedge airfoils. The airfoil configurations used were similar to those studied in [39,42]. The results of the semiempirical quasi-steady analysis were compared with both experimental results and those obtained using Newtonian and PT unsteady aerodynamics. Two fundamental conclusions from this study were as follows:

1) The moment related to damping in pitch is important to the flutter solution.

2) The semiempirical quasi-steady approach did not significantly improve the accuracy of flutter predictions compared with approaches based on PT and Newtonian aerodynamics. Some typical results obtained in [51] are shown in Fig. 25.

In a study conducted during the NASP era [6] , the hypersonic aeroelastic behavior of several different delta-wing configurations, with both slab and double-wedge airfoil sections, was investigated experimentally in the NASA Langley Research Center Mach 20 helium tunnel. The configurations were tested at $16.7<M<18.1$, and reduced frequencies were below 0.09 . The results were compared with analytical predictions obtained from linearized second-order PT aerodynamics. Both blunt and sharp leading/trailing edges were considered, and the double-wedge airfoils had a $4 \%$ thickness-to-chord ratio. The principal findings were as follows: 

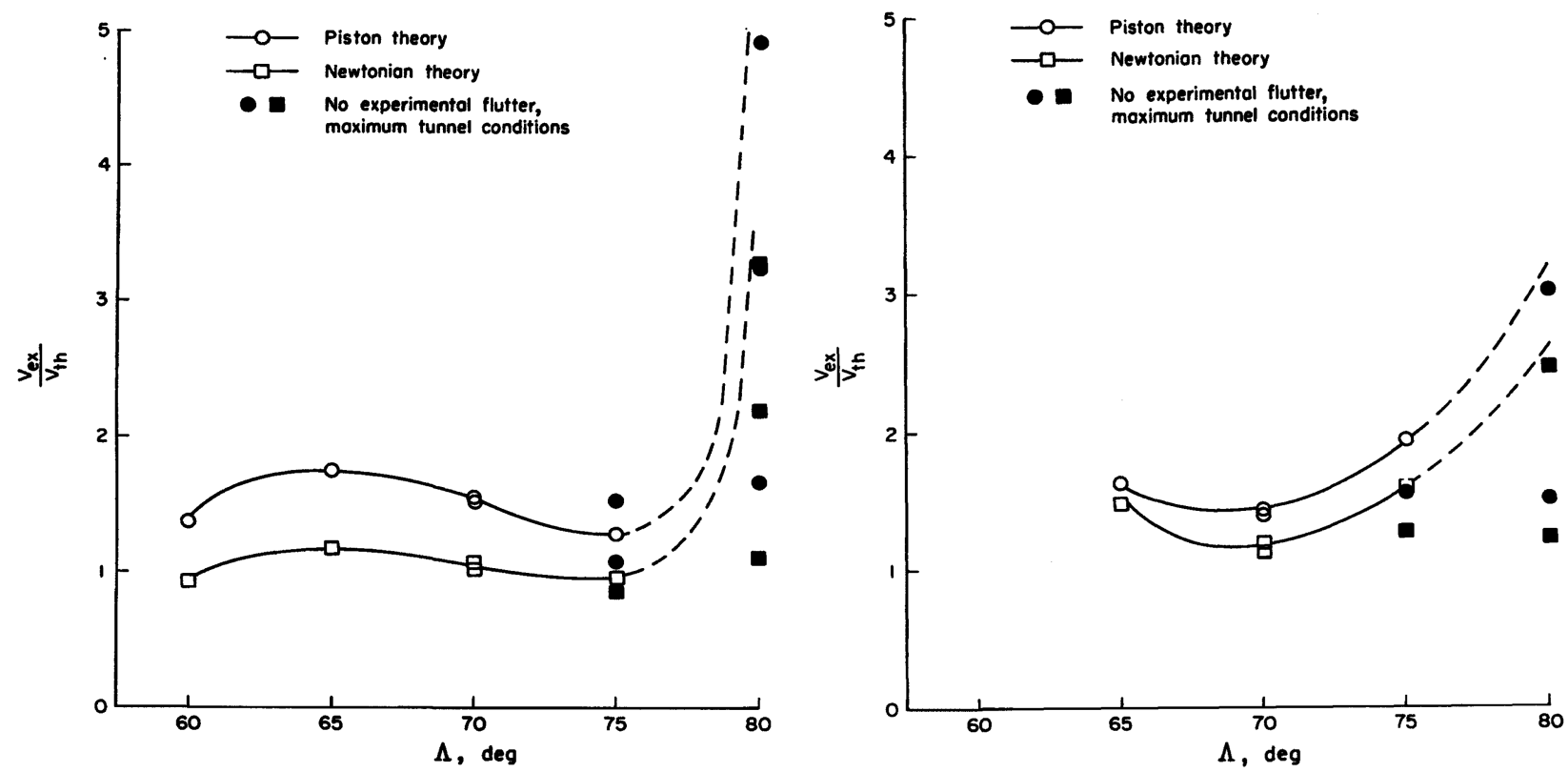

a) Wedge

b) Double Wedge

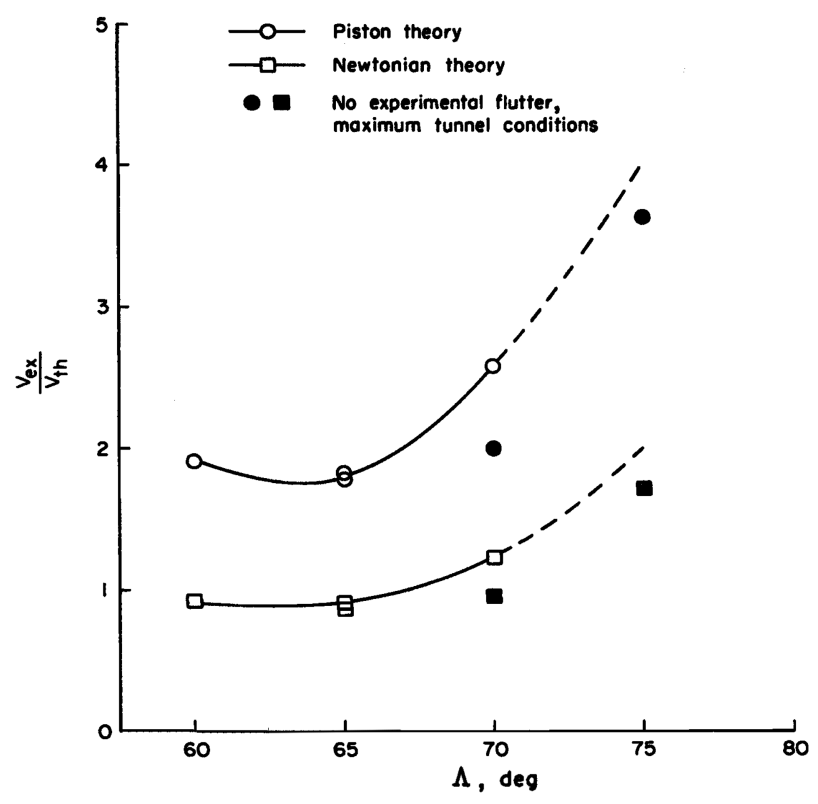

c) Slap

Fig. 24 Ratio of experimental to flutter velocity as a function of leading-edge sweep angle [49].

1) The slab airfoils were more stable than the double-wedge airfoils.

2) The blunt leading edges improved stability compared with the sharp leading edges (leading-edge radii not specified).

3) The experimentally measured flutter dynamic pressures were substantially lower than the analytical results. It was shown that modifying the airfoil shapes with a laminar flat plate boundary-layer displacement thickness improved the agreement between the analytical and experimental results [66], as indicated in Fig. 26. This result emphasizes the potential impact of viscous effects on the aeroelastic behavior of hypersonic vehicles.

The general observations that can be gleaned from the experimental work discussed in this section are as follows:

1) Increasing airfoil thickness and angle of attack is destabilizing.

2) Increasing airfoil bluntness is stabilizing for small leading-edge radii (1\% of chord) and destabilizing for larger leading-edge radii (greater than $3 \%$ of chord).

3) The effect of leading-edge sweep on flutter is inconclusive.

4) Slab airfoil sections are more stable than double-wedge airfoils.
5) Viscous effects are destabilizing, presumably due to inviscidviscous interactions from the boundary-layer displacement effect.

\section{Aerothermoelastic Similarity}

Despite the demonstrated need for aerothermoelastic similarity laws for experimental testing, work in this area has been quite limited. To the authors' knowledge, the most recent publication is by Dugundji and Calligeros [156] in 1962. The scaling relations developed in [156] were limited to Mach numbers less than 3.5 and temperatures less than $1000^{\circ} \mathrm{F}$. Despite these assumptions, this study provides exceptional insight into aerothermoelastic similarity for hypersonic flow. It shows that, for the general aerothermoelastic problem, one is limited to full-scale testing due to practical considerations. However, for specialized cases (e.g., wing structures, thin solid plates, and panel flutter), the similarity laws are less restrictive and scaled model testing is possible. It is also shown that, for cases where scaled testing is either difficult or impossible, two alternatives may be pursued: 1) incomplete aerothermoelastic testing 

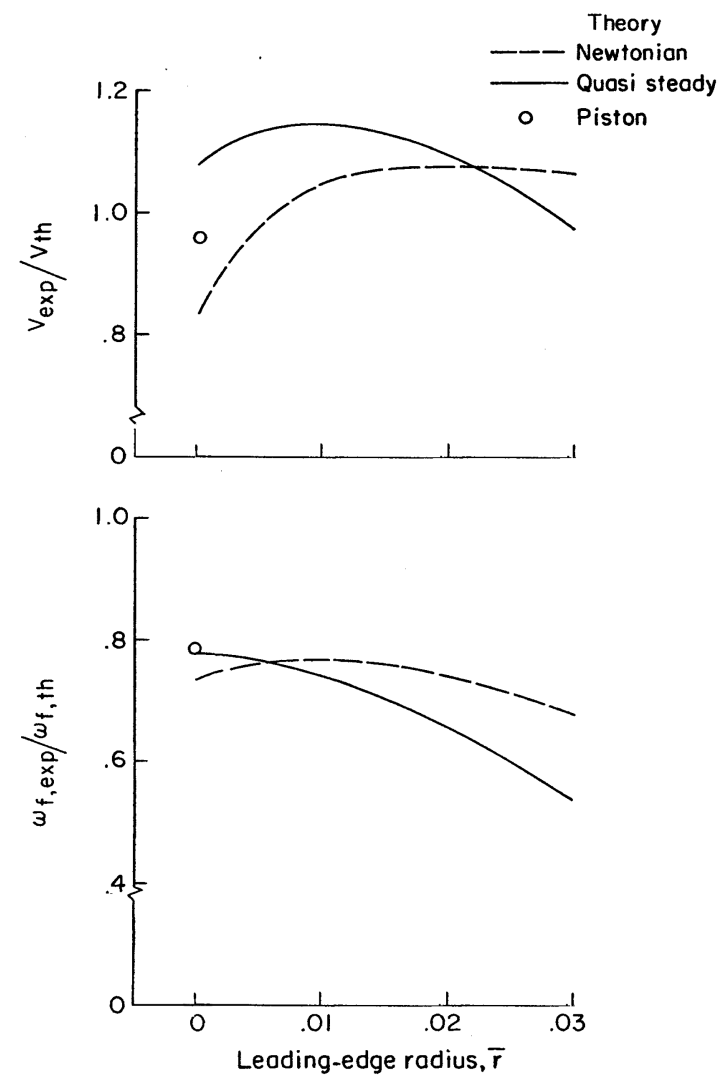

Fig. 25 Comparison of flutter results generated using a semiempirical quasi-steady approach, unsteady Newtonian, and PT aerodynamics relative to experimental results [푸].

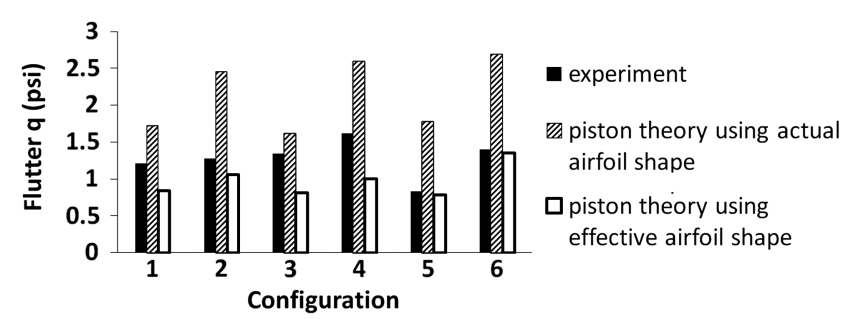

Fig. 26 Comparison of analytical and experimental dynamic pressures at flutter [66].

and 2) restricted purpose models. The first approach relies on the aerodynamic pressures and/or heating rates to be estimated in advance and applied artificially to the model. The second approach is for cases where certain couplings can be neglected between the aerodynamic pressure, aerodynamic heating, heat conduction, and stress-deflection phenomena. It is important to note, however, that the development of aerothermoelastically scaled models becomes increasingly difficult at higher Mach numbers. This is due to the need for additional similarity laws that must account for real-gas effects, viscous interactions, material and gas property variations with temperature, radiation effects, ablation, plasticity, creep, fatigue, etc. [156].

\section{Panel Flutter}

Panel flutter is an aeroelastic instability that occurs in a localized region on the surface of supersonic or hypersonic vehicles, primarily affecting skin panels. The combination of minimum-weight requirements and high-speed flow results in thin panels subject to substantial in-plane (due to heating) and out-of-plane (due to pressure) loads. With certain simplifying assumptions, the treatment of this problem is relatively straightforward. This has enabled extensive work on panel flutter. Thus, a complete survey is beyond the scope of this paper. Rather, the studies discussed in this paper are limited to those deemed most relevant to the current state of hypersonic aeroelastic and aerothermoelastic research. An in-depth review specific to panel flutter is provided by Mei et al. [147].

Early studies $[35,157]$ dealt with relatively simple panel flutter analyses using first-order quasi-steady aerodynamics (e.g., linear PT) and linear plate models. In particular, Bisplinghoff and Dugundji [35] used such a model to study the fundamental effects of aerodynamic heating on panel flutter. An early series of papers dealing with hypersonic aerothermoelasticity [45-47] identified panel flutter as significant for the design of reentry vehicles, as well as hypersonic cruise vehicles. Furthermore, it was noted that panels are susceptible to a flutter instability when in-plane loading is present, suggesting that aerodynamic heating plays an important role in panel flutter.

Early experimental studies of panel flutter revealed that the panels exhibited limit-cycle oscillations rather than catastrophic failure due to nonlinear membrane forces induced by moderate plate deflections. This limit-cycle behavior was subsequently reproduced numerically for isotropic plates by Dowell [158] using the moderate deflection von Kármán plate theory. Subsequently, Friedmann and Hanin [159] extended this model to an orthotropic plate subject to arbitrary flow direction, where it was concluded that orthotropicity and flow direction have a substantial impact on the flutter boundary of panels.

More recent studies of panel flutter have used finite elements to model relatively complex composite panels and temperature effects. Xue and Mei [160] included the effects of aerodynamic heating in isotropic plates using the FEM for spatial discretization, while separately, Gray and Mei [161] and Abbas et al. [162] extended the model to orthotropic plates. The effect of panel location on the vehicle, panel curvature, and comparisons between PT and Euler aerodynamics in hypersonic flow was studied by Bein et al. [163]. The analysis was extended by Nydick et al. [65] by introducing increased generality in the plate temperature distributions, and a comparison of the unsteady pressure was computed using PT, Euler, and NS aerodynamics. This comparison of the unsteady pressure [65] is shown in Fig. 27. For $M_{\infty}=10.0$ and a typical plate vibration

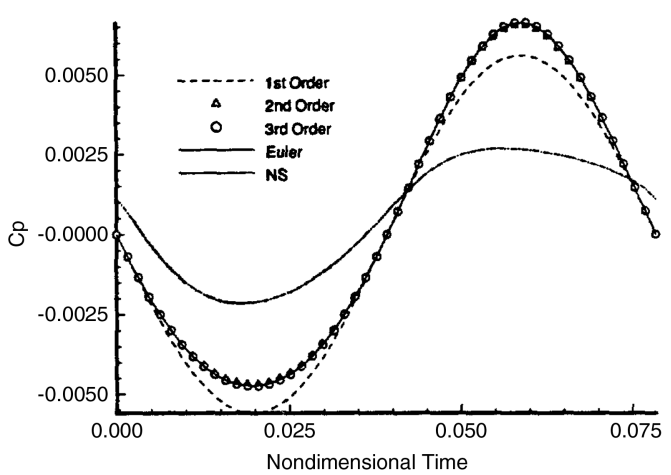

b) Pressure coefficient on midpanel

a) Schematic of 2-D unsteady hypersonic flowfield

Fig. 27 Comparison of unsteady pressures for an oscillating panel using different aerodynamic theories [65]. 


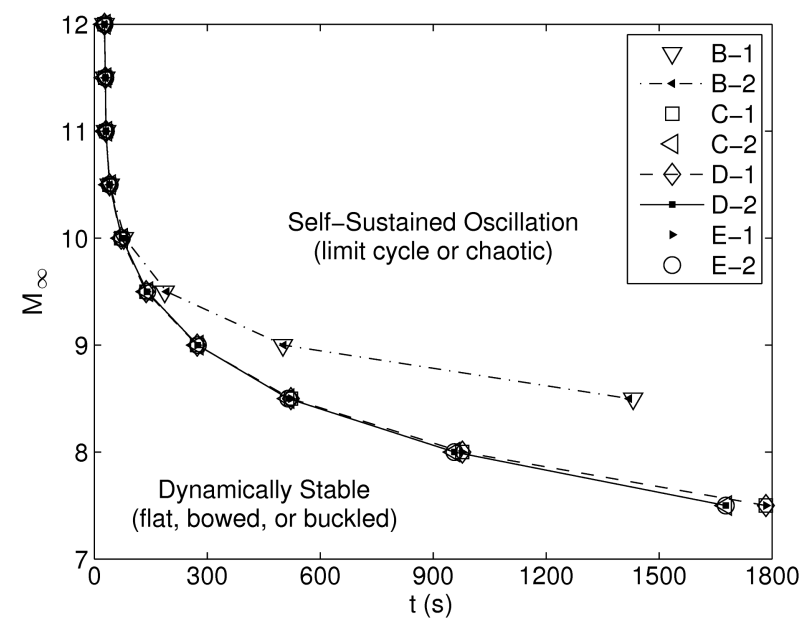

Fig. 28 Aerothermoelastic flutter boundary predictions for a hypersonic surface panel [73].

frequency, there was only a 5\% difference between the unsteady pressure coefficient calculated using third-order PT and the unsteady pressure coefficient calculated using the Euler equations. However, there was approximately a $60 \%$ difference between the Euler solution and the pressure coefficient calculated by solving the NS equations. This result emphasizes the important role viscosity may have in hypersonic aeroelasticity.

It is evident from recent work $[73,146,164-167]$ that continued research into panel flutter is active and ongoing. In these studies, various in-plane edge restraints and imperfect geometry effects [164] are investigated: cylindrical panels under yawed high-speed flow [167] and nonlinear aerothermoelastic panel flutter behavior $[\overline{73}, 146,165,166,168]$. Consider the aerothermoelastic panel flutter boundary, shown in Fig. 28, computed in [73] for the cases listed in Table 1. It is evident that the neglect of temperature-dependent material properties (B-1 and B-2) can lead to significant overprediction of the aerothermoelastic stability. Furthermore, there is no threshold Mach number below which the panel response is dynamically stable. Also, as noted earlier, differences between the different modeling cases increase with flight time. However, approximations of the aerothermal-aeroelastic coupling by a quasistatic or time-averaged dynamic temporal coupling displays a negligible impact on the flutter boundary for the cases considered.

In a follow-on study [169], the aerothermoelastic analysis of surface panels was expanded by 1) comparing the aerothermoelastic stability of panels that buckle up, into the flow (convex buckling), to those that buckle down, out of the flow (concave buckling); and 2) incorporating prescribed acoustic pressures that approximate loads introduced by engine excitation noise and/or fluctuating pressures in a turbulent boundary layer [169]. Results indicated that the onset time of panel flutter was increased by a factor of four for panels that buckle down, out of the flow, compared with up, into the flow. Also, the combined effect of deformation-induced unsteady pressures and the prescribed acoustic loads resulted in panel instabilities that would not be present otherwise. This is illustrated in Fig. 29, where the response of a skin panel was computed using four

Table 1 Aerothermoelastic modeling cases

\begin{tabular}{ccc}
\hline \hline Case & $\begin{array}{c}\text { Temperature-dependent } \\
\text { properties }\end{array}$ & Aerothermal-aeroelastic coupling \\
\hline B-1 & None & One-way quasi static \\
B-2 & None & Two-way quasi static \\
C-1 & $E(T), \alpha(T)$ & One-way quasi static \\
C-2 & $E(T), \alpha(T)$ & Two-way quasi static \\
D-1 & $E(T), \alpha(T)$ & One-way dynamic \\
D-2 & $E(T), \alpha(T)$ & Two-way dynamic \\
E-1 & $E(T), \alpha(T)$ & One-way time-averaged dynamic \\
E-2 & $E(T), \alpha(T)$ & Two-way time-averaged dynamic \\
\hline \hline
\end{tabular}

different load cases [169]. In all four cases, the panel response to a spatiotemporally varying surface heat flux was computed based on predicted aerodynamic heating conditions. Responses in the bottom half were computed with the panel in a high Mach number mean flow. Responses in the bottom half were computed by neglecting mean flow effects. The right half of Fig. 29 was computed with a low amplitude acoustic load, while the left half was computed with no acoustic load.

The bottom left quadrant depicts the panel thermally buckling in response to the heat load only. Adding a relatively weak acousticonly pressure load (bottom right quadrant) resulted in small amplitude vibrations about its postbuckled response. When the mean flow was added without the acoustic load (upper left quadrant), the panel responded similarly to the heat-load-only case until onset of a limit-cycle oscillation at approximately $25 \mathrm{~s}$. The most interesting, and severe, response occurred when both the mean flow and acoustic load were combined (upper right quadrant). In this case, large amplitude oscillations began immediately. This demonstrates a strong need to completely understand the source of loads in hypersonic systems.

A characterization of the impact in uncertainty in aerodynamic heat flux predictions and laminar-to-turbulent boundary-layer transition was examined in [73] using the panel model from [168]. The uncertainty propagation was carried out using stochastic collocation, which provides a computationally efficient alternative to direct Monte Carlo simulations by using polynomial response surfaces to approximate the functional relationship between uncertain inputs and an output of interest. The resulting probability distribution function (PDF) for Mach 8.0, shown in Fig. 30, indicates that uncertainty in aerodynamic heating rates and transition location have a significant probability of reducing the time to onset of flutter.

\section{Computational Studies of Wings and Complete Vehicles}

Limited ability to replicate operational hypersonic conditions in ground-based facilities [75], combined with the inability to construct scaled hypersonic models [156], has led to the use of computational modeling and simulation for the majority of aeroelastic and aerothermoelastic studies conducted on vehicles operating in hypersonic flow. This body of work can be separated into hypersonic aeroelastic studies that neglect the effects of aerodynamic heating and aerothermoelastic investigations. Because of the complexity of the problem, the aerothermoelastic studies conducted to date have relied upon significant approximations.

\section{A. Aeroelastic Studies}

The NASP program (1984 to 1994) produced the first FEM-based computational aeroelastic (CAE) studies of hypersonic vehicles $[\underline{4}, \underline{21}, 25,66, \underline{98}, 170-176]$. An overview of the research effort is presented by Ricketts et al. [21]. Spain et al. [4] conducted a supersonic and hypersonic aeroelastic analysis of the X-30 NASP demonstrator model, an unclassified version of the National Program Office classified finite element model. The analysis used secondorder Van Dyke quasi-steady aerodynamics for $1.6<M<8.0$, corresponding to reduced frequencies of $0.04<k_{\omega}<0.18$. As shown in Fig. 31a, a body-freedom flutter was identified at the Mach numbers considered due to coupling between the short-period mode and the wing-pivot mode. A weaker elastic mode flutter involving the coupling of the wing-pivot mode with the fuselage-bending mode was also noted at $M=2.3$. It was found that shifting the allmoveable wing aft on the fuselage was destabilizing. This result is illustrated in Fig. 31b. Note that, for all the cases considered, flutter involved the all-movable wing-pivot vibration mode.

These aeroelastic studies conducted on the NASP configuration have been followed by several studies dealing with newer hypersonic vehicle configurations, such as the X-33, X-34, and X-43. The X-33 was a half-scale fully functional technology demonstrator modeled upon the Lockheed Martin VentureStar, while the X-34 was developed by the Orbital Sciences Corporation for NASA's RLV 


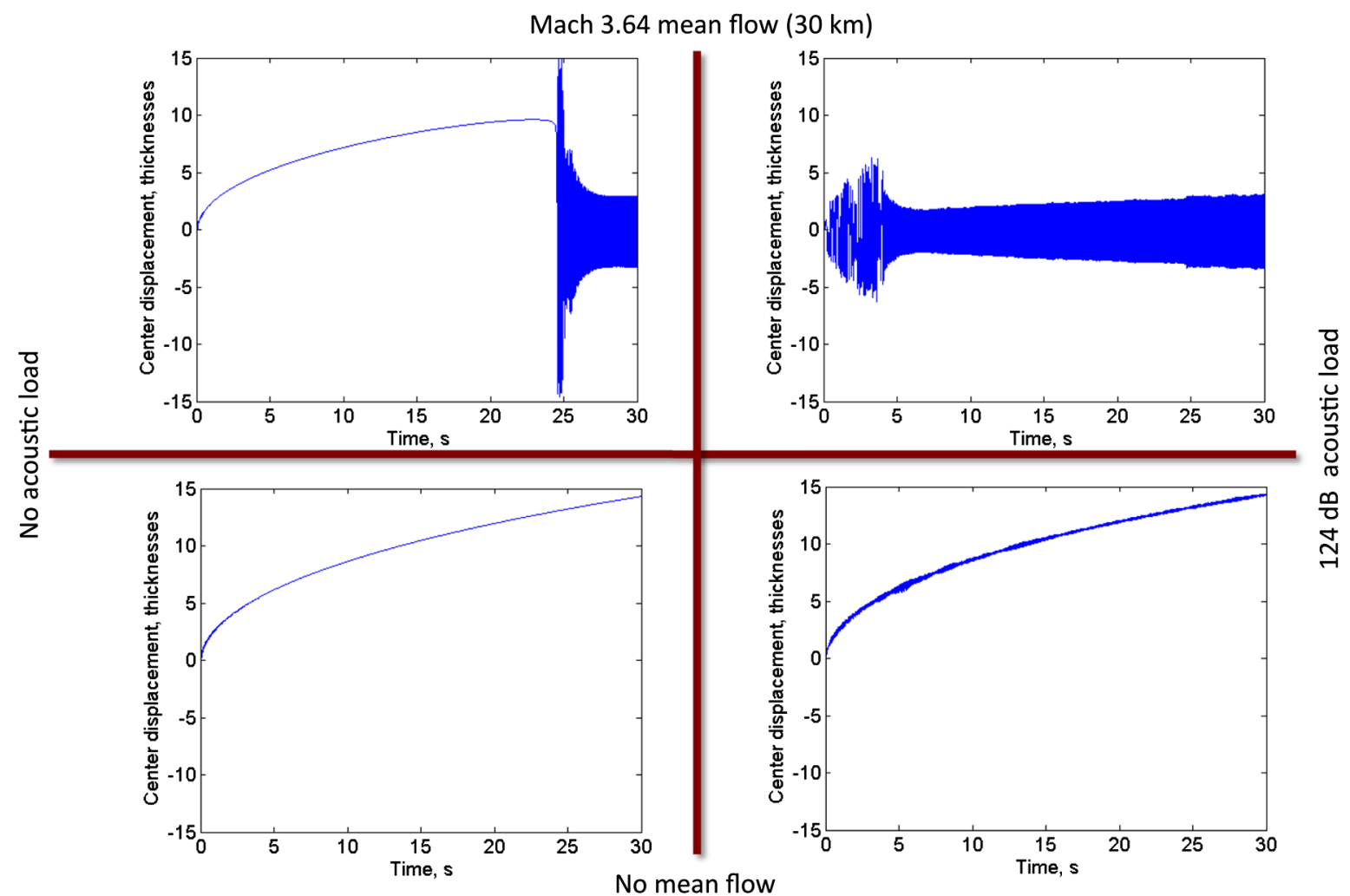

Fig. 29 Center point displacement response, in panel thicknesses, of an aluminum panel subject to combined loads [169].

program. The NASA X-43, mentioned earlier, was developed to demonstrate the feasibility of airbreathing scramjet engine technologies. Schematic depictions of these vehicles were provided in Fig. 1.

Blades et al. [177] studied the aeroelastic behavior of the X-34 launch vehicle in free flight using MSC NASTRAN. The NASTRAN code is primarily a finite element structural/heat transfer code; however, it also contains an aeroelastic module that uses approximate aerodynamics. For the hypersonic regime, the aeroelastic module uses PT aerodynamics. The aeroelastic behavior of the vehicle was studied for a representative trajectory, with a maximum Mach number of $M=8.0$. Instabilities were found at speeds above $M=5.0$, in the primary bending modes, due to the control system.

As discussed previously, Gupta et al. [22] conducted a CFD-based flutter analysis for the aeroelastic analysis of the X-43 configuration using an ARMA-based order reduction of the aerodynamic DOFs.

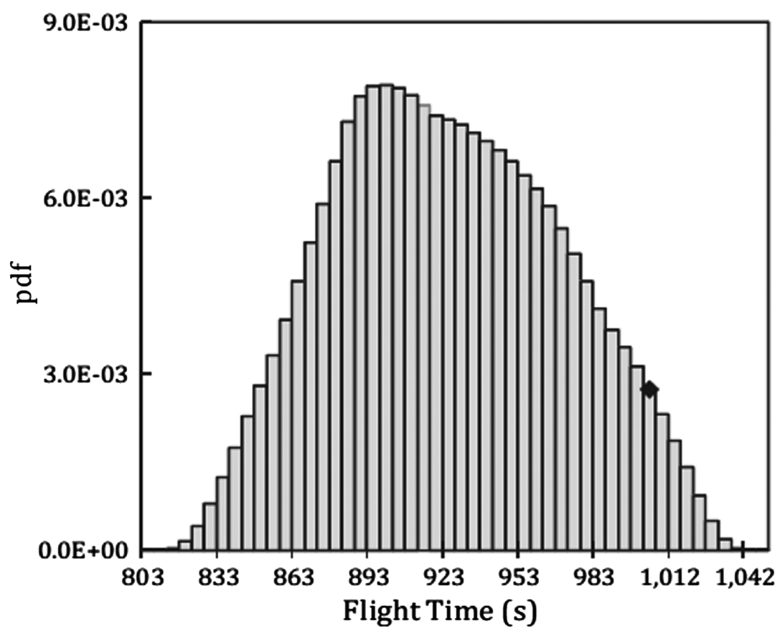

Fig. 30 PDF for the flight time to onset of flutter at Mach 8.0, $33 \mathrm{~km}$. The black diamond indicates the deterministic value [168].
The ARMA approach describes the modal response force of a system at a given time as a summation of scaled previous outputs, and scaled values of modal displacement inputs to the system, for small perturbations of the system. Both the structure and the fluid were discretized using the finite element approach. The results of the analysis, shown in Fig. 32, indicate that the same flutter point is predicted for $M_{\infty}=7.0$ using either Euler or PT aerodynamics. The study does not specify which order of PT was used. It is also evident from the location of the flutter point relative to the Mach 7 X-43 trajectory, shown in Fig. 33, that the vehicle was predicted to be aeroelasticity stable for the operating conditions shown.

Nydick and Friedmann [178] examined the aeroelastic behavior of a complete unrestrained generic hypersonic vehicle resembling the X-33 RLV. Flutter was found to be present at very high Mach numbers and altitudes. However, the unsteady aerodynamics were modeled using first-order PT, which is not reliable for accurate prediction of the hypersonic loads [71]. The inclusion of flexible trim and the presence of fuel had moderate effects on the flutter boundaries computed. However, as shown in Fig. 34, the flutter boundaries were quite sensitive to variations in parameters governing vehicle stiffness, implying that geometrically scaled models are not appropriate for aeroelastic analysis of a given vehicle [178].

More recently, a number of studies on the hypersonic aeroelastic behavior of generic RLVs and lifting surfaces [67-70,179,180] have been conducted. The aeroelastic analysis was carried out using the NASA Langley CFL3D code $[181,182]$ and an independently developed aeroelastic code based on PT aerodynamics. The primary goal of these studies was to examine the aeroelastic behavior of the generic hypersonic vehicle configuration [180], depicted in Fig. 35, and a 3-D low-aspect-ratio wing [70]. The low-aspect-ratio wing was considered to be representative of a fin or control surface on a hypersonic vehicle. The flutter boundaries for these two configurations are shown in Figs. 36 and 37. For both configurations, higher grid resolution near the surface was required at high Mach numbers due to the reduced thickness of the shock layer $[70,180]$. In addition, note that, for the full vehicle configuration, the use of PT resulted in large errors $(25 \%)$ in flutter boundary predictions due to 3 -D flow effects [180]. 


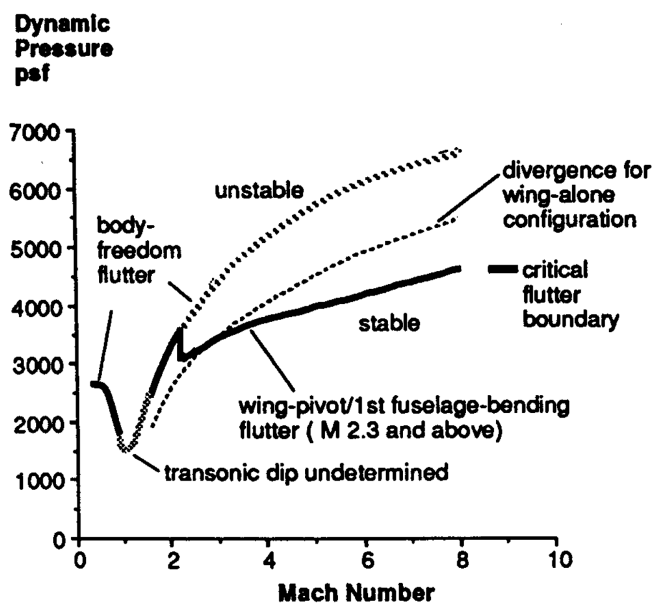

a) Predicted stability boundaries for the NASP demonstrator

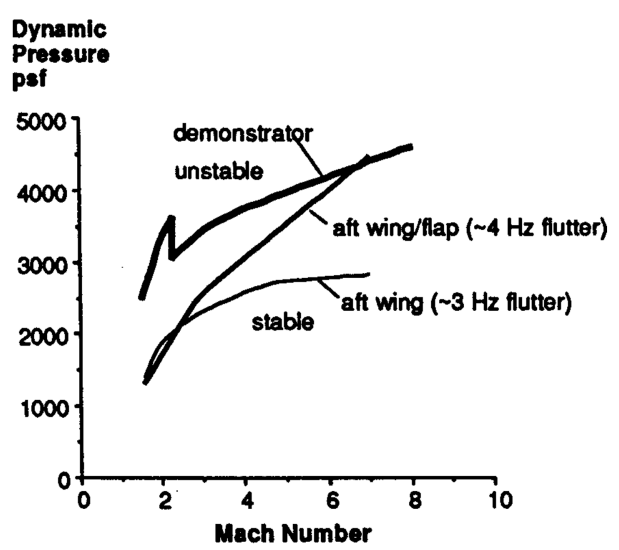

b) Comparison between the stability boundaries for the baseline demonstrator design and two additional variations

Fig. 31 Critical supersonic/hypersonic flutter boundaries for a NASP demonstrator model [4].

It is evident from results computed using both inviscid and viscous flows (i.e., Figs. $6,7,26,27$, and 36 ) that the precise role of viscosity in hypersonic aeroelasticity is not completely clear. Some of the configurations and operating conditions produce large differences between the viscous and inviscid results, while others do not. Thus, more work is needed to better understand the precise role of viscosity for this class of vehicles. It is also evident that classical approximate theories, such as PT, are inadequate when 3-D flow and viscous effects are important. Furthermore, from the flutter boundaries presented in Figs. 6, 7, 32-34, 36, and 37, it is clear that the neglect of aerodynamic heating in the aeroelastic analysis results in unrealistic predictions of Mach number and altitude combinations at flutter. Thus, the incorporation of aerodynamic heating in the analysis is essential for reliable predictions of the aeroelastic response. Studies involving aerodynamic heating are discussed next.

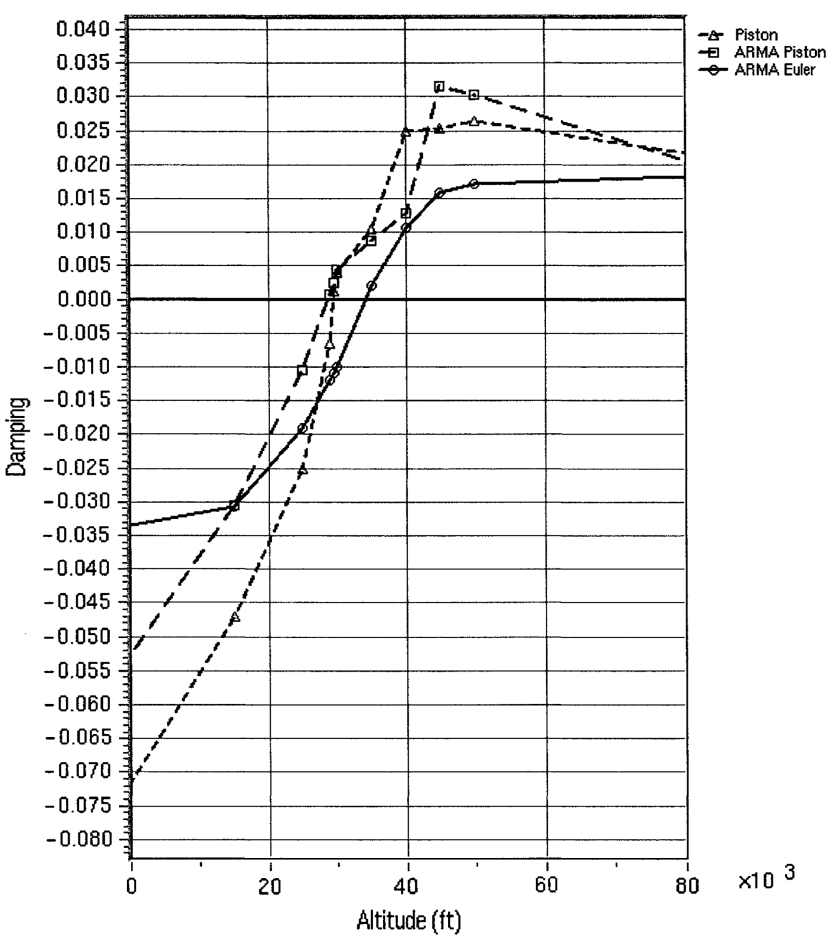

Fig. 32 Flutter boundary of the $\mathrm{X}-43$ hypersonic vehicle, at Mach 7.0, predicted using PT, ARMA PT, and ARMA Euler unsteady aerodynamics [22].

\section{B. Aerothermoelastic Studies}

In an early aerothermoelastic study [183], the effect of thermal stresses on the static aeroelastic stability of a cantilever wing with a double-wedge cross section was examined. Thermal stresses were introduced into the wing using a chordwise parabolic heat distribution. It was found that thermal stresses affected the stability of the wing by influencing both torsional rigidity and the anticlastic effect.

The effect of aerodynamic heating on divergence, control effectiveness, and flutter was considered by Bisplinghoff and Dugundji [35]. The flutter boundary of a solid aluminum wing, with a rectangular planform (6 ft semispan) and 4\% thick double-wedge airfoil section ( $3 \mathrm{ft}$ chord), at $35,000 \mathrm{ft}$ was reduced by up to $60 \%$ due to temperature-dependent material properties in the presence of small temperature gradients.

Runyan and Jones [184] carried out an aerothermoelastic analysis of a thin wing in heated flow in order to determine the effect of thermal stresses on aeroelastic stability and to develop approximate methods for predicting this behavior. A flutter analysis of a solid wing, with a rectangular planform and $65 \mathrm{~A}$ series airfoil, was conducted using the Van Dyke second-order supersonic theory for the unsteady aerodynamics and work by Budiansky and Mayers [185] to estimate the reduction in stiffness due to thermal stresses. The wing was assumed to be in Mach 2 flow at both 300 and $800^{\circ} \mathrm{F}$. It was found that the wing did not flutter for the lower temperature flow $\left(300^{\circ} \mathrm{F}\right)$. However, in the $800^{\circ} \mathrm{F}$ flow, the model began to flutter after $2 \mathrm{~s}$, and it continued to flutter for two additional seconds, at which point aeroelastic stability was gradually regained. This behavior was validated experimentally.

The aerothermoelastic characteristics of an aluminum finned missile in the Mach number range $3 \leq M \leq 6$ were studied by Ericsson et al. [186]. The analysis considered both a constant temperature and a parabolic temperature distribution in the chordwise direction, and it neglected spanwise distributions. The maximum temperature considered was $650^{\circ} \mathrm{F}$. The unsteady aerodynamic loads were computed using third-order PT aerodynamics. It was found that the parabolic temperature distribution resulted in a lower flutter speed when compared with the isothermal distribution.

A limited number of aerothermoelastic studies have also been conducted on the NASP vehicle project discussed earlier. Spain et al. [170] implemented an aerothermoelastic analysis on two different structural configurations: a titanium-aluminide (baseline) configuration and a carbon-carbon configuration. The temperature distributions were obtained by using radiation equilibrium surface temperature conditions. The vehicle geometry and the effect of heating on the system are shown in Fig. 38. From these results, it is apparent that aerodynamic heating reduces the flutter boundary and 
Hyper-X Fiutter Prediction

Relative to the Mach 7 Trajectory

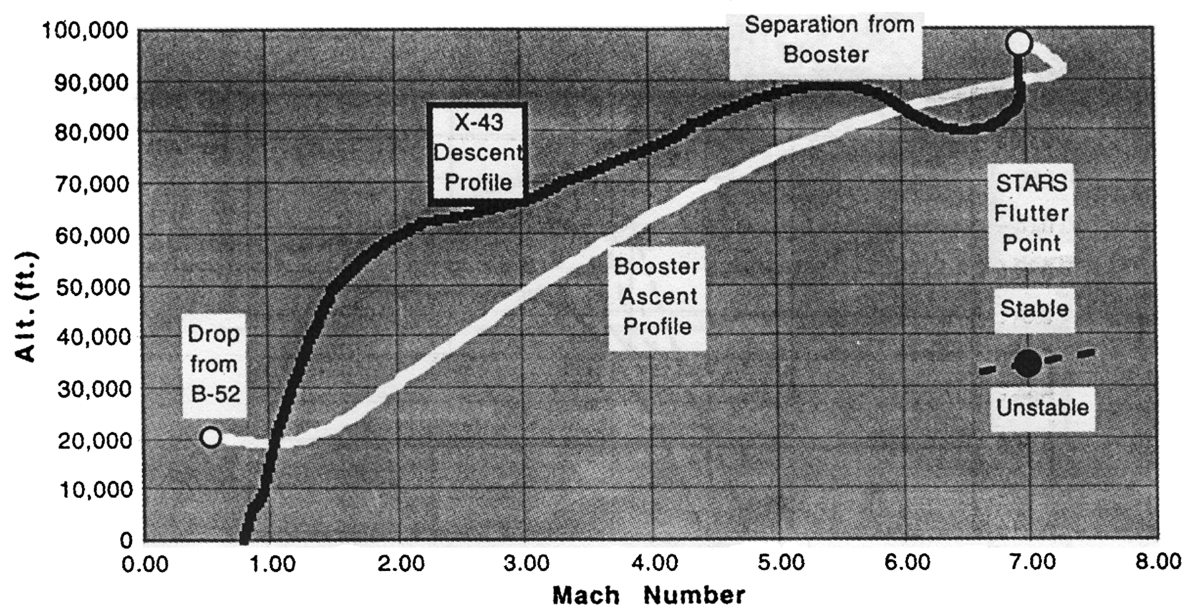

Fig. 33 Predicted flutter point and flight trajectory of the $X-43$ [22].

that the heated carbon-carbon structure had a higher flutter boundary than the heated titanium-aluminide structure.

An aerothermoelastic analysis of a NASP vertical fin, using different temperature distributions, was conducted by Rodgers [171]. The aerodynamic heating was approximated using experimental data generated from flights of the NASA X-15 experimental aircraft, scaled to reasonable values for the aluminum model used in the analysis. Several different temperatures were used, as illustrated in Fig. 39, ranging from $600^{\circ} \mathrm{F}$ at the leading edge of the fin to $100^{\circ} \mathrm{F}$ at the trailing edge of the fin. A finite element model was used to determine the structural characteristics using the different temperature distributions. It was found that two modes were of primary importance: namely, the flap mode, which consisted of control surface rotation about a hinge line, and a fin bending mode, which

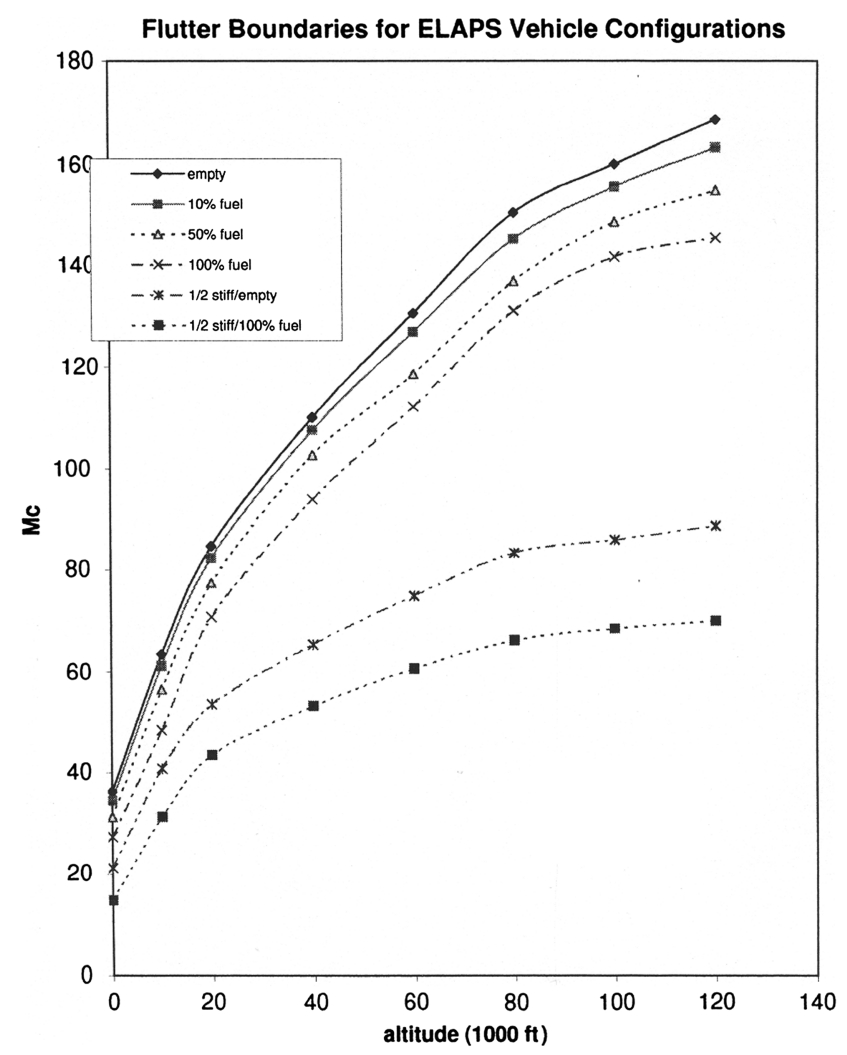

Fig. 34 Flutter boundaries for a generic hypersonic vehicle resembling the $\mathrm{X}-33$ [178] (ELAPS denotes equivalent laminated plate solution). consisted of a primary bending mode with some control surface rotation. The flap mode natural frequency was reduced by nearly $50 \%$, while the bending mode frequency was reduced by approximately $20 \%$. The unsteady aerodynamic loads were computed using VD. As shown in Fig. 40, the relatively constant temperature distributions had little effect on the flutter boundary. However, the spike 1 distribution decreased the flutter boundary by up to $37 \%$. This emphasizes the importance of chordwise thermal gradients and thermal stresses on the flutter behavior of hypersonic vehicles.

An aerothermoelastic analysis of the NASP vehicle was conducted by Heeg et al. [173] using blended Van Dyke/Newtonian aerodynamics for the calculation of the aerodynamic loads. The effect of aerodynamic heating on the aeroelastic behavior of the vehicle was approximated by modifying the material properties of the structure due to increased temperature. The structural analysis was conducted using the X-30 NASP Demonstrator finite element model, and surface temperatures on the vehicle were obtained with the Aerodynamic Preliminary Analysis System (APAS) code [187]. It was noted that the highest surface temperatures $\left(5000^{\circ} \mathrm{F}\right.$ on the nose portion of the vehicle) occurred at a moderate operating condition $\left(M_{\infty}=15\right.$ and $\left.\sim 100,000 \mathrm{ft}\right)$ along the proposed NASP ascent trajectory. Aerodynamic heating of the vehicle decreased the natural frequencies of the system by up to $30 \%$. Furthermore, as illustrated in Fig. 41, the cold vehicle experienced body-freedom flutter, while the hot vehicle was primarily susceptible to elastic mode flutter. In a follow-on study [174], the analysis was extended by including the effect of thermal stresses in the aerothermoelastic calculations. In this case, aerodynamic heating reduced the first six natural frequencies by 13-20\%, and it lowered the flutter boundary by up to $25 \%$. However, some improvements in the flutter boundary were achievable via active control. Note that this study also served as a basis for additional control studies on hypersonic vehicles with aerothermoelastic effects, conducted by Lind et al. [188,189].

The CATE approach discussed previously, from [70], was demonstrated by considering the aerothermoelastic behavior of a low-aspect-ratio wing operating in hypersonic flow. To account for the path dependency of the structural properties and heat transfer on operating conditions, the aerothermoelastic analysis was carried out over a trajectory based on the DARPA/USAF FALCON hypersonic cruise vehicle $[10,70]$. Aerodynamic heating along the trajectory resulted in $20-30 \%$ reductions in the second, third, and fifth modal frequencies of the wing. In particular, the maximum reduction in stiffness occurred for the first torsional mode (second modal frequency), which is a critical mode for flutter.

The aerothermoelastic behavior of the wing along the trajectory, illustrated in Fig. 42, was computed by holding Mach number and free vibration frequencies constant for each point on the trajectory and increasing the dynamic pressure until flutter [70]. Thus, the 


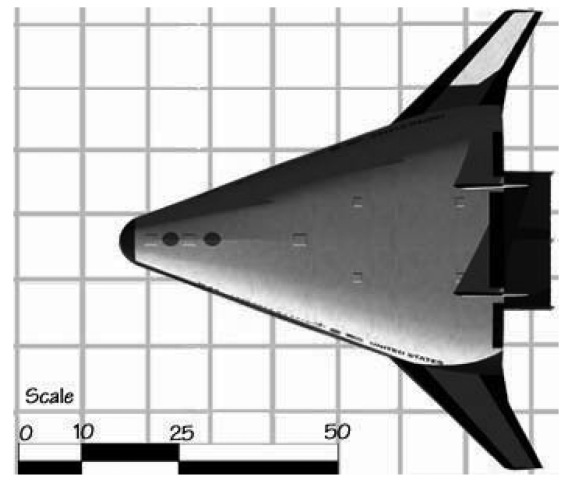

a) $\mathrm{X33}$, top view

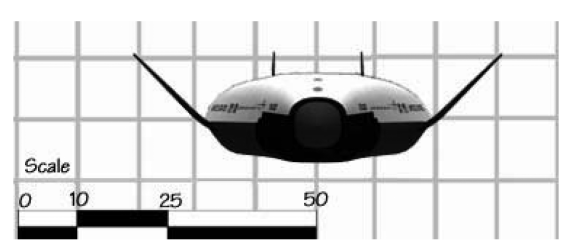

c) $X 33$, front view

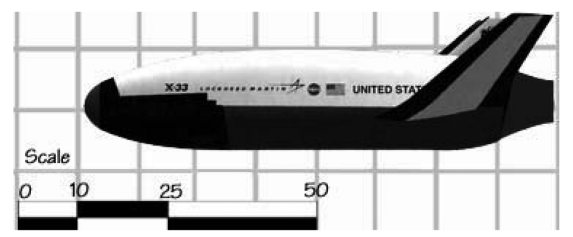

e) $\mathrm{X33}$, side view

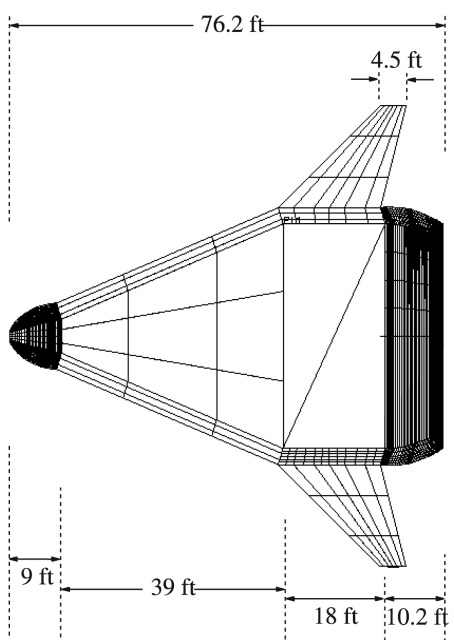

b) Generic vehicle, top view

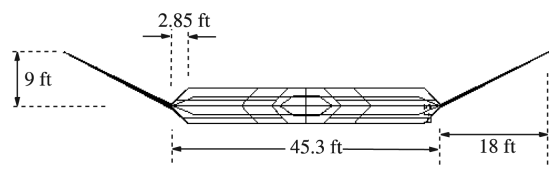

d) Generic vehicle, front view

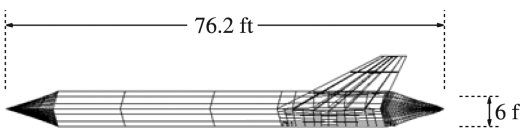

f) Generic vehicle, side view

Fig. $35 \mathrm{X}-33$ and generic RLV [68].

results represent a flutter margin based on the ratio between a virtual flutter dynamic pressure to freestream dynamic pressure along the trajectory. It is evident from these results that aerodynamic heating reduces the flutter margin by up to $40 \%$. However, the minimum dynamic pressure ratios were approximately $\mathcal{O}(10)$. Note that modest angle-of-attack variations had a negligible impact on the flutter margin. However, increasing the Mach number by $25 \%$ resulted in approximately a $30 \%$ reduction in the dynamic pressure ratio at flutter. Finally, note that the sharp drops in the margin represent the onset of thermal buckling. Thus, it is apparent from the large dynamic pressure ratios that, for this type of trajectory and structural configuration, thermal buckling was the critical mode of failure. This is likely due to the low density air present at the nearspace environment of the representative trajectory.

In a similar approach to [70], Gupta et al. [190] extended the FEMbased aeroelastic analysis framework in [22] to include thermal effects by carrying out a heat conduction analysis [190] subsequent to a steady-state flow analysis. The resulting temperature distributions were used to compute the heated modes and frequencies of the structure for use in an aeroelastic analysis of the system. The updated capability was used to examine the aerothermoelastic behavior of both a 3-D wing and the X-43 vehicle. The inclusion of heating was

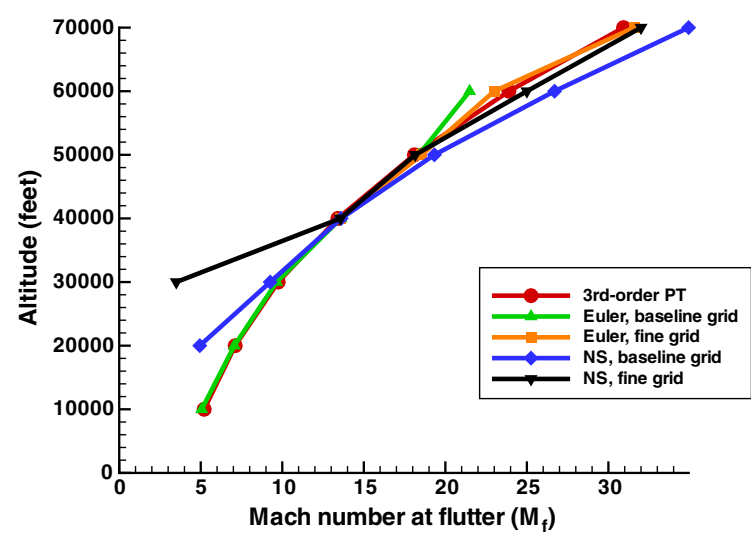

a) Mach number

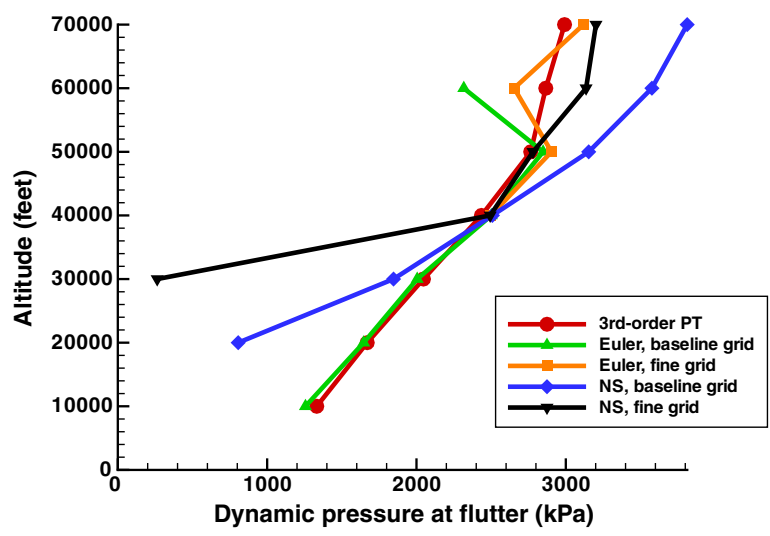

b) Dynamic pressure

Fig. 36 Flutter envelope of the low-aspect-ratio wing, calculated using third-order PT, Euler, and NS aerodynamics [ㅁ]]. 


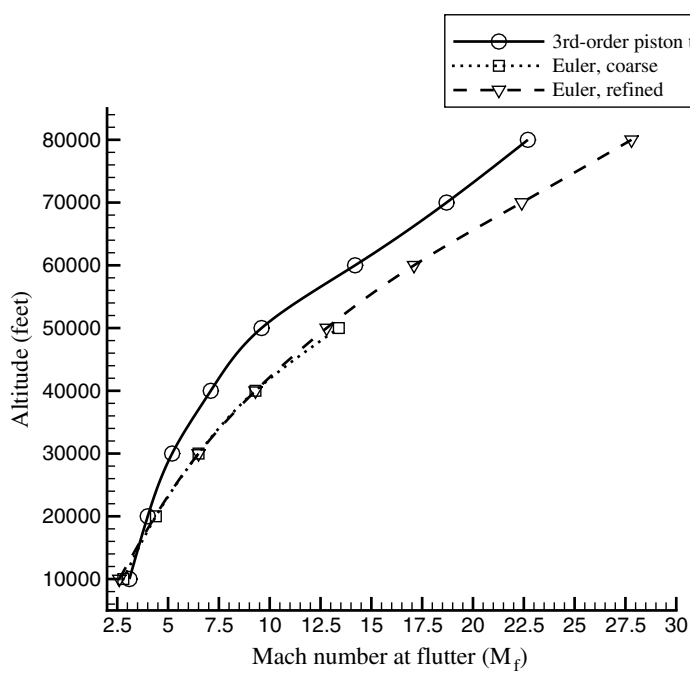

a) Mach number

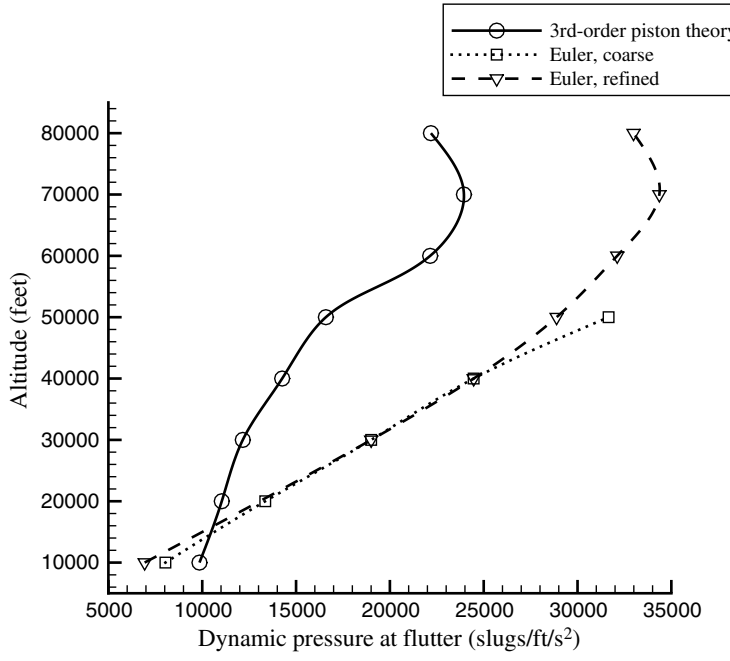

b) Dynamic pressure

Fig. 37 Flutter envelope of the generic hypersonic vehicle, calculated using PT and Euler aerodynamics [180].

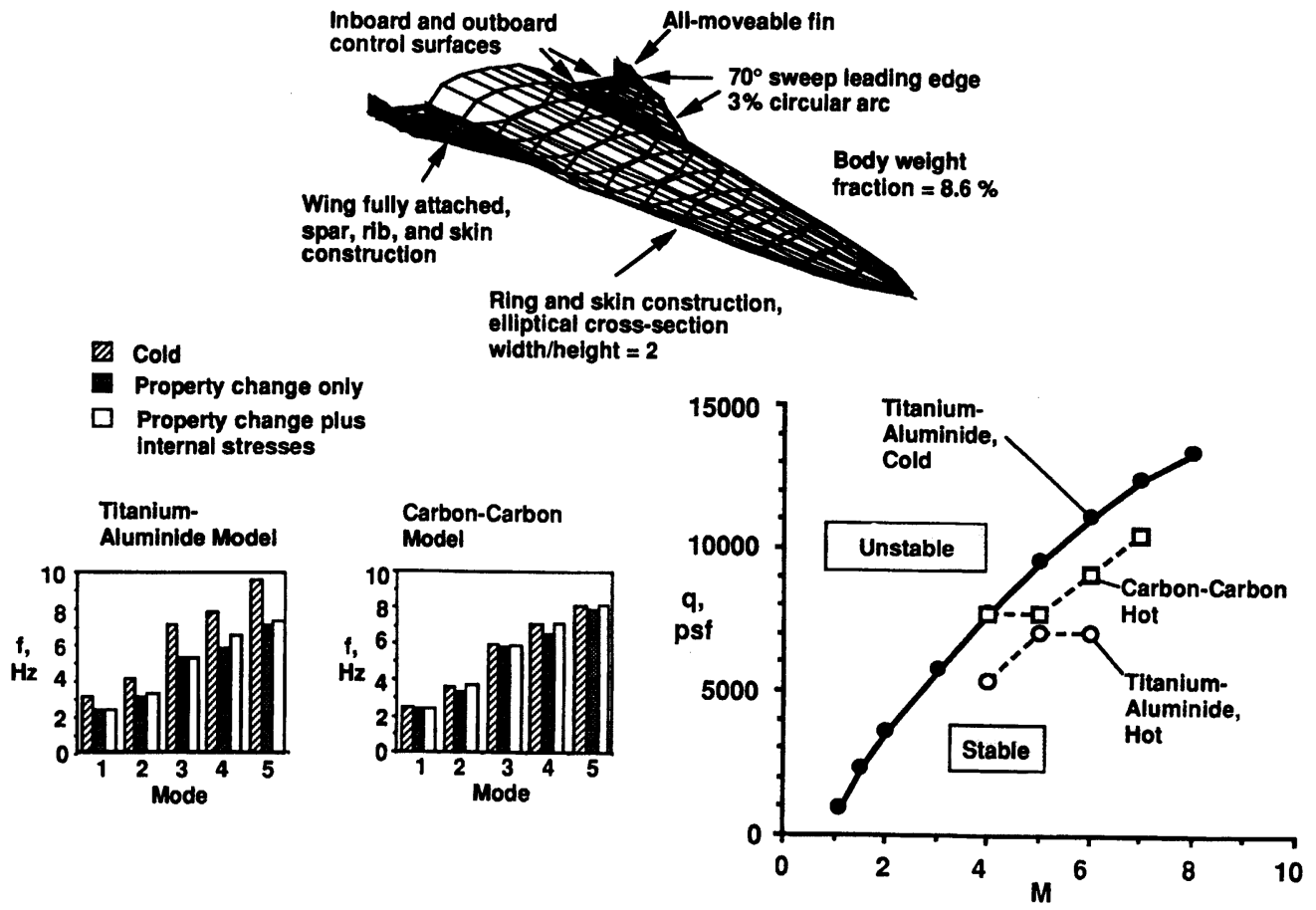

Fig. 38 Calculated effects of heating on the flutter characteristics of a generic NASP design [37,170].

found to significantly alter the aeroelastic response of the wing, and it resulted in flutter at conditions that were aeroelastically stable for the unheated wing.

A reduced-order aerothermoelastic analysis of a similar lowaspect-ratio wing was conducted in [191]. Several of the reducedorder modeling techniques discussed earlier were used for the analysis: namely, a kriging surrogate for the aerodynamic heating [92], POD for the reduced-order thermal modeling [104], and assumed modes for the reduced-order structural model. Third-order PT aerodynamics were used for the unsteady aerodynamic pressures. A flowchart for the aerothermoelastic analysis is shown in Fig. $\underline{43}$, illustrating the interactions between the ROMs for each discipline. The ROMs were used to conduct a continuous time-accurate twoway coupled aerothermoelastic analysis of the control surface for a time record of $20 \mathrm{~min}$. Representative results are shown in Fig. 44, where aerothermoelastic effects resulted in up to an $8 \%$ change in the lift and $17 \%$ change in the drag from a rigid configuration.

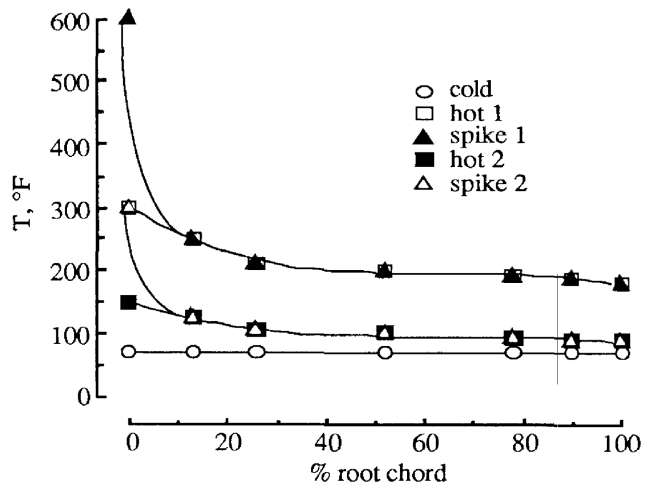

Fig. 39 Temperature distributions applied to a NASP-type vertical fin [171]. 


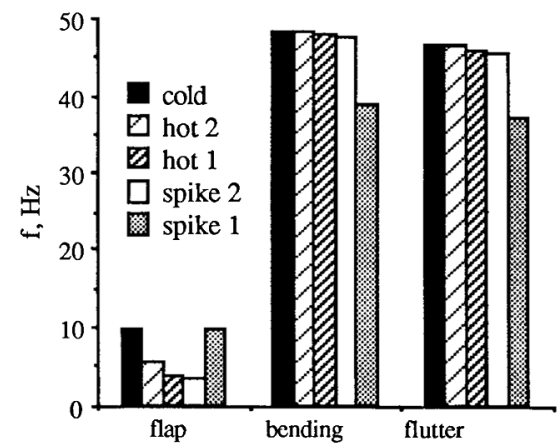

a) Vibration and flutter frequencies

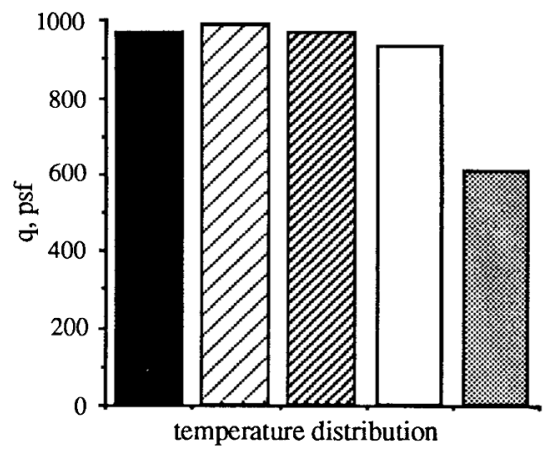

b) Flutter q

Fig. 40 Effects of aerodynamic heating on the frequencies and flutter boundary of a NASP-type vertical fin [171].

\section{Summary of Vehicle/Wing Scale Studies}

For comparison, the various aeroelastic/aerothermoelastic studies and modeling approaches conducted on more recent hypersonic configurations are summarized in Table 2. Note that the second column indicates the aerodynamic models used to compute the GAFs, while the fourth column indicates the models used to compute the heat flux boundary conditions for a heat transfer analysis. It is evident that only a few studies have incorporated aerodynamic heating in a full vehicle analysis. The demonstrated importance of viscosity and aerodynamic heating in hypersonic aeroelastic behavior indicates that more work is needed in this area for complete vehicles.

\section{New Frontiers}

Within the last five years, two research areas have emerged with a central focus on hypersonic aeroelasticity and aerothermoelasticity: ASTEP interactions and IADs. The first has become a concern for multidisciplinary analysis and optimization (MDAO) and control design and evaluation for hypersonic vehicles due to the tight coupling present between the various subsystems. The latter has emerged from the desire of NASA to increase payload sizes for planetary exploration and the increase in the drag-to-weight and drag-to-launch volume ratios that IADs offer. The existing body of literature in both of these areas is described next.

\section{A. Aeroservothermoelastic-Propulsive Interactions}

As mentioned earlier, and shown in Figs. 45 and 46, airbreathing hypersonic vehicle configurations exhibit significant and complex ASTEP interactions between the structural, control, propulsion, and lifting components $[2,27-30,192,193]$. Therefore, aerothermoelasticity plays a central role in hypersonic vehicle dynamics and control, $\mathrm{MDAO}$, and airframe-propulsion integration. Recently, a number of studies have considered these problems, focusing mainly on

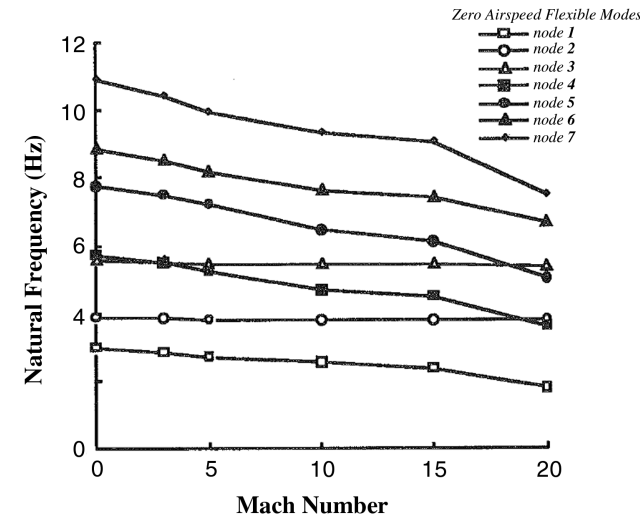

a) Natural frequencies

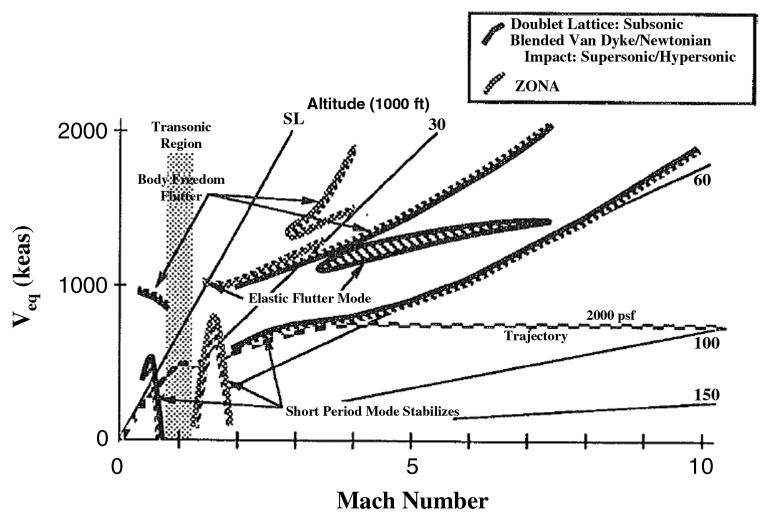

b) Unheated flutter boundary

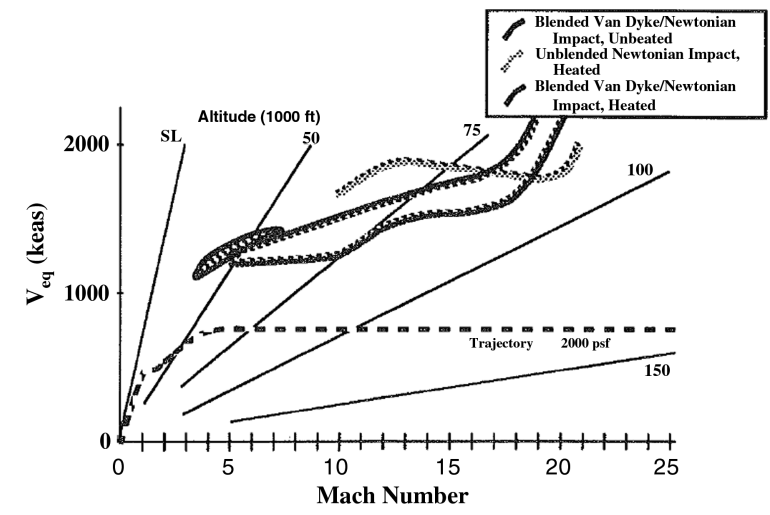

c) Heated flutter boundary

Fig. 41 Effects of aerodynamic heating on the frequencies and flutter boundary of a NASP-like hypersonic vehicle [173] (ZONA denotes ZONA Technology, Inc., SL denotes sea level, and keas denotes knots equivalent airspeed). 

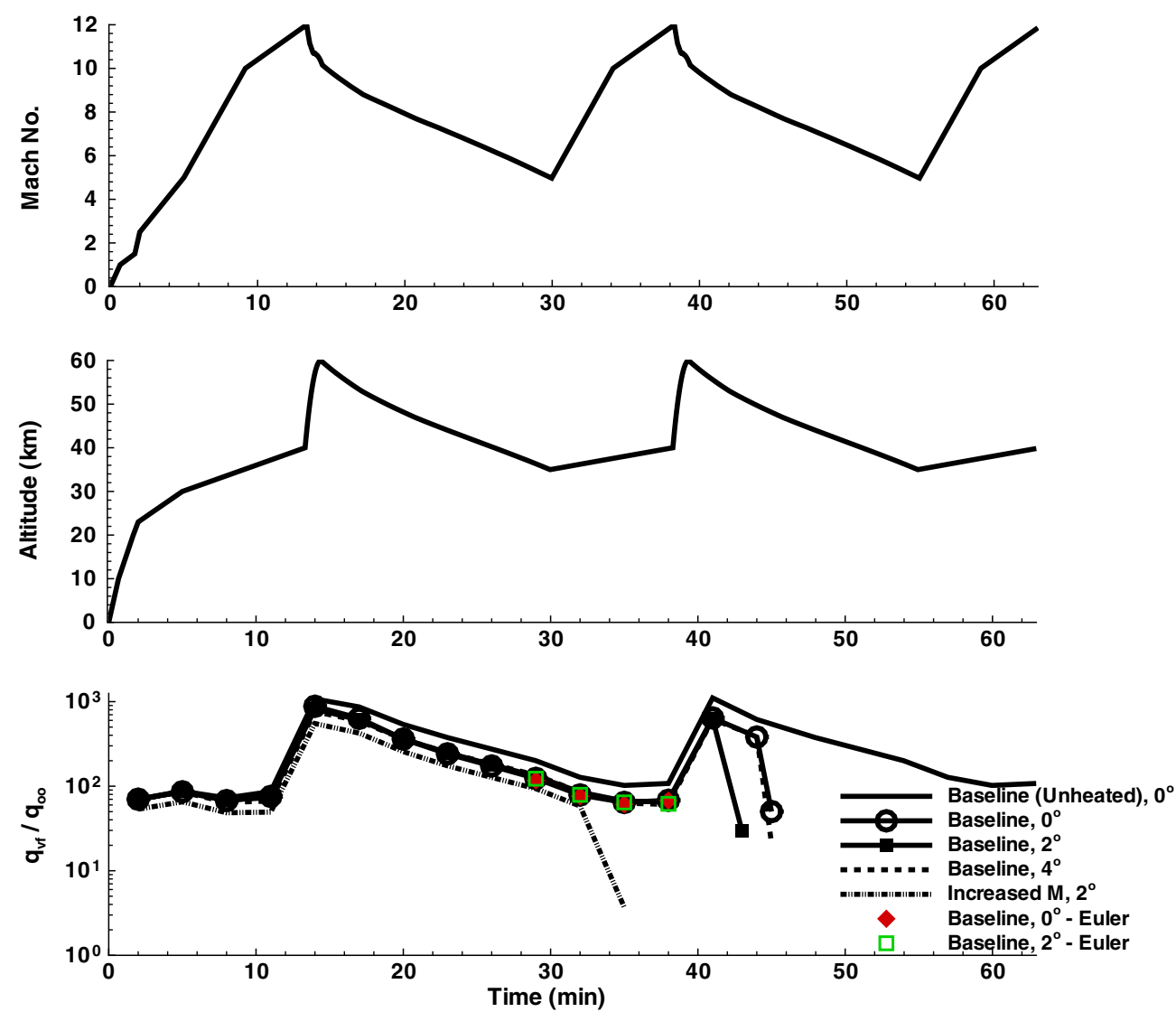

Fig. 42 Aerothermoelastic flutter margin of the modified low-aspect-ratio wing along a representative hypersonic trajectory [0].

airbreathing configurations resembling the conceptual NASP and NASA experimental X-43 aircraft.

\section{Dynamics and Control of Hypersonic Vehicles}

One of the first vehicle scale comprehensive dynamics and control models was developed by Chavez and Schmidt [194], who considered the longitudinal dynamics of a generic hypersonic vehicle operating at Mach 8.0, 85,000 ft. The structural model was based on a modal representation of the vehicle computed from a FEA of a hypersonic vehicle resembling the NASP X-30. However, only the first bending mode of the fuselage was retained in the analysis. The aerodynamics were computed using both Newtonian and shockexpansion aerodynamics. The engine flowpath was modeled as 1-D flow with heat addition. Viscous and aerodynamic heating effects were neglected. Control effectors consisted of aerodynamic pitchcontrol surfaces, engine throttle, and diffuser area ratio. Results indicated a strong coupling between the airframe/engine/elastic

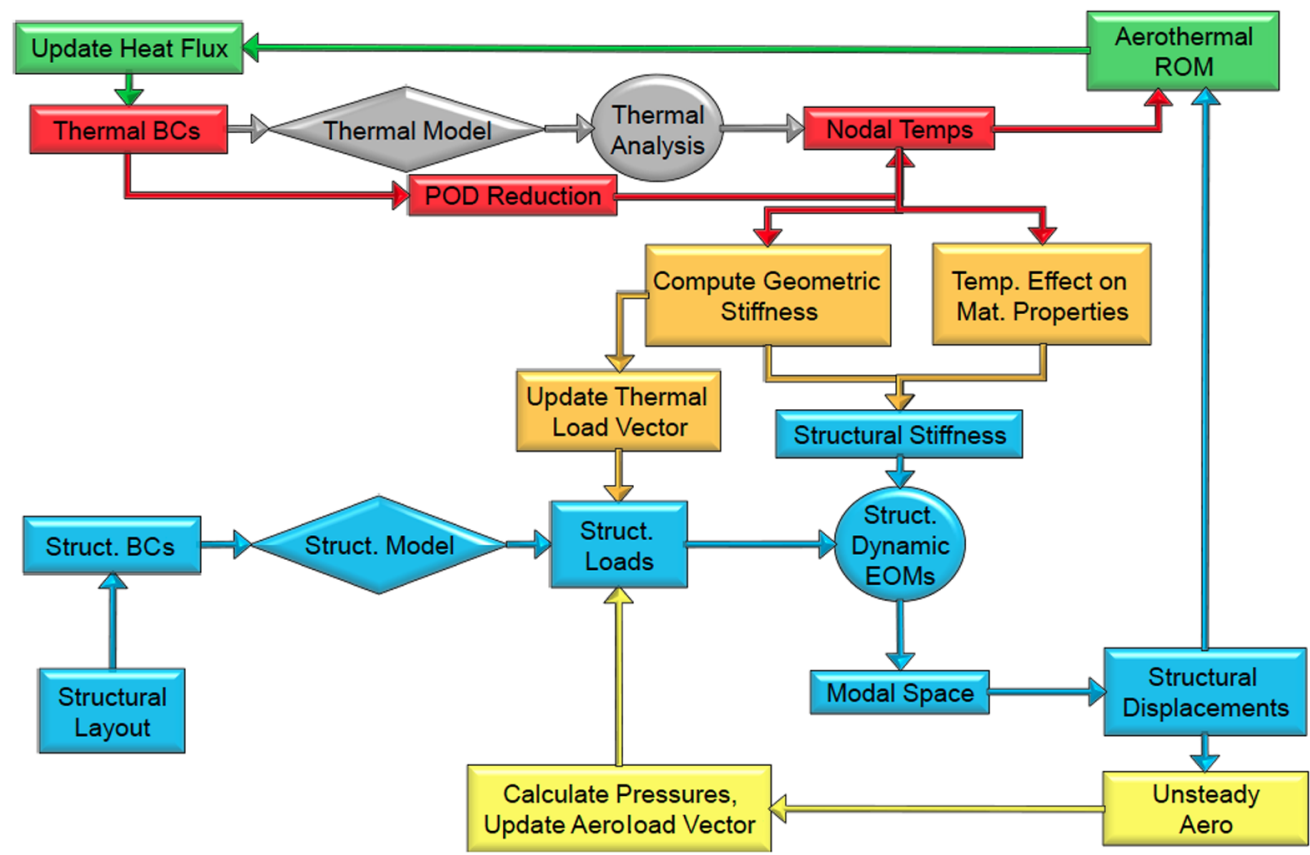

Fig. 43 Reduced-order aerothermoelastic framework [191] (BC denotes boundary condition, and EOM denotes equation of motion). 


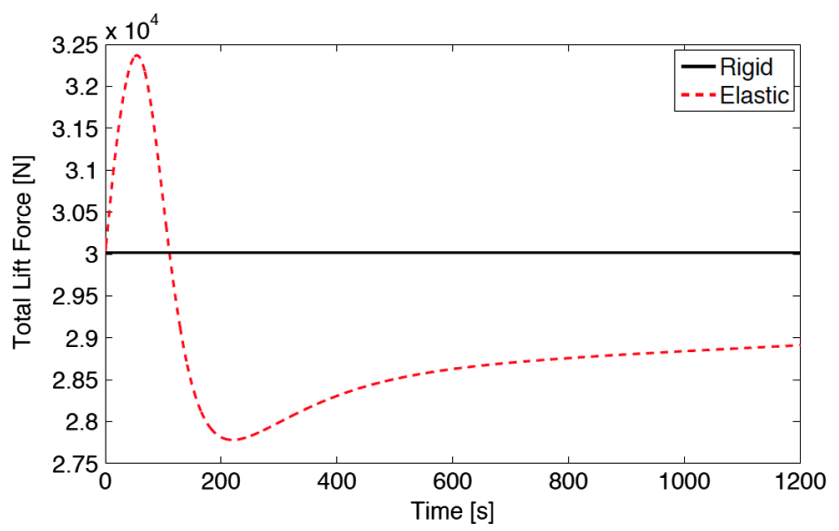

a) Lift

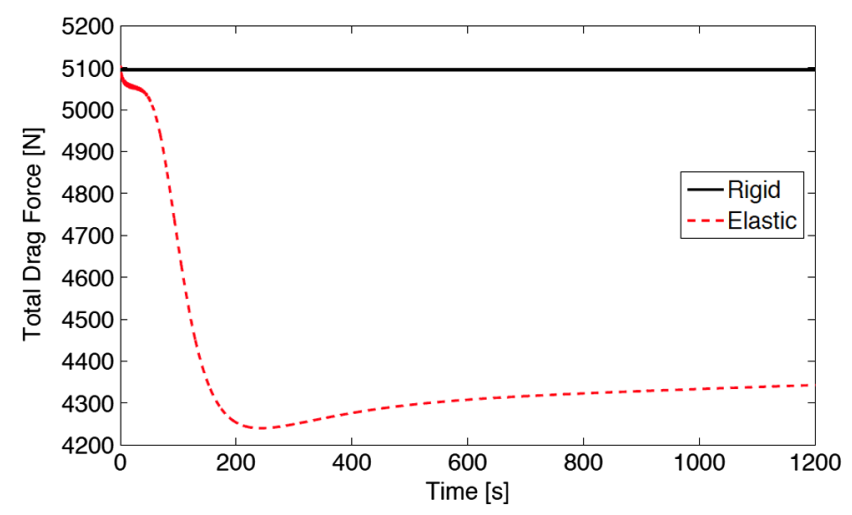

b) Drag

Fig. 44 Comparison of total lift and drag for both rigid and flexible low-aspect-ratio control surfaces at Mach 8.0, 85,000 ft [191].

models and instability in pitch of the vehicle. In a follow-on study [195], uncertainty models for multivariable control robustness were examined, where important sources of uncertainty were the vehicle structural dynamic characteristics and aerodynamic loads. Furthermore, the flexible DOFs were found to be quite important for flight-control synthesis of airbreathing hypersonic vehicles.

Rudd and Pines [196] investigated the dynamics of hypersonic wave riders at Mach $\overline{10}$ and an altitude of $30 \mathrm{~km}$. A finite difference method was employed to model the aerodynamic pressures, while the Eckert reference temperature method [26] was used to compute the drag. It was concluded that the propulsion effects must be accurately modeled in order to develop the system controller.

A more recent study [197] noted that there is a lack of complete models that adequately include and quantify the unique

Table 2 Summary of aeroelastic and aerothermoelastic studies of hypersonic vehicles and lifting surfaces

\begin{tabular}{|c|c|c|c|}
\hline Configuration & GAFs & Structure & Aeroheating \\
\hline & Vehicles & & \\
\hline NASP [4] & PT, VD & FEM & - \\
\hline NASP $[\underline{25}, \underline{170}, \underline{173}, \underline{174}]$ & $\begin{array}{l}\text { PT, blended } \\
\text { VD/NI }\end{array}$ & FEM & APAS \\
\hline $\mathrm{X}-33$ [178] & PT & Equiv. plate & - \\
\hline $\mathrm{X}-33[\overline{180}]$ & PT, Euler & FEM & - \\
\hline $\mathrm{X}-34[\overline{177}]$ & PT & FEM & - \\
\hline$X-43[\overline{22]}$ & PT, ARMA Euler & FEM & - \\
\hline $\mathrm{X}-43[\underline{190}]$ & $\begin{array}{c}\mathrm{NS} \\
\text { Lifting/control surfaces }\end{array}$ & FEM & NS \\
\hline NASP [171] & VD & FEM & $\mathrm{X}-15$ data \\
\hline Generic $[70,71]$ & PT, Euler, NS & FEM & - \\
\hline Generic $[\overline{70}]-$ & PT, Euler & FEM & NS \\
\hline Generic [191] & PT, ROM & ROM & $\begin{array}{l}\text { NS-based } \\
\text { ROM }\end{array}$ \\
\hline
\end{tabular}

characteristics of airbreathing hypersonic vehicles. A review of the integrated problem is provided, and the development of a highfidelity CFD-based model of a full-scale hypersonic vehicle is discussed. As a first step toward this goal, a simple two-dimensional geometry is studied at Mach 10 and an altitude of $30 \mathrm{~km}$. The scramjet combustion process was modeled using 1-D flow with heat addition. The CFD data were generated using the FLUENT code, assuming an ideal gas. In a follow-on investigation [198], a general approach to controlling an airbreathing hypersonic vehicle is presented based on a linear time-varying plant model.

A comprehensive, nonlinear open source model of an airbreathing hypersonic vehicle has been developed by the AFRL [15,199-204]. The model includes the interaction of vehicle aerodynamics, propulsion, and structural dynamics, and it has been used for several [205-214] control design and simulation studies. In the first part of model development [15], the aerodynamic pressures were computed using shock-expansion theory, while the structural dynamics were modeled using a simple joined-beam configuration. The propulsion system was modeled assuming a 1-D flow with heat addition. Subsequently, the model was improved by 1) including the effect of aerodynamic heating on the structural dynamics of the vehicle [199]; 2) employing LPT aerodynamics to incorporate unsteady aerodynamic forces [200]; 3) including the effect of reduced vehicle mass, due to fuel burn, on the structural dynamics of the vehicle [201,202]; and 4) incorporation of an improved propulsion model: the Michigan-AFRL Scramjet In Vehicle (MASIV) [215-218]. In $[199,201,202]$, it was concluded that reduced vehicle mass has a significant effect on the control of hypersonic vehicles, while increased temperature is less important. However, note that the internal structural layout, the effect of thermal stresses, and leadingedge temperatures were neglected in these studies. The impact of reduced mass on the first and second frequencies, and dynamics of the vehicle, are shown in Fig. 47. It is evident from these figures that the effect of reduced mass due to fuel burn is significant, and it should be considered in ASTEP modeling of hypersonic vehicles.

Recently, a significant body of work has emerged focusing on reducing the amount of approximation used in previous ASTEP modeling efforts. This work includes CFD/FEM-based aerothermoelastic modeling, using the coupled aerothermodynamic and thermoelastic ROMs discussed previously [92,102-104,191]; a 3-D 6-DOF flight simulation framework for ASTEP interactions $[28,193]$; and the previously mentioned MASIV propulsion code [215-219].

\section{Airframe-Propulsion Integration and Multidisciplinary Analysis and Optimization}

The impact of aeroelasticity on the performance of an airbreathing propulsion system, for a configuration resembling the NASP, was investigated by Raney et al. [175]. The structural dynamics and response were computed using the free vibration modes of the structure, the propulsion model was developed using the SRGULL hypersonic propulsion code [220], and the unsteady aerodynamics were computed using second-order PT. A flowchart of the analysis is shown in Fig. 48. The propulsion model exhibited a pronounced sensitivity to angle of attack and elastic fuselage deflections. Furthermore, this had a significant impact on the vehicle rigid-body flight dynamics.

It is noted by Schmidt and Lovell [221] that maximum system efficiency is critical to successful mission operations of airbreathing hypersonic vehicles. Therefore, maximizing efficiency of the highly coupled subsystems is essential. Using a relatively simple system model, the results obtained indicated that the maximum achievable orbital mass fraction is a strong function of propulsion system efficiencies. This, in conjunction with the work by Raney et al. [175], emphasizes the importance of accurately modeling the vehicle structure. Also, heating constraints were found to have a significant effect on operation efficiency and mission performance.

Cockrell et al. [222] described a high-fidelity CFD analysis of the aeropropulsive performance, i.e., interaction between the aerodynamics and propulsion systems for the X-43. Figure 49 provides an 


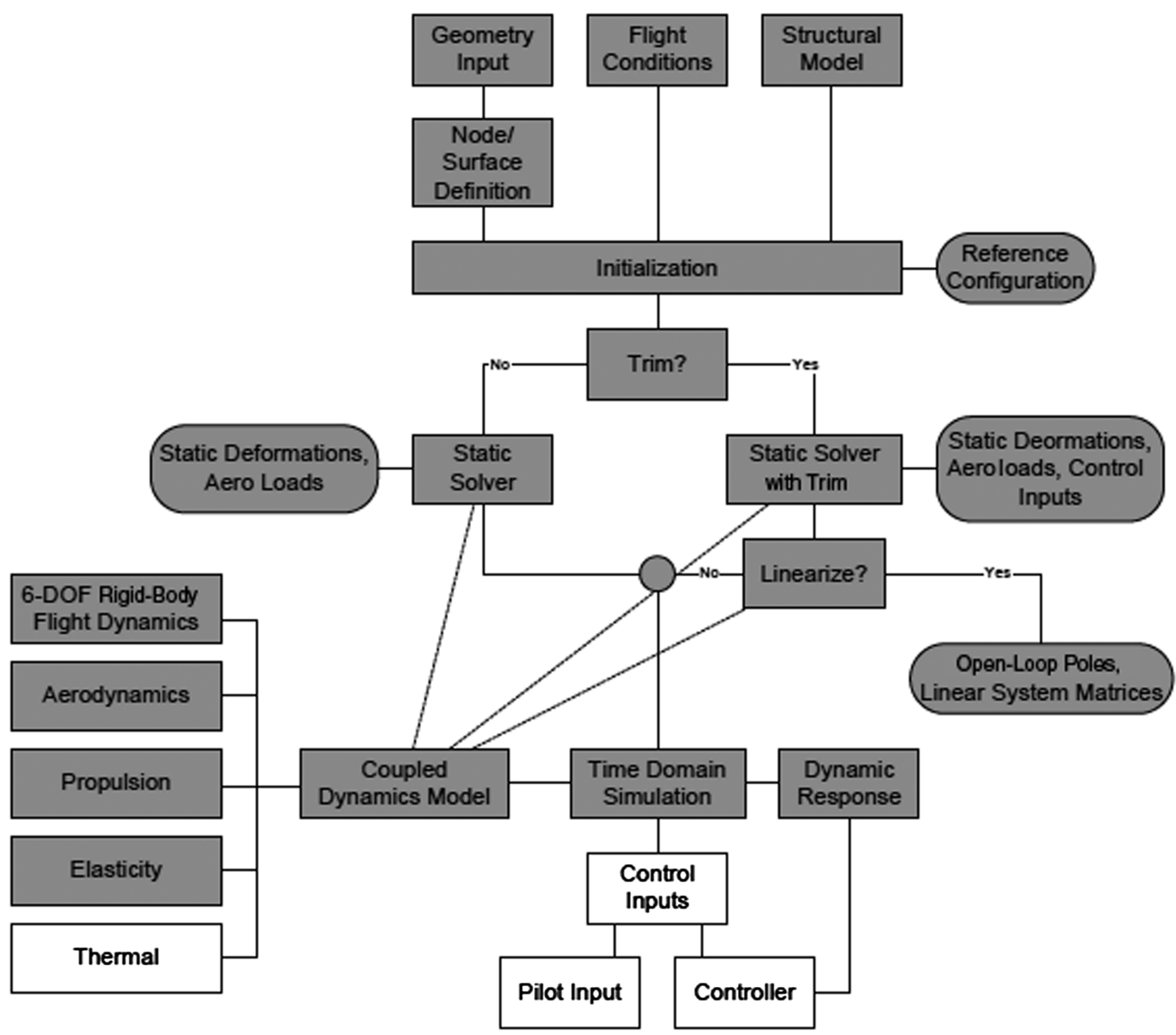

Fig. 45 ASTEP simulation framework [193].

excellent summary and perspective of the important flow physics and modeling requirements for such a problem. An overview on the methods used in the analysis and preflight database development for the X-43 test flights was also provided [222]. The GASP code [223] was the primary CFD tool used in the $\bar{X}-43$ preflight performance analysis. This code is a NS solver capable of modeling frozen, equilibrium, or finite rate chemistry with models for hydrogen-air combustion. The internal analysis of the propulsion flowpath was carried out using the SHIP [224,225] and SGRULL [220] codes. Note that the effect of the structure was not included in the analysis.

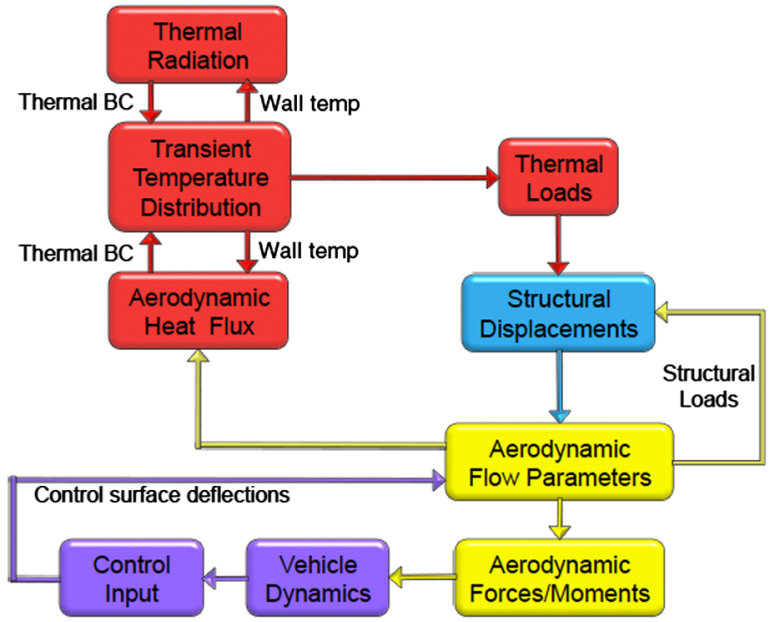

Fig. 46 Coupling between aerodynamic heating, heat transfer, elastic airframe, aerodynamics, vehicle dynamics, and a controller [191].
Bowcutt [226] investigated the development and implementation of a multidisciplinary design optimization (MDO) procedure that coupled the propulsion, aerodynamics, mass properties, and vehicle volume. The MDO process was implemented so as to optimize the geometry of a hypersonic cruise missile for maximum overall mission range. In the study, the aerodynamic pressures were computed using shock-expansion theory, while the viscous drag was estimated from a table lookup based on wetted area, Mach number, and operating altitude. It was found that the optimization results were sensitive to coupled interactions in the vehicle.

Stewart et al. [227] investigated fluid-thermal-structural interactions in an airbreathing hypersonic engine using off-the-shelf solvers to loosely couple the fluid, chemistry, thermal, and structural environments. The hypersonic flow over the vehicle forebody and into the engine inlet was computed using OVERFLOW [228-231], the combustor fluid-chemistry analysis was simulated using VULCAN [232], and the engine strut thermal and structural analyses were computed using ANSYS. Using this methodology, quantitative results were generated for inlet performance, engine combustion, heat transfer and thermal management, and structural deflections/stresses. It was found, however, that the effort required to set up the single discipline simulations, for comprehensive analysis of the engine only, was on the order of months. Furthermore, the process was complicated by the effort required to couple the single discipline computations, due to both the manual labor of transferring the relevant input/output between the codes and the disparate execution times for the different component solvers.

Clark et al. [233] carried out a comprehensive, computational aeropropulsive analysis of a full-scale hypersonic vehicle as a followon to the work by Mirmirani et al. [197]. In particular, simulations using the FLUENT code were employed to construct a complete set of aerodynamic and coupled aeropropulsion data for the vehicle. It was found that the hypersonic control law design is characterized by 


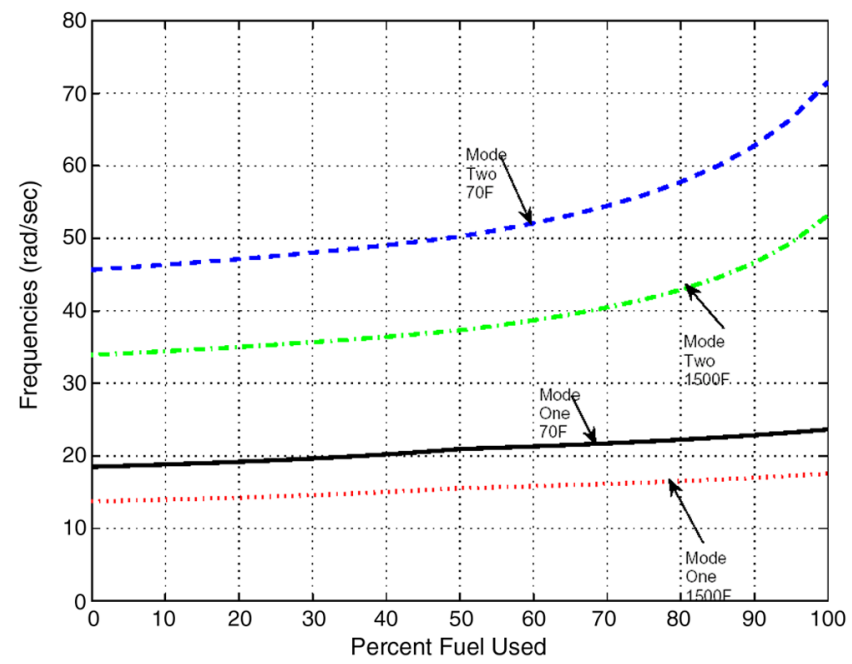

a) Natural frequencies

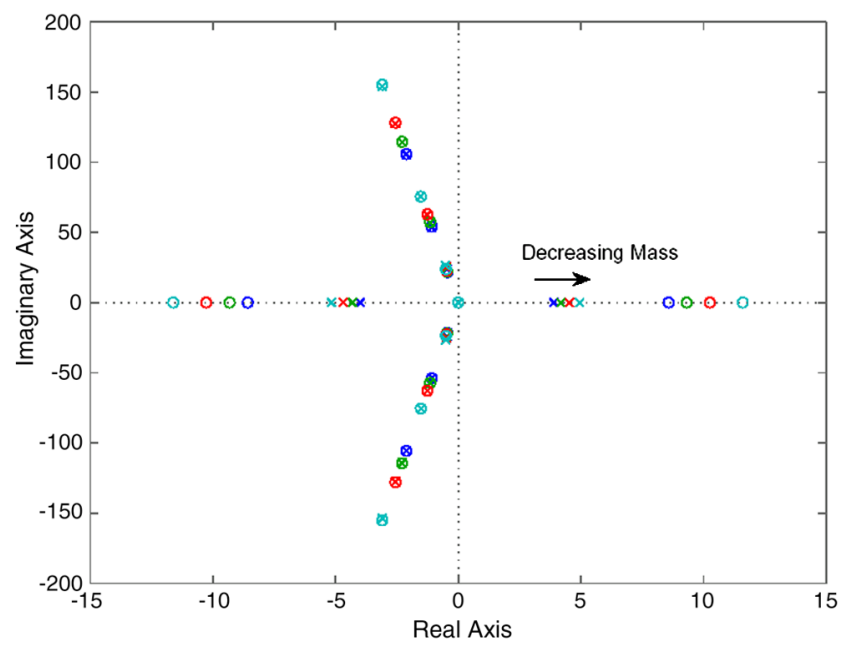

b) Pole-Zero map

Fig. 47 Effect of reduced mass, due to fuel burn, on the natural frequencies and dynamics of an airbreathing hypersonic vehicle [201].

a large of amount of system uncertainty due to coupling effects that were ignored. Thus, accurate simulation models are needed for the appropriate inclusion of system coupling into the comprehensive analysis [233].

Recently, Starkey et al. [29,234] have developed an integrated ASTEP approach intended for scramjet hypersonic MDAO. The goal of the effort was to develop a conceptual-design/analysis tool for rapid assessment of scramjet-powered vehicles in order to perform optimization, stability and control law implementation, and performance estimates. The modeling environment provided improvements to the Chavez and Schmidt [194] model discussed previously.
Primary areas of improvement were the development of an improved scramjet inlet/engine model and a closed-loop control methodology.

A somewhat similar effort is currently being pursued by the Guidance, Navigation, and Controls group of NASA's Hypersonics Fundamental Aeronautics Program. The goal of this work is to develop a controls integrated design environment (CIDE) [192,235] that enables control considerations to influence the early stages of the MDAO process. An overview schematic of the CIDE is shown in Fig. 50. The various components of the required ASTEP model are being developed based on previously discussed work using the following: either CFD/FEM-based aerothermoelastic ROMs $[92,103,104,191]$ or fundamental aerothermoelastic models [235]; the $\overline{M A} \overline{S I V}$ propulsion model [215-218]; 6-DOF 3-D vehicle dynamics $[28,193,219,235]$; and stochastic uncertainty propagation [168]. A first-generation implementation of the CIDE is discussed in [235].

\section{B. Inflatable Aerodynamic Decelerators}

NASA's goal of manned space exploration has reinvigorated research into IADs [236-251]. These devices are desirable for planetary entry, since they can provide a significant increase in drag during the entry phase while being packaged in relatively small volumes during the launch and transit phases of space travel. Recent survey papers on IADs can be found in [236,238,249]. General examples of these devices are shown in Fig. 51. Smith et al. [249] indicate that trailing IADs provide less drag than attached counterparts due to a momentum deficit in the wake relative to the freestream. However, an advantage to this is that they experience less heating. Tension cones have the highest coefficient of drag. However, there are concerns for using this class of IAD in hypersonic flow due to the concave surface geometry that may lead to embedded shocks and high localized heating rates due to shock impingements [249]. As described by Bartels et al. [236], modeling challenges include fluid/structure coupling of highly flexible structures to CFD, incorporation of heating effects, nonlinearity in both the fluid and structural domains, modeling of nonlinear membrane behavior (including wrinkling), and experimental validation of structural modeling and aeroelastic analysis. In terms of the latter, concerns include aeroelastic scaling and the difficulty in obtaining in situ stress measurement on curved membranes due to the stiffness added by measurement devices [249].

Only a few studies have investigated the aeroelastic and aerothermoelastic behavior of IADs in hypersonic flow. The first computational studies known to the authors were conducted by Rohrschneider and Braun [243] and Scott et al. [241]. Both of these studies investigated the aeroelastic behavior of membrane structures using a loosely coupled analysis procedure. In [243], LS-DYNA [252] was selected for the structural solver, while several different approaches were used for the aerodynamic loads: NASCART-GT $[253,254]$, Newtonian impact aerodynamics $[1,71]$, and the direct simulation Monte Carlo analysis code (DAC) [흘] . NASCART-GT (high fidelity) and the Newtonian impact aerodynamics (low fidelity) were used in the continuum flow regions of the analysis, DAC was used for the rarefied regime, and a bridging function was used for the transitional regime. The effect of aerodynamic heating on the

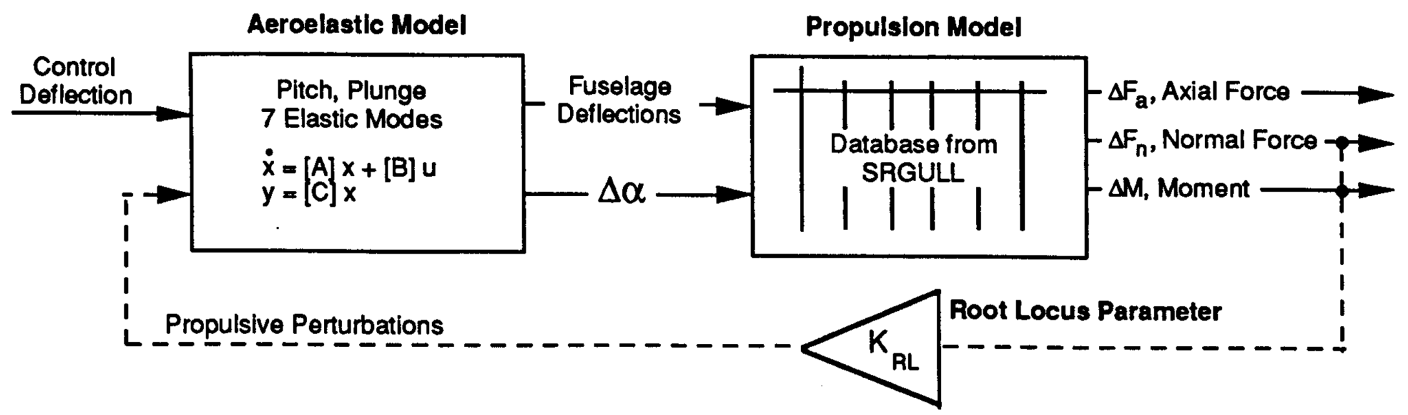

Fig. 48 Block diagram showing analysis procedure [175]. 
External Flowfield/Airframe

- Prediction of Surface Pressure, Skin

Friction, Heat Transfer

- Transition and Turbulence Modeling

- High-Temperature Gas Effects
External Nozzle/Aftbody Region

- Exhaust Plume Characteristics: Effects of

Exit Plane Nonuniformity, Angle of

Attack, Sideslip Effects.

- Plume Interactions with Airframe/Contro

Surfaces
Forebody/External Cowl

- Shock Shapes/Locations

- Viscous Interaction Effects

- Transition to Turbulence

- Inlet Flow Profiles: Mass, Momentum, Energy Fluxes

mentum,

Fig. $49 \mathrm{X}-43 \mathrm{~A}$ flow physics and modeling requirements [222].

Control Integrated Design Environment

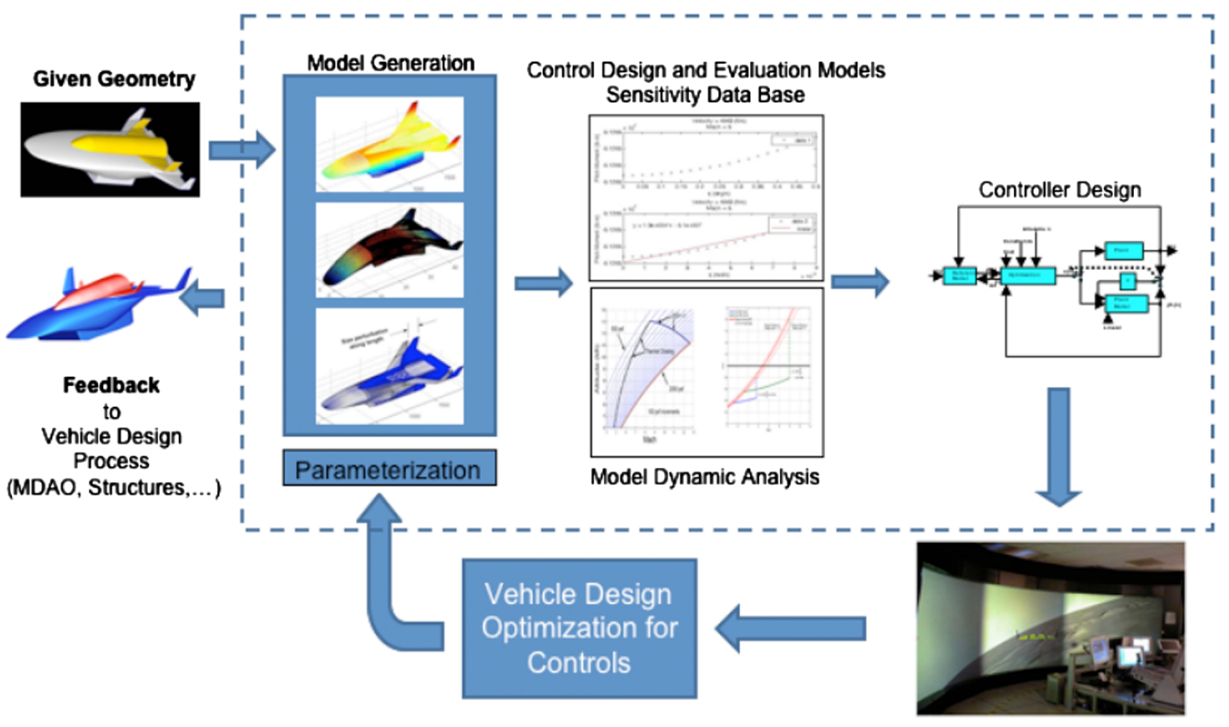

Evaluate Design (FItZ)

Fig. 50 Flowchart of CIDE [192].

structure was modeled using temperature-dependent material properties. Partial validation of the developed framework was carried out using experimental observations by Buck [239] for a flexible tension cone placed in a hypersonic wind tunnel. A comparison of experimental and computational results for the flow over the deformed membrane is shown in Fig. 52. Subsequent to the validation effort, the developed analysis framework was used to examine the aeroelastic response of the tension cone during peak dynamic pressure of two representative Titan aerocapture trajectories. Sample results from this study are shown in Fig. 53. It was found that the stresses and drag were in good agreement between the high-fidelity and low-fidelity aerodynamic modeling approaches. However, there was a $70 \%$ difference in axial displacement of the torus (i.e., the large inflatable ring that connects to the entry module

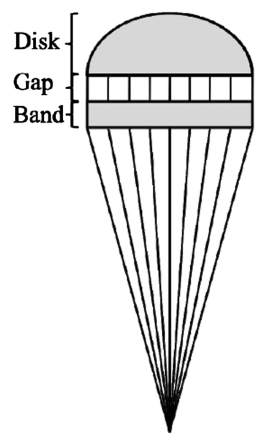

Disk-Gap-Band Parachute
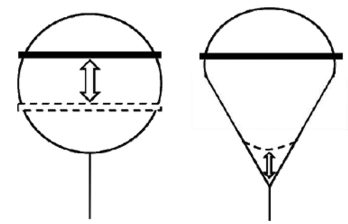

Spherc w/Fence Teardrop w/Fence

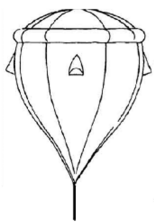

Isotensoid

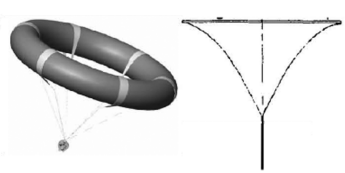

Torus

Trailing IADs

Attached IADs
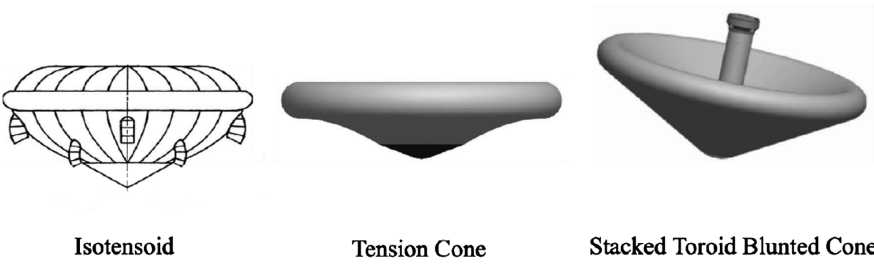

Tension Cone

Stacked Toroid Blunted Cone

Fig. 51 Typical inflatable/deployable aerodynamic decelerators [249]. 


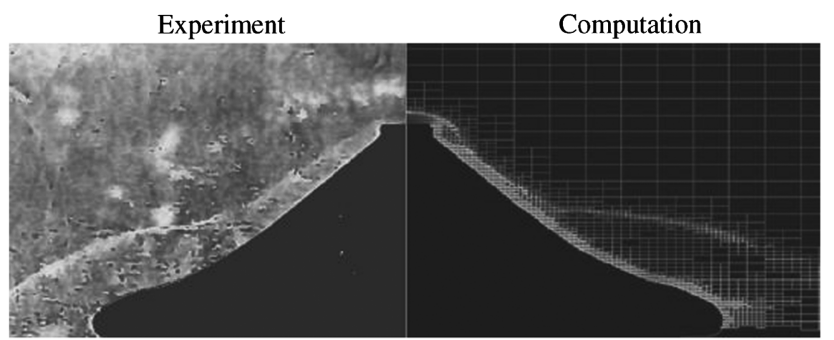

Fig. 52 Comparison of experimental and computational results for the flow over a statically deformed, flexible tension cone in hypersonic flow [243].

via the membrane structure). In a similar study, Wang et al. [251] incorporated Newtonian impact aerodynamics $[1,71]$ into the open source DYNA3D $[\underline{153}, 154]$ structural solver, and they showed good agreement with the static aeroelastic experimental data measured by Buck [239].

Scott et al. [241] implemented a loosely coupled static aeroelastic analysis between CFL3D and both NASTRAN and finite difference models for membranes. In addition, more computationally efficient aeroelastic models were constructed by using third-order PT aerodynamics. Both static and dynamic aeroelastic studies were carried out, where the former used both the CFD-based and PT-based aeroelastic models and the latter used only the PT-based model. Furthermore, the dynamic aeroelastic studies focused on computing membrane flutter, where the NASTRAN membrane model was replaced with a modal representation using modes computed about the nonlinear static aeroelastic deformation at different operating conditions. It was found that the NASTRAN and finite difference membrane models were in excellent agreement during the static aeroelastic analysis. However, there was a significant difference in flutter predictions between the finite difference and NASTRANbased structural models.

Recently, CFD Research Corporation (CFDRC) has completed a three-phase study of the aeroelastic behavior of IADs [250]. In the first phase, CFDRC's multidisciplinary integrated computing environment (MDICE) was demonstrated on thin-walled IAD configurations. In the second phase, the FUN3D, DAC, and ABAQUS codes were used with MDICE to perform aeroelastic simulations of IADs. In the third phase, an aerostructural assessment was performed in order to assess the controllability and strength of IADs during banking maneuvers. In-house aerodynamic and structural solvers, in conjunction with MDICE, were used for this assessment. The effect of aerodynamic heating on the IAD membrane structure was modeled using knockdown factors.

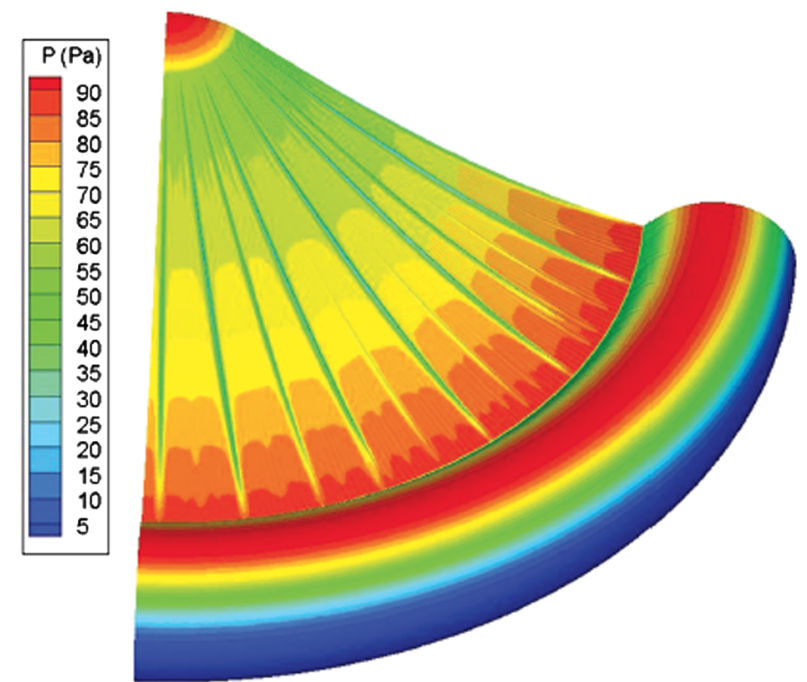

Fig. 53 Surface pressure contours of a tension cone at peak dynamic pressure [243].
The limited amount of previous work, combined with the potential advantages that IADs offer for planetary entry, indicates that research in this area will likely become an important focus for hypersonic aeroelasticity and aerothermoelasticity in the near future. Lacking in the field is a systematic study of fluid-thermal-structural coupling and a detailed treatment of the heat transfer problem. Another missing ingredient is a reliable capability for computing the response of the system during inflation/deployment. The current challenges of accurately computing the aerothermodynamic environment, combined with the need to consider both rarefied fluid dynamics and the transition from rarefied to continuum flow, indicate that probabilistic approaches will play a major role in the analysis and development of these devices. This will likely also be true for the structure, which will exhibit wrinkling and uncertainty in material properties.

\section{Conclusions}

The importance of hypersonic platforms, for both military and civilian applications, is unquestionable. Despite research activity that spans over six decades, the goals of sustained hypersonic flight and flexible decelerators for planetary entry remain unfulfilled. From an aeroelastic point of view, the principal obstacles are associated with the need to design a reliable minimum-weight structure that can withstand extreme heat and pressure loads, without the benefit of experimental data to validate the design as it progresses.

The importance of hypersonic aeroelasticity and aerothermoelasticity in hypersonic flow extends beyond the computation of flutter boundaries. Aerothermoelastic considerations must also be incorporated in the design and life forecasting of surface panels and load carrying integrated thermal protection systems. ASTEP interactions, of which aerothermoelasticity plays a central role, are a first-order concern for both control design/evaluation and multidisciplinary analysis/optimization of hypersonic vehicles. Hypersonic IADs must withstand elevated temperatures on membrane structures and significant structural, material, and aerodynamic nonlinearities. These needs, combined with the dependence of structural properties on vehicle trajectory, indicate that a continuous time-marching analysis is needed for long time records. Thus, this area will require a substantial amount of sustained support so as to allow the construction of responsive, operational hypersonic vehicles and inflatable planetary entry devices.

There have been several important recent advances in CAE and CATE, namely, 1) the development of CFD-based CAE codes, 2) the fundamental study of fluid-thermal-structural interactions in the hypersonic flow regime, and 3) the emergence of reduced-order modeling techniques. However, each of these areas are still immature: more study of the problem is needed to identify all of the relevant physics, and refinements are needed to both high-fidelity and reduced-order CATE codes in order to capture these physics. Furthermore, there are still many unresolved issues in the different disciplines that compose the area, such as 1) uncertainty in aerothermodynamic modeling associated with viscous-inviscid interactions, hypersonic boundary-layer transition, shock-turbulent boundary-layer interactions, wall catalycity, ablation, nonequilibrium real-gas effects, turbulence induced fluctuating pressures, etc.; 2) scramjet propulsion dynamics; and 3) damage progression in the structure. Thus, tractable probabilistic methods are needed to incorporate these uncertainties in a multidisciplinary analysis that spans a full trajectory.

It is clear from this review, and the issues highlighted here, that the field of hypersonic aeroelasticity and aerothermoelasticity is far from mature. Severely needed to improve the status quo are 1) reliable high-fidelity aerothermoelastic analysis codes and 2) reduced-order modeling techniques. The first is needed due to the inability of experimental facilities to completely characterize the aerothermoelastic system, limiting fundamental understanding of the problem. The second is needed to leverage the capabilities of high-fidelity codes into comprehensive and probabilistic simulation environments. However, several years of dedicated and imaginative research are required to handle a wide range of challenges and obstacles. 


\section{References}

[1] Anderson, J. D., Jr., Hypersonic and High-Temperature Gas Dynamics, 2nd ed., AIAA, Reston, VA, 2006.

[2] Bertin, J. J., and Cummings, R. M., "Fifty Years of Hypersonics: Where We've Been and Where We're Going," Progress in Aerospace Sciences, Vol. 39, No. 6-7, April 2003, pp. 511-536. doi:10.1016/S0376-0421(03)00079-4

[3] Livne, E., and Weisshaar, T. A., "Aeroelasticity of Nonconventional Airplane Configurations: Past and Future," Journal of Aircraft, Vol. 40, No. 6, Nov.-Dec. 2003, pp. 1047-1065. doi: $10.2514 / 2.7217$

[4] Spain, C. V., Zeiler, T. A., Gibbons, M. D., Soistmann, D. L., Pozefsky, P., DeJesus, R. O., and Brannon, C. P., "Aeroelastic Character of a National Aerospace Plane Demonstrator Concept," AIAA Paper 19931314, April 1993.

[5] Bille, M., Williams, T., and Villhard, V., "Reusable Space Vehicles: Lessons From Four Decades of Futility," AIAA Paper 2003-0659, Jan. 2003.

[6] Ouzts, P., "The Joint Technology Office on Hypersonics," AIAA Paper 2008-2576, April 2008.

[7] McClinton, C., "X-43 Scramjet Power Breaks the Hypersonic Barrier: Dryden Lectureship in Research for 2006," AIAA Paper 2006-0001, Jan. 2006.

[8] Neuenhahn, T., Olivier, H., and Paull, A., "Development of the Hyshot Stability Demonstrator," AIAA Paper 2006-2960, April 1995.

[9] Mansour, N., Pittman, J., and Olson, L., "Fundamental Aeronautics Hypersonics Project: Overview," AIAA Paper 2007-4263, June 2007.

[10] Walker, S. H., and Rodgers, F., "Falcon Hypersonic Technology Overview," AIAA Paper 2005-3253, May 2005.

[11] Kazmar, R., "Airbreathing Hypersonic Propulsion at Pratt and Whitney: Overview," AIAA Paper 2005-3256, May 2005

[12] Hank, J., Murphy, J., and Mutzman, R., "The X-51A Scramjet Engine Flight Demonstration Program," AIAA Paper 2008-2540, 2008.

[13] Dolvin, D. J., "Hypersonic International Flight Research and Experimentation (HIFiRE) Fundamental Sciences and Technology Development Strategy," AIAA Paper 2008-2581, April-May 2008.

[14] Gaitonde, D., "Magnetohydrodynamic Energy Bypass Procedure in a Three-Dimensional Scramjet," Journal of Propulsion and Power, Vol. 22, No. 3, May-June 2006, pp. 498-510. doi:10.2514/1.14633

[15] Bolender, M. A., and Doman, D. B., "Nonlinear Longitudinal Dynamic Model of an Air-Breathing Hypersonic Vehicle," Journal of Spacecraft and Rockets, Vol. 44, No. 2, March-April 2007, pp. 374387. doi:10.2514/1.23370

[16] Spottswood, S. M., Eason, T. G., Wang, X. Q., and Mignolet, M. P., "Nonlinear Reduced Order Modeling of Curved Beams: A Comparison of Methods," AIAA Paper 2009-2433, May 2009.

[17] Gosse, R., and Kimmel, R., "CFD Study of Three-Dimensional Hypersonic Laminar Boundary Layer Transition on a Mach 8 Elliptic Cone," AIAA Paper 2009-4053, June 2009.

[18] Hollkamp, J. J., and Gordon, R. W., "Coupling Acoustic Modal Models to Nonlinear Structural Reduced-Order Models," AIAA Paper 2010-2542, April 2010.

[19] Hollkamp, J. J., Gordon, R. W., and Beberniss, T. J., "Coupling Acoustics to Nonlinear Structural Models: Predictions and Experiments," AIAA Paper 2010-2544, April 2010.

[20] Gaitonde, D., "An Assessment of CFD for Prediction of 2-D and 3-D High-Speed Flows," AIAA Paper 2010-1284, Jan. 2010.

[21] Ricketts, R. H., Noll, T. E., Whitlow, W., Jr., and Huttsell, L. J., "An Overview of Aeroelasticity Studies for the National Aero-Space Plane," AIAA Paper 1993-1313, April 1993.

[22] Gupta, K. K., Voelker, L. S., Bach, C., Doyle, T., and Hahn, E., "CFDBased Aeroelastic Analysis of the X-43 Hypersonic Flight Vehicle," AIAA Paper 2001-0712, Jan. 2001.

[23] Berry, S. A., Horvath, T. J., Hollis, B. R., Thompson, R. A., and Hamilton, H. H., "X-33 Hypersonic Boundary Layer Transition," AIAA Paper 1999-3560, June-July 1999.

[24] Riley, C. J., Kleb, W. L., and Alter, S. J., "Aeroheating Predictions for X-34 Using an Inviscid-Boundary Layer Method," AIAA Paper 19990880, Jan. 1999.

[25] Cazier, F. W., Doggett, R., and Ricketts, R. H., "Structural Dynamic and Aeroelastic Considerations for Hypersonic Vehicles," AIAA Paper 1991-1255, April 1991.

[26] Bertin, J. J., Hypersonic Aerothermodynamics, AIAA, Reston, VA, 1994.

[27] Fidan, B., Mirmirani, M., and Ionnou, P., "Flight Dynamics and Control of Air-Breathing Hypersonic Vehicles: Review and New
Directions," AIAA Paper 2003-7081, Dec. 2003.

[28] Frendreis, S., and Cesnik, C. E. S., "3D Simulation of a Flexible Hypersonic Vehicle," AIAA Paper 2010-8229, Aug. 2010.

[29] Starkey, R. P., Liu, D. D., Chen, P. C., Sengupta, A., and Chang, K. T., "Integrated Aero-Servo-Thermo-Propulso-Elasticity (ASTPE) Methodology for Hypersonic Scramjet Vehicle Design/Analysis," AIAA Paper 2010-1122, Jan. 2010.

[30] Gupta, K. K., and Meek, J. L., Finite Element Multidisciplinary Analysis, AIAA, Reston, VA, 2nd ed., 2006.

[31] Bisplinghoff, R. L., Ashley, H., and Halfman, R. L., Aeroelasticity, Addison-Wesley, Cambridge, MA, 1955.

[32] Bisplinghoff, R. L., and Ashley, H., Principles of Aeroelasticity, Wiley, New York, NY, 1962.

[33] Livne, E., "Future of Airplane Aeroelasticity," Journal of Aircraft, Vol. 40, No. 6, Nov.-Dec. 2003, pp. 1066-1092. doi: $10.2514 / 2.7218$

[34] Friedmann, P., "Renaissance of Aeroelasticity and Its Future," Journal of Aircraft, Vol. 36, No. 1, Jan.-Feb. 1999, pp. 105-121. doi: $10.2514 / 2.2418$

[35] Bisplinghoff, R. L., and Dugundji, J., Influence of Aerodynamic Heating on Aeroelastic Phenomena, Pergamon, New York, 1958, pp. 288-312.

[36] Lauten, W. T., Levey, G. M., and Armstrong, W. O., "Investigation of an All-Movable Control Surface at a Mach Number of 6.86 for Possible Flutter," NACA RM L58B27, 1958.

[37] Doggett, R., "Experimental Flutter Investigation of Some Simple Models of a Boost-Glide-Vehicle Wing at Mach Numbers of 3.0 and 7.3," NASA TM X-37, 1959.

[38] Miller, R. W., and Hannah, M. E., "Flutter Investigation of 60 deg to 80 deg Delta-Planform Surfaces at a Mach Number of 7.0," NASA TM X-325, 1960.

[39] Hanson, P. W., "Aerodynamic Effects of Some Configuration Variables on the Aeroelastic Characteristics of Lifting Surfaces at Mach Numbers From 0.7 to 6.86," NASA TN D-984, 1961

[40] Sewall, J. L., Hess, R. W., and Watkins, C. E., "Analytical and Experimental Investigation of Flutter and Divergence of SpringMounted Cone Configurations at Supersonic Speeds," NASA TN D1021,1962

[41] Young, L. S., "Effects of Angle of Attack and Thickness Ratio on the Flutter of a Rigid Unswept Diamond-Airfoil-Section Wing at a Mach Number of 10.0," NASA TN D-1380, 1962.

[42] Goetz, R. C., "Effects of Leading-Edge Bluntness on Flutter Characteristics of Some Square-Planform Double-Wedge Airfoils at a Mach Number of 15.4," NASA TN D-1487, 1962

[43] Kordes, E. E., Reed, R. D., and Dawdy, A. L., "Structural Heating Experiences on the X-15 Airplane," NASA TM X-711, 1962.

[44] Jordan, G. H., McLeod, N. J., and Guy, L. D., "Structural Dynamic Experiences of the X-15 Airplane," NASA TN D-1158, 1962.

[45] Garrick, I. E., "A Survey of Aerothermoelasticity" Aerospace Engineering, Vol. 22, No. 1, Jan. 1963, pp. 140-147.

[46] Hedgepeth, J., and Widmayer, E., Jr., "Dynamic and Aeroelastic Problems of Lifting Re-Entry Bodies," Aerospace Engineering, Vol. 22, No. 1, Jan. 1963, pp. 148-153.

[47] Laidlaw, W. R., and Wykes, J. H., "Potential Aerothermoelastic Problems Associated with Advanced Vehicle Design," Aerospace Engineering, Vol. 22, No. 1, Jan. 1963, pp. 154-164.

[48] Schleicher, R. L., "Structural Design of the X-15," Journal of the Royal Aeronautical Society, Vol. 67, No. 10, 1962, pp. 618-636.

[49] Goetz, R. C., "Effects of Leading-Edge Sweep on Flutter Characteristics of Some Delta-Planform Surfaces at a Mach Number of 15.4," NASA TN D-2360, 1964.

[50] Goetz, R. C., and Sewall, J. L., "Experimental Flutter Study of a WingFuselage Configuration at a Mach Number of 15.4 and Comparison With Theory," NASA TN D-3046, 1965.

[51] Goetz, R. C., "Hypersonic Flutter Analysis Using Measured Static Aerodynamic Derivatives and Comparison with Experiment," NASA TN D-5233, 1969.

[52] Rasmussen, M., Hypersonic Flow, Wiley, New York, 1994.

[53] Candler, G. V., Mavriplis, D. J., and Trevino, L., "Current Status and Future Prospects for the Numerical Simulation of Hypersonic Flows," AIAA Paper 2009-0153, Jan. 2009.

[54] Bisplinghoff, R. L., "Some Structural and Aeroelastic Considerations of High-Speed Flight," Journal of the Aeronautical Sciences, Vol. 23, No. 4, April 1956, pp. 289-329, 367.

[55] Michopoulos, J. G., Farhat, C., and Fish, J., "Modeling and Simulation of Multiphysics Systems," Journal of Computing and Information Science in Engineering, Vol. 5, No. 3, Sept. 2005, pp. 198-213. doi:10.1115/1.2031269

[56] Lighthill, M. J., "Oscillating Airfoils at High Mach Numbers," Journal 
of the Aeronautical Sciences, Vol. 20, No. 6, June 1953, pp. 402-406.

[57] Ashley, H., and Zartarian, G., "Piston Theory: A New Aerodynamic Tool for the Aeroelastician," Journal of the Aeronautical Sciences, Vol. 23, No. 12, Dec. 1956, pp. 1109-1118.

[58] Van Dyke, M., "A Study of Second-Order Supersonic Flow Theory," NACA TR 1081, 1951

[59] Morgan, H. G., Huckel, V., and Runyan, H. L., "Procedure for Calculating Flutter at High Supersonic Speed Including Camber Deflections, and Comparison with Experimental Results," NACA TN 4335, 1958.

[60] Zartarian, G., Hsu, P. T., and Ashley, H., "Dynamic Airloads and Aeroelastic Problems at Entry Mach Numbers," Journal of the Aeronautical Sciences, Vol. 28, No. 3, March 1961, pp. 209-222.

[61] Morgan, H. G., Runyan, H. L., and Huckel, V., "Theoretical Considerations of Flutter at High Mach Numbers," Journal of the Aeronautical Sciences, Vol. 25, No. 6, June 1958, pp. 371-381.

[62] Yates, E., and Bennett, R., "Analysis of Supersonic-Hypersonic Flutter of Lifting Surfaces at Angle of Attack," AIAA Paper 1971-0327, April 1971

[63] Liu, D. D., Yao, Z. X., Sarhaddi, D., and Chavez, F., "From Piston Theory to a Unified Hypersonic-Supersonic Lifting Surface Method," Journal of Aircraft, Vol. 34, No. 3, May-June 1997, pp. 304-312. doi: $10.2514 / 2.2199$

[64] Chen, P. C., and Liu, D. D., "Unified Hypersonic/Supersonic Panel Method for Aeroelastic Applications to Arbitrary Bodies," Journal of Aircraft, Vol. 39, No. 3, May-June 2002, pp. 499-506. doi: $10.2514 / 2.2956$

[65] Nydick, I., Friedmann, P. P., and Zhong, X., "Hypersonic Panel Flutter Studies on Curved Panels," AIAA Paper 1995-1485, April 1995.

[66] Spain, C. V., Zeiler, T. A., Bullock, E. P., and Hodge, J. S., "A Flutter Investigation of All-Moveable NASP-Like Wings at Hypersonic Speeds," AIAA Paper 1993-1315, April 1993.

[67] Thuruthimattam, B. J., Friedmann, P. P., McNamara, J. J., and Powell, K. G., "Modeling Approaches to Hypersonic Aerothermoelasticity with Application to Reusable Launch Vehicles," AIAA Paper 20031967, April 2003.

[68] McNamara, J. J., Friedmann, P. P., Powell, K. G., Thuruthimattam, B. J., and Bartels, R. E., "Three-Dimensional Aeroelastic and Aerothermoelastic Behavior in Hypersonic Flow," AIAA Paper 20052175, April 2005

[69] McNamara, J. J., and Friedmann, P. P., "Flutter-Boundary Identification for Time-Domain Computational Aeroelasticity," AIAA Journal, Vol. 45, No. 7, July 2007, pp. 1546-1555. doi: $10.2514 / 1.26706$

[70] McNamara, J. J., Friedmann, P. P., Powell, K. G., Thuruthimattam, B. J., and Bartels, R. E., "Aeroelastic and Aerothermoelastic Behavior in Hypersonic Flow," AIAA Journal, Vol. 46, No. 10, Oct. 2008, pp. 2591-2610. doi: $10.2514 / 1.36711$

[71] McNamara, J. J., Crowell, A. R., Friedmann, P. P., Glaz, B., and Gogulapati, A., "Approximate Modeling of Unsteady Aerodynamics for Hypersonic Aeroelasticity," Journal of Aircraft, Vol. 47, No. 6, Nov.-Dec. 2010, pp. 1932-1945. doi:10.2514/1.C000190

[72] Eckert, E. R. G., "Engineering Relations for Heat Transfer and Friction in High-Velocity Laminar and Turbulent Boundary-Layer Flow Over Surfaces With Constant Pressure and Temperature," Transactions of the ASME, Vol. 78, No. 6, Aug. 1956, pp. 1273-1283.

[73] Culler, A. J., and McNamara, J. J., "Studies on Fluid-ThermalStructural Coupling for Aerothermoelasticity in Hypersonic Flow," AIAA Journal, Vol. 48, No. 8, Aug. 2010, pp. 1721-1738 doi:10.2514/1.J050193

[74] Thornton, E. A., Thermal Structures for Aerospace Applications, AIAA, Reston, VA, 1996, pp. 253-284.

[75] Bertin, J. J., and Cummings, R. M., "Critical Hypersonic Aerothermodynamic Phenomena," Annual Review of Fluid Mechanics, Vol. 38, Jan. 2006, pp. 129-157. doi:10.1146/annurev.fluid.38.050304.092041

[76] Blevins, R. D., Holehouse, I., and Wentz, K. R., "Thermoacoustic Loads and Fatigue of Hypersonic Vehicle Skin Panels," Journal of Aircraft, Vol. 30, No. 6, Nov.-Dec. 1993, pp. 971-978. doi: $10.2514 / 3.46441$

[77] Wu, M., and Martín, P., "Analysis of Shock Motion in Shockwave and Turbulent Boundary Layer Interaction Using Direct Numerical Simulation Data," Journal of Fluid Mechanics, Vol. 594, 2008, pp. 7183. doi:10.1017/S0022112007009044

[78] Edwards, J. R., "Numerical Simulations of Shock/Boundary Layer Interactions Using Time-Dependent Modeling Techniques: A Survey of Recent Results," AIAA Paper 2008-0525, Jan. 2008.

[79] Wu, M., and Martín, P., "Direct Numerical Simulation of a ReflectedShock-Wave/Turbulent-Boundary-Layer Interaction," AIAA Journal, Vol. 47, No. 5, May 2009, pp. 1173-1185. doi:10.2514/1.38821

[80] Duarte, C. A., and Kim, D. J., "Analysis and Applications of a Generalized Finite Element Method with Global-Local Enrichment Functions," Computer Methods in Applied Mechanics and Engineering, Vol. 197, Nos. 6-8, Jan. 2008, pp. 487-504. doi:10.1016/j.cma.2007.08.017

[81] Hall, K. C., Thomas, J. P., and Dowell, E. H., "Proper Orthogonal Decomposition Technique for Transonic Unsteady Aerodynamic Flows," AIAA Journal, Vol. 38, No. 10, Oct. 2000, pp. 1853-1862. doi: $10.2514 / 2.867$

[82] Lucia, D. J., Beran, P. S., and Silva, W. A., "Reduced Order Modeling: New Approaches for Computational Physics," Progress in Aerospace Sciences, Vol. 40, Nos. 1-2, Feb. 2004, pp. 51-117. doi:10.1016/j.paerosci.2003.12.001

[83] Dowell, E. H., and Hall, K. C., "Modeling of fluid-structure Interaction," Annual Review of Fluid Mechanics, Vol. 33, 2001, pp. $445-490$ doi:10.1146/annurev.fluid.33.1.445

[84] Tang, L., Chen, P., Liu, D., Gao, X., Shyy, W., Utturkar, Y., and Zhang, B., "Proper Orthogonal Decomposition and Response Surface Method for TPS/RLV Structural Design and Optimization: X-34 Case Study," AIAA Paper 2005-0839, Jan. 2005.

[85] Silva, W. A., "Identification of Nonlinear Aeroelastic Systems Based on the Volterra Theory: Progress and Opportunities," Nonlinear Dynamics, Vol. 39, Nos. 1-2, Jan. 2005, pp. 25-62. doi:10.1007/s11071-005-1907-z

[86] Cowan, T. J., Arena, A. S., and Gupta, K. K., "Accelerating Computational Fluid Dynamics Based Aeroelastic Analysis Predictions Using System Identification," Journal of Aircraft, Vol. 38, No. 1, Jan.-Feb. 2001, pp. 81-87. doi: $10.2514 / 2.2737$

[87] Suresh, S., Omkar, S. N., Mani, V., and Guru Prakash, T. N., "Lift Coefficient Prediction at High Angle of Attack Using a Recurrent Neural Network," Aerospace Science and Technology, Vol. 7, No. 8, 2003, pp. 595-602. doi:10.1016/S1270-9638(03)00053-1

[88] Gupta, K. K., and Bach, C., "Systems Identification Approach for a Computational-Fluid-Dynamics-Based Aeroelastic Analysis," AIAA Journal, Vol. 45, No. 12, Dec. 2007, pp. 2820-2827. doi: $10.2514 / 1.28647$

[89] Trizila, P. C., Kang, C., Visbal, M. R., and Shyy, W., "A Surrogate Model Approach in 2D Versus 3D Flapping Wing Aerodynamic Analysis," AIAA Paper 2008-5914, 2008.

[90] Glaz, B., Liu, L., and Friedmann, P. P., "Reduced-Order Nonlinear Unsteady Aerodynamic Modeling Using a Surrogate-Based Recurrence Framework," AIAA Journal, Vol. 48, No. 10, 2010, pp. $2418-2429$ doi: $10.2514 / 1.52068$

[91] Glaz, B., Liu, L., Friedmann, P. P., Bain, J., and Sankar, L., "A Surrogate Based Approach to Reduced-Order Dynamic Stall Modeling," AIAA Paper 2010-3042, April 2010.

[92] Crowell, A. R., McNamara, J. J., Kecskemety, K. M., and Goerig, T., "A Reduced Order Aerothermodynamic Modeling Framework for Hypersonic Aerothermoelasticity," AIAA Paper 2010-2969, April 2010.

[93] Queipo, N. V., Haftka, R. T., Shyy, W., Goel, T., Vaidyanathan, R., and Tucker, P. K., "Surrogate-Based Analysis and Optimization," Progress in Aerospace Sciences, Vol. 41, No. 1, Jan. 2005, pp. 1-28. doi:10.1016/j.paerosci.2005.02.001

[94] Forrester, A., Sobester, A., and Keane, A., Engineering Design via Surrogate Modeling: A Practical Guide, Wiley, New York, 2008.

[95] Lucia, D. J., "Reduced Order Modeling for High Speed Flows with Moving Shocks," Ph.D. Thesis, Air Force Institute of Technology, Wright-Patterson AFB, OH, 2001

[96] Sacks, J., Welch, W. J., Mitchell, T. J., and Wynn, H. P., "Design and Analysis of Computer Experiments," Statistical Science, Vol. 4, No. 4 1989, pp. 409-435. doi: $10.1214 / \mathrm{ss} / 1177012413$

[97] Martin, J., and Simpson, T., "Use of Kriging Models to Approximate Deterministic Computer Models," AIAA Journal, Vol. 43, No. 4, April 2005, pp. 853-863. doi: $10.2514 / 1.8650$

[98] Scott, R. C., and Pototzky, A. S., "Quasisteady Aerodynamics for Flutter Analysis Using Steady Computational Fluid Dynamics Calculations," Journal of Aircraft, Vol. 33, No. 1, Jan.-Feb. 1996, 
pp. 191-197.

doi: $10.2514 / 3.46921$

[99] Zhang, W. W., Ye, Z. Y., Zhang, C. A., and Liu, F., "Supersonic Flutter Analysis Based on Local Piston Theory," AIAA Journal, Vol. 47, No. 10 , Oct. 2009 , pp. 2321-2328. doi:10.2514/1.37750

[100] Lighthill, M. J., "On Displacement Thickness," Journal of Fluid Mechanics, Vol. 4, No. 4, April 1958, pp. 383-392. doi:10.1017/S0022112058000525

[101] Sankar, L. N., Malone, J. B., and Schuster, D., "Euler Solutions for Transonic Flow Past a Fighter Wing," Journal of Aircraft, Vol. 24, No. 1, Jan. 1987, pp. 10-16. doi: $10.2514 / 3.45404$

[102] Falkiewicz, N., and Cesnik, C. E. S., "A Reduced Order Modeling Framework for Integrated Thermo-Elastic Analysis of Hypersonic Vehicles," AIAA Paper 2009-2308, May 2009.

[103] Falkiewicz, N., Cesnik, C. E. S., Bolender, M., and Doman, D., "Thermoelastic Formulation of a Hypersonic Vehicle Control Surface for Control-Oriented Simulation," AIAA Paper 2009-6284, Aug. 2009.

[104] Falkiewicz, N., and Cesnik, C. E. S., "Proper Orthogonal Decomposition for Reduced-Order Thermal Solution in Hypersonic Aerothermoelastic Simulations," AIAA Paper 2010-2798, April 2010.

[105] Spottswood, S. M., Hollkamp, J. J., and Eason, T. G., "On the use of Reduced-Order Models for a Shallow Curved Beam under Combined Loading," AIAA Paper 2008-2235, April 2008.

[106] Perez, R., Wang, X. Q., and Mignolet, M. P., "Nonlinear Reduced Order Models for Thermoelastodynamic Response of Isotropic and FGM Panels," AIAA Paper 2009-2309, May 2009.

[107] Perez, R., Wang, X. Q., and Mignolet, M. P., "Unsteady Nonlinear Thermoelastodynamic Response of Isotropic and FGM Panels by Reduced Order Models," AIAA Paper 2010-2724, April 2010.

[108] Przekop, A., and Rizzi, S. A., "Nonlinear Reduced Order Random Response Analysis of Structures with Shallow Curvature," AIAA Journal, Vol. 44, No. 8, Aug. 2006, pp. 1767-1778. doi: $10.2514 / 1.18868$

[109] Przekop, A., and Rizzi, S. A., "Dynamic Snap-Through of ThinWalled Structures by a Reduced-Order Method," AIAA Journal, Vol. 45, No. 10, Oct. 2007, pp. 2510-2519. doi: $10.2514 / 1.26351$

[110] Przekop, A., and Rizzi, S. A., "Nonlinear Reduced-Order Analysis with Time-Varying Spatial Loading Distributions," Journal of Aircraft, Vol. 46, No. 4, July-Aug. 2009, pp. 1395-1402. doi: $10.2514 / 1.39790$

[111] Botto, D., Zucca, S., and Gola, M., "A Methodology for On-Line Calculation of Temperature and Thermal Stress Under Nonlinear Boundary Conditions," International Journal of Pressure Vessels and Piping, Vol. 80, No. 1, 2003, pp. 21-29. doi:10.1016/S0308-0161(02)00139-4

[112] Petit, D., Hachette, R., and Veyret, D., "A Modal Identification Method to Reduce a High-Order Model: Application to Heat Conduction Modelling," International Journal of Modelling and Simulation, Vol. 17, No. 3, 1997, pp. 242-250.

[113] Girault, M., and Petit, D., "Identification Methods in Nonlinear Heat Conduction. Part I: Model Reduction," International Journal of Heat and Mass Transfer, Vol. 48, No. 1, 2005, pp. 105-118. doi:10.1016/j.ijheatmasstransfer.2004.06.032

[114] Girault, M., and Petit, D. "Identification Methods in Nonlinear Heat Conduction. Part II: Inverse Problem Using a Reduced Model," International Journal of Heat and Mass Transfer, Vol. 48, No. 1, 2005, pp. 119-133. doi:10.1016/j.ijheatmasstransfer.2004.06.033

[115] Shore, C. P., "Reduction Method for Thermal Analysis of Complex Aerospace Structures," NASA TP-2373, 1985.

[116] Cardona, A., and Idelsohn, S., "Solution of Nonlinear Thermal Transient Problems by a Reduction Method," International Journal for Numerical Methods in Engineering, Vol. 23, No. 6, 1986, pp. $1023-1042$ doi:10.1002/nme.1620230604

[117] Nour-Omid, B., "Lanczos Method for Heat Conduction Analysis," International Journal for Numerical Methods in Engineering, Vol. 24, No. 1, 1987, pp. 251-262. doi:10.1002/nme.1620240117

[118] Camarda, C. J., "Development of Advanced Modal Methods for Calculating Transient Thermal and Structural Response," NASA TM 104102, 1989

[119] Balakrishnan, N. V., "Nonlinear Transient Thermal Analysis by the Force-Derivative Method," Ph.D. Thesis, Old Dominion Univ., Norfolk, VA, 1995.
[120] Bialecki, R. A., Kassab, A. J., and Fic, A., "Proper Orthogonal Decomposition and Modal Analysis for Acceleration of Transient FEM Thermal Analysis," International Journal for Numerical Methods in Engineering, Vol. 62, No. 6, Feb. 2005, pp. 774-797. doi: $10.1002 / \mathrm{nme} .1205$

[121] Fic, A., Bialecki, R. A., and Kassab, A. J., "Solving Transient Nonlinear Heat Conduction Problems by Proper Orthogonal Decomposition and the Finite-Element Method," Numerical Heat Transfer, Part B: Fundamentals, Vol. 48, No. 2, Aug. 2005, pp. $103-$ 124. doi:10.1080/10407790590935920

[122] Culler, A. J., and McNamara, J. J., "Coupled Flow-Thermal-Structural Analysis for Response Prediction of Hypersonic Vehicle Skin Panels," AIAA Paper 2010-2965, April 2010.

[123] Bendiksen, O. O., "A New Approach to Computational Aeroelasticity," AIAA Paper 1991-0939, April 1991.

[124] Donea, J., Guiliani, S., and Halleux, J. P., "An Arbitrary LagrangianEulerian Finite Element Method for Transient Dynamic FluidStructure Interactions," Computer Methods in Applied Mechanics and Engineering, Vol. 33, Nos. 1-3, Sept. 1982, pp. 689-723. doi:10.1016/0045-7825(82)90128-1

[125] Farhat, C., and Lin, T., "Transient Aeroelastic Computations Using Multiple Moving Frames of Reference," AIAA Paper 1990-3053, Aug. 1990.

[126] Tezduyar, T. E., Behr, M., and Liou, J., "A New Strategy for Finite Element Computations Involving Moving Boundaries and Interfaces: The Deforming-Spatial-Domain/Space-Time Procedure: I. The Concept and the Preliminary Numerical Tests," Computer Methods in Applied Mechanics and Engineering, Vol. 94, No. 3, 1992, pp. 339351. doi:10.1016/0045-7825(92)90059-S

[127] Masud, A., and Hughes, T. R., "A Space-Time Galerkin/Least-Squares Finite Element Formulation of the Navier-Stokes Equations for Moving Domain Problems," Computer Methods in Applied Mechanics and Engineering, Vol. 146, Nos. 1-2, 1997, pp. 91-126. doi:10.1016/S0045-7825(96)01222-4

[128] Bartels, R., and Sayma, A., "Computational Aeroelastic Modelling of Airframes and Turbomachinery: Progress and Challenges," Philosophical Transactions:Series A, Mathematical, Physical, and Engineering Sciences, Vol. 365, No. 1859, 2007, pp. 2469-2499. doi:10.1098/rsta.2007.2018

[129] Kamakoti, R., and Shyy, W., "fluid-structure Interaction for Aeroelastic Applications," Progress in Aerospace Sciences, Vol. 40 No. 8, 2004, pp. 535-558. doi:10.1016/j.paerosci.2005.01.001

[130] Henshaw, M. J., Badcock, K. J., Vio, G. A., Allen, C. B., Chamberlin, J., Kaynes, I., Dimitriadis, G., Cooper, J. E., Woodgate, M. A., Rampurawala, A. M., Jones, D., Fenwick, C., Gaitonde, A. L., Taylor, N. V., Amor, D. S., Eccles, T. A., and Denley, C. J., "Non-Linear Aeroelastic Prediction for Aircraft Applications," Progress in Aerospace Sciences, Vol. 43, Nos. 4-6, 2007, pp. 65-137. doi:10.1016/j.paerosci.2007.05.002

[131] Farhat, C., Lesoinne, M., and Maman, N., "Mixed Explicit/Implicit Time Integration of Coupled Aeroelastic Problems: Three-Field Formulation, Geometric Conservation and Distributed Solution," International Journal for Numerical Methods in Fluids, Vol. 21, No. 10, 1995, pp. 807-835. doi:10.1002/fld.1650211004

[132] Farhat, C., van der Zee, K., and Geuzaine, P., "Provably Second-Order Time-Accurate Loosely-Coupled Solution Algorithms for Transient Nonlinear Computational Aeroelasticity," Computer Methods in Applied Mechanics and Engineering, Vol. 195, Nos. 17-18, 2006, pp. 1973-2001. doi:10.1016/j.cma.2004.11.031

[133] Farhat, C., Lesoinne, M., and LeTallec, P., "Load and Motion Transfer Algorithms for Fluid/Structure Interaction Problems with NonMatching Discrete Interfaces: Momentum and Energy Conservation, Optimal Discretization and Application to Aeroelasticity," Computer Methods in Applied Mechanics and Engineering, Vol. 157, Nos. 1-2, 1998, pp. 95-114. doi:10.1016/S0045-7825(97)00216-8

[134] Smith, M. J., Hodges, D. H., and Cesnik, C. E. S., "Evaluation of Computational Algorithms for Fluid-Structure Interactions," Journal of Aircraft, Vol. 37, No. 2, March-April 2000, pp. 282-294. doi: $10.2514 / 2.2592$

[135] Jaiman, R., Jio, X., Geubelle, P., and Loth, E., "Assessment of Conservative Load Transfer for Fluid-Solid Interface with NonMatching Meshes," International Journal for Numerical Methods in Engineering, Vol. 64, No. 15, 2005, pp. 2014-2038. 
doi:10.1002/nme.1434

[136] Strganac, T. W., and Mook, D. T., "Numerical Model of Unsteady Subsonic Aeroelastic Behavior," AIAA Journal, Vol. 28, No. 5, 1990, pp. 903-909. doi: $10.2514 / 3.25137$

[137] Pramono, E., and Weeratunga, S. K., "Aeroelastic Computations for Wings Through Direct Coupling on Distributed Memory MIMD Parallel Computers," AIAA Paper 1994-0095, Jan. 1994.

[138] Morton, S. A., Melville, R. B., and Visbal, M. R., "Accuracy and Coupling Issues of Aeroelastic Navier-Stokes Solutions of Deforming Meshes," AIAA Paper 1997-1085, April 1997.

[139] Gordnier, R. E., and Melville, R. B., "Transonic Flutter Simulations using an Implicit Aeroelastic Solver," Journal of Aircraft, Vol. 37, No. 5 , 2000, pp. 872-879. doi: $10.2514 / 2.2683$

[140] Rogers, M., "Aerothermoelasticity," Aerospace Engineering, Vol. 17, No. 10 , Oct. 1958 , pp. 34-43,64.

[141] Thornton, E. A., and Dechaumphai, P., "Coupled Flow, Thermal, and Structural Analysis of Aerodynamically Heated Panels," Journal of Aircraft, Vol. 25, No. 11, Nov. 1988, pp. 1052-1059. doi: $10.2514 / 3.45702$

[142] Dechaumphai, P., Thornton, E. A., and Wieting, A. R., "FlowThermal-Structural Study of Aerodynamically Heated Leading Edges," Journal of Spacecraft and Rockets, Vol. 26, No. 4, JulyAug. 1989, pp. 201-209. doi: $10.2514 / 3.26055$

[143] Kontinos, D., "Coupled Thermal Analysis Method with Application to Metallic Thermal Protection Panels," Journal of Thermophysics and Heat Transfer, Vol. 11, No. 2, April-June 1997, pp. 173-181. doi: $10.2514 / 2.6249$

[144] Kontinos, D. A., and Palmer, G., "Numerical Simulation of Metallic TPS Panel Bowing," AIAA Paper 1998-0866, Jan. 1998.

[145] Gee, D. J., and Sipcic, S. R., "Coupled Thermal Model for Nonlinear Panel Flutter," AIAA Journal, Vol. 37, No. 5, May 1999, pp. 642-650. doi: $10.2514 / 2.765$

[146] Pourtakdoust, S. H., and Fazelzadeh, S. A., "Nonlinear Aerothermoelastic Behavior of Skin Panel with Wall Shear Stress Effect," Journal of Thermal Stresses, Vol. 28, No. 2, 2005, pp. 147169. doi:10.1080/014957390523714

[147] Mei, C., Abdel-Motagaly, K., and Chen, R., "Review of Nonlinear Panel Flutter at Supersonic and Hypersonic Speeds," Applied Mechanics Reviews, Vol. 52, No. 10, Oct. 1999, pp. 321-332. doi:10.1115/1.3098919

[148] Blevins, R. D., Bofilios, D., Holehouse, I., Hwa, V. W., Tratt, M. D., Laganelli, A. L., Pozefsky, P., and Pierucci, M., "Thermo-VibroAcoustic Loads and Fatigue of Hypersonic Flight Vehicle Structure: Phase II Report," Rohr Industries, Rept. RHR 89-202, Chula Vista, CA, Nov. 1989.

[149] Wieting, A. R., Dechaumphai, P., Bey, K., Thornton, E., and Morgan, K., "Application of Integrated Fluid-Thermal-Structural Analysis Methods," NASA TM 100625, 1988

[150] Loehner, R., Yang, C., Cebral, J., Baum, J., Luo, H., Pelessone, D., and Charman, C., "Fluid-Structure-Thermal Interaction Using a Loose Coupling Algorithm and Adaptive Unstructured Grids," AIAA Paper 1998-2419, June 1998.

[151] Baum, J. D., Luo, H., and Loehner, R., "The Numerical Simulation of Strongly Unsteady Flows with Hundreds of Moving Bodies," AIAA Paper 1998-0788, 1998.

[152] MacNeal, R., "NASTRAN Theoretical Manual,"NASA Scientific and Technical Information Office, 1981.

[153] Lin, J. I., "DYNA3D: A Nonlinear, Explicit, Three-Dimensional Finite Element for Solid and Structural Mechanics: User Manual," Lawrence Livermore National Labs. UCRL-MA-107254, Livermore, CA, Jan. 2005.

[154] Goudreau, G. L., and Hallquist, J. O., "Recent Developments in LargeScale Finite Element Lagrangian Hydrocode Technology," Computer Methods in Applied Mechanics and Engineering, Vol. 33, Nos. 1-3, 1982, pp. 725-757. doi: $10.1016 / 0045-7825(82) 90129-3$

[155] Tran, H., and Farhat, C., "An Integrated Platform for the Simulation of Fluid-Structure-Thermal Interaction Problems," AIAA Paper 20021307, April 2002.

[156] Dugundji, J., and Calligeros, J. M., "Similarity Laws for Aerothermoelastic Testing," Journal of the AeroSpace Sciences, Vol. 29, No. 8, Aug. 1962, pp. 935-950.

[157] Hedgepeth, J. M., "Flutter of Rectangular Simply Supported Panels at High Supersonic Speeds," Journal of the Aeronautical Sciences, Vol. 24, No. 8, Aug. 1957, pp. 563-573,586.
[158] Dowell, E. H., "Nonlinear Oscillations of a Fluttering Plate," AIAA Journal, Vol. 4, No. 7, July 1966, pp. 1267-1275. doi: $10.2514 / 3.3658$

[159] Friedmann, P. P., and Hanin, M., "Supersonic Non Linear Flutter of Orthotropic or Isotropic Panels with Arbitrary Flow Direction," Israel Journal of Technology, Vol. 6, Nos. 1-2, Feb. 1968, pp. 46-57.

[160] Xue, D. Y., and Mei, C., "Finite Element Nonlinear Panel Flutter with Arbitrary Temperatures in Supersonic Flow," AIAA Journal, Vol. 31, No. 1, Jan. 1993, pp. 154-162. doi: $10.2514 / 3.11332$

[161] Gray, C. E., Jr., and Mei, C., "Large-Amplitude Finite Element Flutter Analysis of Composite Panels in Hypersonic Flow," AIAA Journal, Vol. 31, No. 6, June 1993, pp. 1090-1099. doi: $10.2514 / 3.49051$

[162] Abbas, J. F., Ibrahim, R. A., and Gibson, R. F., "Nonlinear Flutter of Orthotropic Composite Panel Under Aerodynamic Heating," AIAA Journal, Vol. 31, No. 8, Aug. 1993, pp. 1478-1488. doi: $10.2514 / 3.11798$

[163] Bein, T., Friedmann, P. P., Zhong, X., and Nydick, I., "Hypersonic Flutter of a Curved Shallow Panel with Aerodynamic Heating," AIAA Paper 1993-1318, April 1993.

[164] Librescu, L., Marzocca, P., and Silva, W. A., "Supersonic/Hypersonic Flutter and Postflutter of Geometrically Imperfect Circular Cylindrical Panels," Journal of Spacecraft and Rockets, Vol. 39, No. 5, Sept.Oct. 2002, pp. 802-812. doi: $10.2514 / 2.3882$

[165] Cheng, G., and Mei, C., "Finite Element Modal Formulation for Hypersonic Panel Flutter Analysis with Thermal Effects," AIAA Journal, Vol. 42, No. 4, April 2004, pp. 687-695. doi: $10.2514 / 1.9553$

[166] Librescu, L., Marzocca, P., and Silva, W. A., "Linear/Nonlinear Supersonic Panel Flutter in a High-Temperature Field," Journal of Aircraft, Vol. 41, No. 4, July-Aug. 2004, pp. 918-924. doi:10.2514/1.679

[167] Azzouz, M., and Mei, C., "Nonlinear Flutter of Cylindrical Panels Under Yawed Supersonic Flow Using Finite Elements," AIAA Paper 2005-2373, April 2005.

[168] Lamorte, N., Glaz, B., Friedmann, P. P., Culler, A. J., Crowell, A. R., and McNamara, J. J., "Uncertainty Propagation in Hypersonic Aerothermoelastic Analysis," AIAA Paper 2010-2964, April 2010.

[169] Miller, B. A., McNamara, J. J., Culler, A. J., and Spottswood, S. M., "The Impact of Flow Induced Loads on Snap-Through Behavior of Acoustically Excited, Thermally Buckled Panels," AIAA Paper 20102540, April 2010.

[170] Spain, C. V., Soistmann, D. L., and Linville, T. W., "Integration of Thermal Effects Into Finite Element Aerothermoelastic Analysis with Illustrative Results," NASA CR 1059, Aug. 1989.

[171] Rodgers, J. P., "Aerothermoelastic Analysis of a NASP-Like Vertical Fin," AIAA Paper 1992-2400, April 1992

[172] Soistmann, D. L., and Spain, C. V., "An Experimental and Analytical Study of a Lifting-Body Wind-Tunnel Model Exhibiting BodyFreedom Flutter," AIAA Paper 1993-1316, April 1993.

[173] Heeg, J., Zeiler, T. A., Pototzky, A. S., Spain, C. V., and Engelund, W. C., "Aerothermoelastic Analysis of a NASP Demonstrator Model," AIAA Paper 1993-1366, April 1993.

[174] Heeg, J., Gilbert, M. G., and Pototzky, A. S., "Active Control of Aerothermoelastic Effects for a Conceptual Hypersonic Aircraft," Journal of Aircraft, Vol. 30, No. 4, July-Aug. 1993, pp. 453-458. doi: $10.2514 / 3.56890$

[175] Raney, D. L., McMinn, J. D., Pototzky, A. S., and Wooley, C. L., "Impact of Aeroelasticity on Propulsion and Longitudinal Flight Dynamics of an Air-Breathing Hypersonic Vehicle," AIAA Paper 1993-1367, April 1993.

[176] Cole, S. R., Florance, J. R., Thomason, L. B., Spain, C. V., and Bullock, E. P., "Supersonic Aeroelastic Instability Results for a NASPLike Wing Model,” AIAA Paper 1993-1369, April 1993.

[177] Blades, E. L., Ruth, M., and Fuhrmann, H. D., "Aeroelastic Analysis of the X-34 Launch Vehicle," AIAA Paper 1999-1352, April 1999.

[178] Nydick, I., and Friedmann, P. P., "Aeroelastic Analysis of a Generic Hypersonic Vehicle," CEAS/AIAA/ICASE/NASA Langley International Forum on Aeroelasticity and Structural Dynamics, Williamsburg, VA, NASA Paper 1999-209136/PT2, 1999, pp. 777-810.

[179] McNamara, J. J., Thuruthimattam, B. J., Friedmann, P. P., Powell, K G., and Bartels, R. E., "Hypersonic Aerothermoelastic Studies for Reusable Launch Vehicles," AIAA Paper 2004-1590, April 2004.

[180] Thuruthimattam, B. J., Friedmann, P. P., Powell, K. G., and Bartels, R. E., "Computational Aeroelastic Studies of a Generic Hypersonic Vehicle," The Aeronautical Journal, Vol. 113, No. 1150, Dec. 2009, pp. 763-774. 
[181] Krist, S. L., Biedron, R. T., and Rumsey, C. L., "CFL3D User’s Manual (Version 5.0)," NASA TM 1998-208444, 1997.

[182] Bartels, R. E., Rumsey, C. L., and Biedron, R. T., "CFL3D User's Manual: General Usage and Aeroelastic Analysis (Version 6.4)," NASA TM 2006-214301, 2006.

[183] Biot, M. A., "Influence of Thermal Stresses on the Aeroelastic Stability of Supersonic Wings," Journal of the Aeronautical Sciences, Vol. 24, No. 6, June 1957, pp. 418-420, 429.

[184] Runyan, H. L., and Jones, N. H., "Effect of Aerodynamic Heating on the Flutter of a Rectangular Wing at a Mach Number of 2," NACA RM L58C31, 1958 .

[185] Budiansky, B., and Mayers, J., "Influence of Aerodynamic Heating on the Effective Torsional Stiffness of Thin Wings," Journal of the Aeronautical Sciences, Vol. 23, No. 12, Dec. 1956, pp. 1081-1093, 1108.

[186] Ericsson, L., Almroth, B., and Bailie, J., "Hypersonic Aerothermoelastic Characteristics of a Finned Missile," AIAA Paper 1978-0231, Jan. 1978.

[187] Sova, G., and Divan, P., "Aerodynamic Preliminary Analysis System II: Part II Users Manual," NASA CR 182077, 1981.

[188] Lind, R., Buffington, J., and Sparks, A., "Multi-Loop Aeroservoelastic Control of a Hypersonic Vehicle," AIAA Paper 1999-4123, Aug. 1999.

[189] Lind, R., "Linear Parameter-Varying Modeling and Control of Structural Dynamics with Aerothermoelastic Effects," Journal of Guidance, Control, and Dynamics, Vol. 25, No. 4, July-Aug. 2002, pp. 733-739. doi: $10.2514 / 2.4940$

[190] Gupta, K. K., C. S. B., and Ibrahim, A., "Development of an Aerothermoelastic-Acoustics Simulation Capability of Flight Vehicles," AIAA Paper 2010-0050, Jan. 2010.

[191] Falkiewicz, N., Cesnik, C. E. S., Crowell, A. R., and McNamara, J. J., "Reduced-Order Aerothermoelastic Framework for Hypersonic Vehicle Control Simulation," AIAA Journal (accepted for publication).

[192] Soloway, D. I., Ouzts, P. J., Wolpert, D. H., Moerder, D. D., and Benivides, J. V., "The Role of Guidance, Navigation, and Control in Hypersonic Vehicle Multidisciplinary Design and Optimization," AIAA Paper 2009-7329, Oct. 2009.

[193] Frendreis, S., Skujins, T., and Cesnik, C. E. S., "Six-Degree-ofFreedom Simulation of Hypersonic Vehicles," AIAA Paper 20095601, Aug. 2009

[194] Chavez, F. R., and Schmidt, D. K., "Analytical Aeropropulsive/ Aeroelastic Hypersonic-Vehicle Model with Dynamic Analysis," Journal of Guidance, Control, and Dynamics, Vol. 17, No. 6, Nov.Dec. 1994, pp. 1308-1319. doi: $10.2514 / 3.21349$

[195] Chavez, F. R., and Schmidt, D. K., "Uncertainty Modeling For Multivariable-Control Robustness Analysis of Elastic High-Speed Vehicles," Journal of Guidance, Control, and Dynamics, Vol. 22, No. 1, Jan.-Feb. 1999, pp. 87-95. doi: $10.2514 / 2.4354$

[196] Rudd, L., and Pines, D., "Integrated Propulsion Effects on Dynamic Stability and Control of Hypersonic Waveriders," AIAA Paper 20003826 , July 2000

[197] Mirmirani, M., Wu, C., Clark, A., Choi, S., and Colgren, R., "Modeling for Control of a Generic Air-Breathing Hypersonic Vehicle," AIAA Paper 2005-6256, Aug. 2005

[198] Fidan, B., Kuipers, M., Iannou, P., and Mirmirani, M., "Longitudinal Motion Control of Air-Breathing Hypersonic Vehicles Based on TimeVarying Models," AIAA Paper 2006-8074, Nov. 2006.

[199] Bolender, M., and Doman, D., "Modeling Unsteady Heating Effects on the Structural Dynamics of a Hypersonic Vehicle," AIAA Paper 2006-6646, Aug. 2006.

[200] Oppenheimer, M. W., and Doman, D. B., "A Hypersonic Vehicle Model Developed With Piston Theory," AIAA Paper 2006-6637, Aug. 2006.

[201] Williams, T., Bolender, M., Doman, D., and Morataya, O., "An Aerothermal Flexible Mode Analysis of a Hypersonic Vehicle," AIAA Paper 2006-6647, Aug. 2006.

[202] Culler, A. J., Williams, T., and Bolender, M. A., "Aerothermal Modeling and Dynamic Analysis of a Hypersonic Vehicle," AIAA Paper 2007-6395, Aug. 2007.

[203] Oppenheimer, M. W., Doman, D. B., McNamara, J. J., and Culler, A. J., "Viscous Effects for a Hypersonic Vehicle Model," AIAA Paper 2008-6382, Aug. 2008.

[204] Skujins, T., Cesnik, C. E. S., Oppenheimer, M. W., and Doman, D. B., "Canard-Elevon Interactions on a Hypersonic Vehicle," Journal of Spacecraft and Rockets, Vol. 47, No. 1, Jan. 2010, pp. 90-100. doi: $10.2514 / 1.44743$
[205] Groves, K. P., Sigthorsson, D. O., Serrani, A., Yurkovich, S., Bolender, M., and Doman, D., "Reference Command Tracking for a Linearized Model of an Air-Breathing Hypersonic Vehicle," AIAA Paper 20056144, Aug. 2005.

[206] Groves, K. P., Serrani, A., Yurkovich, S., Bolender, M., and Doman, D., "Anti-Windup Control for an Air-Breathing Hypersonic Vehicle Model," AIAA Paper 2006-6557, Aug. 2006.

[207] Sigthorsson, D. O., Serrani, A., Yurkovich, S., Bolender, M., and Doman, D., "Tracking and Control for an Overactuated Hypersonic Air-Breathing Vehicle with Steady-State Constraints," AIAA Paper 2006-6558, Aug. 2006.

[208] Parker, J. T., Serrani, A., Yurkovich, S., Bolender, M., and Doman, D., "Control-Oriented Modeling of an Air-Breathing Hypersonic Vehicle," Journal of Guidance, Control, and Dynamics, Vol. 30 No. 3, May-June 2007, pp. 856-869. doi: $10.2514 / 1.27830$

[209] Sigthorsson, D., Serrani, A., Yurkovich, S., Bolender, M., and Doman, D., "Robust Linear Output Feedback Control of an Airbreathing Hypersonic Vehicle," Journal of Guidance, Control, and Dynamics, Vol. 31, No. 4, July-Aug. 2008, pp. 1052-1066. doi: $10.2514 / 1.32300$

[210] Gibson, T., and Annaswamy, A., "Adaptive Control of Hypersonic Vehicles in the Presence of Thrust and Actuator Uncertainties," AIAA Paper 2008-6961, Aug. 2008.

[211] Bhat, S., and Lind, R., "Linear Parameter-Varying Control for Variations in Thermal Gradients Across Hypersonic Vehicles," AIAA Paper 2009-5952, Aug. 2009.

[212] Wilcox, Z., Bhat, S., Lind, R., and Dixon, W., "Control Performance Variation Due to Nonlinear Aerothermoelasticity in a Hypersonic Vehicle: Insights for Structural Design," AIAA Paper 2009-6184, Aug. 2009

[213] Sigthorsson, D. O., Serrani, A., Bolender, M., and Doman, D., "LPV Control Design for Over-Actuated Hypersonic Vehicle Models," AIAA Paper 2009-6280, Aug. 2009.

[214] Florentini, L., Serrani, A., Bolender, M., and Doman, D., "Nonlinear Robust Adaptive Control of Flexible Air-Breathing Hypersonic Vehicles," Journal of Guidance, Control, and Dynamics, Vol. 32, No. 2, March-April 2009, pp. 402-417. doi: $10.2514 / 1.39210$

[215] Torrezz, S. M., Scholten, N. A., Micka, D. J., Driscoll, J. F., Bolender, M. A., Doman, D. B., and Oppenheimer, M. W., "A Scramjet Engine Model Including Effects of Precombustion Shocks and Dissociation," AIAA Paper 2008-4619, July 2009.

[216] Torrezz, S. M., Driscoll, J. F., Bolender, M. A., Oppenheimer, M. W., and Doman, D. B., "Effects of Improved Propulsion Modelling on the Flight Dynamics of Hypersonic Vehicles," AIAA Paper 2008-6386, Aug. 2008.

[217] Torrezz, S. M., Driscoll, J. F., and Dalle, D. J., "Scramjet Engine Model MASIV: Role of Mixing, Chemistry and Wave Interactions," AIAA Paper 2009-4939, Aug. 2009.

[218] Torrezz, S. M., Driscoll, J. F., Dalle, D. J., Bolender, M. A., and Doman, D. B., "Hypersonic Vehicle Thrust Sensitivity to Angle of Attack and Mach Number," AIAA Paper 2009-6152, Aug. 2009.

[219] Dalle, D. J., Frendreis, S. G., Cesnik, C., and Driscoll, J. F., "Hypersonic Vehicle Flight Dynamics with Coupled Aerodynamic and Reduced-Order Propulsive Models," AIAA Paper 2010-7930, Aug. 2010

[220] Walton, J. T. "SRGULL: An Advanced Engineering Module for the Prediction of Integrated Scramjet Cycle Performance," NASA John H. Glenn Research Center at Lewis Field Rept. LEW-15093, Cleveland, OH, 14 Dec. 2009

[221] Schmidt, D., and Lovell, T., "Mission Performance and Design Sensitivities of Air-Breathing Hypersonic Launch Systems," Journal of Spacecraft and Rockets, Vol. 34, No. 2, March-April 1997, pp. 158164. doi: $10.2514 / 2.3204$

[222] Cockrell, C., Engelund, W., Bittner, R., Jentink, T., Dilley, A., and Frendi, A., "Integrated Aeropropulsive Computational Fluid Dynamics Methodology for the Hyper-X Flight Experiment," Journal of Spacecraft and Rockets, Vol. 38, No. 6, Nov.-Dec. 2001, pp. 836843. doi: $10.2514 / 2.3773$

[223] Godfrey, A., General Aerodynamic Simulation Program Version 3.0 User's Manual, Aerosoft, Blacksburg, VA, May 1996.

[224] Markotos, N., Spalding, D., and Tatchell, D., "Combustion of Hydrogen Injected into a Supersonic Airstream (The SHIP Computer Program)," NASA CR-2802, April 1977.

[225] Ferlemann, P., "Improvements to the SHIP Computer Code and Predictions of Vorticity Enhanced Turbulent Supersonic Mixing," 
M.S. Thesis, George Washington Univ., Washington, D. C., 1993.

[226] Bowcutt, K. G., "Multi-Disciplinary Optimization of Air-Breathing Hypersonic Vehicles," Journal of Propulsion and Power, Vol. 17, No. 6, Nov.-Dec. 2001, pp. 1184-1190. doi: $10.2514 / 2.5893$

[227] Stewart, M., Suresh, A., Liou, M., Owen, A., and Messit, D., "Multidisciplinary Analysis of a Hypersonic Engine," AIAA Paper 2002-5127, Sept. 2002.

[228] Buning, P. G., Chiu, I. T., Obayashi, S., Rizk, Y. M., and Steger, J. L., "Numerical Simulation of the Integrated Space Shuttle Vehicle in Ascent," AIAA Paper 1988-4359, Aug. 1988.

[229] Renze, K. J., Buning, P. G., and Rajagopalan, R. G., "A Comparative Study of Turbulence Models for Overset Grids," AIAA Paper 19920437, Jan. 1992.

[230] Kandula, M., and Buning, P., "Implementation of LU-SGS Algorithm and Roe Upwinding Scheme in OVERFLOW Thin-Layer NavierStokes Code," AIAA Paper 1994-2357, June 1994.

[231] Jespersen, D., Pulliam, T., and Buning, P., "Recent Enhancements to OVERFLOW (Navier-Stokes Code)," AIAA Paper 1997-0644, Jan. 1997.

[232] White, J., and Morrison, J., "A Psuedo-Temporal Multi-Grid Relaxation Scheme for Solving the Parabolized Navier-Stokes Equations," AIAA Paper 1999-3360, 1999.

[233] Clark, A., Wu, C., Mirmirani, M., Choi, S., and Kuipers, M., "Development of an Airframe-Propulsion Generic Hypersonic Vehicle Model," AIAA Paper 2006-218, Jan. 2006.

[234] Starkey, R. P., "Effect of Chemistry Modeling on Multidisciplinary Hypersonic Vehicle Design," AIAA Paper 2010-3007, April 2010.

[235] Kelkar, A. G., Vogel, J. M., Inger, G., Whitmer, C., Sidlinger, A., and Ford, C., "Modeling and Analysis Framework for Early Stage TradeOff Studies for Scramjet-Powered Hypersonic Vehicles," AIAA Paper 2009-7325, Oct. 2009.

[236] Bartels, R. E., Moses, R. W., Scott, R. C., Templeton, J. D., Cheatwood, F. M., Gnoofo, P. A., and Buck, G. M., "A Proposed Role of Aeroelasticity in NASA's New Exploration Vision," International Forum on Aeroelasticity and Structural Dynamics, Munich, Paper IFASD-2005-013, June 2005.

[237] Masciarelli, J. P., Lin, J. K. H., Ware, J. S., Rohrschneirder, R. R., Braun, R. D., Bartels, R. E., Moses, R. W., and Hall, J. L., "Ultra Lightweight Ballutes for Return to Earth from the Moon," AIAA Paper 2006-1698, May 2006.

[238] Cruz, J., and Lingard, J., "Aerodynamic Decelerators for Planetary Exploration: Past, Present, and Future," AIAA Paper 2006-6792, Aug. 2006.

[239] Buck, G., "Testing of Flexible Ballutes in Hypersonic Wind Tunnels for Planetary Aerocapture," AIAA Paper 2006-1319, Jan. 2006.

[240] Brown, G. J., Lingard, J. S., Darley, M. G., and Underwood, J. C., "Inflatable Aerocapture Decelerators for Mars Orbiters," AIAA Paper 2007-2543, May 2007.

[241] Scott, R. C., Bartels, R. E., and Kandil, O. A., "An Aeroelastic Analysis of a Thin Flexible Membrane," AIAA Paper 2007-2316,
April 2007.

[242] Reza, S., Hund, R., Kustas, F., Willcockson, W., Songer, J., and Brown, G., "Aerocapture Inflatable Decelerator (AID) for Planetary Entry," AIAA Paper 2007-2516, May 2007.

[243] Rohrschneider, R. R., and Braun, R. D., "Static Aeroelastic Analysis of Thin-Film Clamped Ballute for Titan Aerocapture," Journal of Spacecraft and Rockets, Vol. 45, No. 4, July-Aug. 2008, pp. 785-801. doi: $10.2514 / 1.33350$

[244] Gilmanov, A., Acharya, S., and Gilmanov, T., "Flow-Structure Interaction Simulations for Ballutes in Supersonic Flow," AIAA Paper 2009-2906, May 2009.

[245] Del Corso, J. A., Bruce, W. E., Liles, K. A., and Hughes, S. J., "Thermal Analysis and Testing of Candidate Materials for PAIDAE Inflatable Aeroshell," AIAA Paper 2009-2925, May 2009.

[246] Hughes, S. J., Ware, J. S., Del Corso, J. A., and Lugo, R. A., "Deployable Aeroshell Flexible Thermal Protection System Testing," AIAA Paper 2009-2926, May 2009.

[247] Karagiozis, K., Cirak, F., Kamakoti, R., Pantano, C., Gidzak, V., Nompelis, I., Stein, K., and V., C. G., "Computational Fluid-Structure Interaction Methods for Simulation of Inflatable Aerodynamic Decelerators," AIAA Paper 2009-2968, May 2009.

[248] Clark, I. G., Cruz, J. R., Hughes, M. F., Ware, J. S., Madlangbayan, A., and Braun, R. D., "Aerodynamic and Aeroelastic Characteristics of a Tension Cone Inflatable Aerodynamic Decelerator," AIAA Paper 2009-2967, May 2009.

[249] Smith, B. P., Tanner, C. L., Mahzari, M., Clark, I. G., Braun, R. D., and Cheatwood, F. M., "A Historical Review of Inflatable Aerodynamic Decelerator Technology Development," IEEE Aerospace Conference, Big Sky, MT, IEEE Paper 1276, Piscataway, NJ, March 2010.

[250] Sheta, E. F., Venugopalan, V., Tan, X. G., Liever, P. A., and Habchi, S. D., "Aero-Structural Assessment of an Inflatable Aerodynamic Decelerator," NASA CR-2010-216731, Aug. 2010.

[251] Wang, Z., Yang, S., Liu, D. D., Wang, X. Q., Mignolet, M. P., and Bartels, R. E., "Nonlinear Aeroelastic Analysis for a Wrinkling Aeroshell/Ballute System," AIAA Paper 2010-2879, April 2010.

[252] LS-DYNA Keyword User's Manual, 970th ed., Livermore Software Technology Corp., Livermore, CA, 2003.

[253] Tu, S., and Run, S., "Solution Adaptive, Unstructures Cartesian-Grid Methodology for Chemically Reacting Flows," AIAA Paper 20023097, June 2002.

[254] Marshall, D., and Run, S., "A New Inviscid Wall Boundary Condition Treatment for Embedded Boundary Cartesian Grid Schemes," AIAA Paper 2004-0583, Jan. 2004.

[255] LeBeau, G., and Lumpkin, F. E. I., "Application Highlights of the DSMC Analysis Code (DAC) Software for Simulating Rarefied Flows," Computer Methods in Applied Mechanics and Engineering, Vol. 191, Nos. 6-7, 2001, pp. 595-609. doi: $10.1016 / \mathrm{S} 0045-7825(01) 00304-8$

P. Givi

Associate Editor 